\title{
In-training assessment in a work-based postgraduate medical education context
}

Citation for published version (APA):

Ringsted, C. (2004). In-training assessment in a work-based postgraduate medical education context. [Doctoral Thesis, Maastricht University]. Datawyse / Universitaire Pers Maastricht. https://doi.org/10.26481/dis.20040702cr

Document status and date:

Published: 01/01/2004

DOI:

10.26481/dis.20040702cr

Document Version:

Publisher's PDF, also known as Version of record

\section{Please check the document version of this publication:}

- A submitted manuscript is the version of the article upon submission and before peer-review. There can be important differences between the submitted version and the official published version of record.

People interested in the research are advised to contact the author for the final version of the publication, or visit the DOI to the publisher's website.

- The final author version and the galley proof are versions of the publication after peer review.

- The final published version features the final layout of the paper including the volume, issue and page numbers.

Link to publication

\footnotetext{
General rights rights.

- You may freely distribute the URL identifying the publication in the public portal. please follow below link for the End User Agreement:

www.umlib.nl/taverne-license

Take down policy

If you believe that this document breaches copyright please contact us at:

repository@maastrichtuniversity.nl

providing details and we will investigate your claim.
}

Copyright and moral rights for the publications made accessible in the public portal are retained by the authors and/or other copyright owners and it is a condition of accessing publications that users recognise and abide by the legal requirements associated with these

- Users may download and print one copy of any publication from the public portal for the purpose of private study or research.

- You may not further distribute the material or use it for any profit-making activity or commercial gain

If the publication is distributed under the terms of Article $25 \mathrm{fa}$ of the Dutch Copyright Act, indicated by the "Taverne" license above, 


\section{In-training assessment}

in a work-based postgraduate medical education context

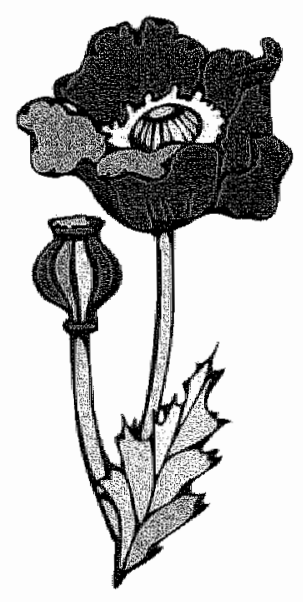


(c) 2004 C. Ringsted, Copenhagen, Denmark

ISBN $90-5278421-3$

Dolawyse / Universtaire Pers Maastricht, the Netherlands 


\title{
In-training assessment
}

in a work-based postgraduate medical education context

\author{
PROEFSCHRIFT
}

ter verkrijging van de graad van doctor

aan de Universiteit Maastricht,

op gezag van de Rector Magnificus,

Prof. G.P.M.F. Mols

volgens het besluit van het College van Decanen,

in het openbaar te verdedigen

op vrijdag 2 juli 2004 om 16.00 uur

door

Charlotte Ringsted

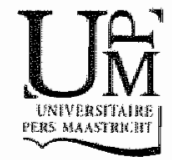




\section{PROMOTORES}

Prof dr. A.J.J.A. Scherpbier

Prof. dr. C.P.M. van der Vleuten

\section{BEOORDELINGSCOMMISSIE}

Prof. dr. M.von Meyenfeldt (voorzitter)

Ass. Prof. dr B. Eika (Aarhus University, Denmark)

Prof. dr. M.van Kleef

Dr. $Y$ van Leeuwen

Prof. dr. E. Petrusa (Duke University, South Carolina, USA)

The research studies of this thesis were supported by the Copenhagen Hospital Corporation Postgraduate Medical Institute and in part by grants from the Ministry of Health, Denmark and from the Danish Society of Anaesthesiology and Intensive Care Medicine. 
To Camilla, Thomas, and Timne- who are my joy and inspiration

To my father and mother - who gave me love, strength, and cournge 


\section{Table of contents}

Introduction

Chapter 1: Designing an in-training assessment (ITA) programme

Embracing the new paradigm of assessment in residency training. An assessment programme for first year residency training in anaesthesiology. Ringsted C, $\varnothing$ stergaard D, Scherpbier $A$

Published in Medical Teacher 2003; $25: 54-62$.

http:/tandf.co wh/joumals.

Chapter 2: Content validity of ITA

Consultants' opinion on a new practice based assessment programme for first year residents in anaesthesiology. Ringsted $C$, Østergaard D, Scherpbier A.

Published in Actn Anaesthesiologica Scandinavica 2002; 46: 1119-23.

\section{Chapter 3: Feasibility of scoring forms}

A feasibility study comparing checklists and global rating forms to assess resident performance in clinical skills. Ringsted $C$, Ostergaand D, Ravn L, Pedersen DA, Berlac PA, Van der Vleuten C.M.

Published in Medicat Tencher" 2003; 25:654-8.

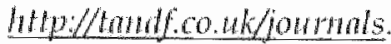

Chapter 4: Implementation of ITA

Implementation of a formal in-training assessment programme in anaesthesiology and prelminary data on acceptability. Ringsted C, Ostergaard D, Van der Vleuten CPM.

Published in Acto Amosthesiologicn Scondinanica 2003; 47: 1196-1203. 
Chapter 5: Educational impact of ITA

Educational impact of in-training assessment (ITA) in postgraduate medical education. A qualitative study of an ITA programme in actual practice. Ringsted C, Henriksen AH, Skaarup AM, Van der Vleuten CPM.

Published in Medical Education 2004 (in press).

Chapter 6: Effect of ITA on clinical confidence

The effect of in-training assessment on clinical confidence in postgraduate education. Ringsted $C$, Pallisgaard $I$, Ostergaard D, Scherpbier A.

Published in Medical Education 2004 (in press).

Conclusion and discussion

Summary

Samenvatting

Acknowledgements

Curriculum vitae 



\section{Introduction}

Postgraduate specialist education is built on top of a long undergraduate medical education and in some countries an additional internship. This makes it the longest formal education seen in any profession with a huge investment of human and financial resources. For accountability reasons alone there is cause to make this education as effective and efficient as possible and to provide evidence of the outcome.' Some unique conditions of postgraduate education are additional significant reasons to assure efficacy and quality of the programmes. These conditions pose a major challenge to the educators who are responsible for choosing assessment strategies with sufficient feasibility and educational impact. Postgraduate education is primarily work-based and the learning environment is not a teaching institution but a highly complex and busy working context of which the primary role is health service. The teachers are clinicians and they do not necessarily have strong incentives or protected time for their role as educators. ${ }^{2}$ Both trainees and trainers often perceive education in conflict with the service demands and hence efficient and feasible strategies of education and assessment are needed. ${ }^{2,3}$ Postgraduate trainees constitute a substantial part of the medical work force ${ }^{3}$ and trainees frequently work unsupervised. 4,5 This means that quality of care and patient safety rely on strategies that ensure trainees' competence along the way during their training as well as by the end of training $4,5,6$

Society requires responsibility from the medical profession and expects high quality of doctors practicing medicine with respect for patients' integrity. Prevailing mechanisms by which various jurisdictions formally grant recognition of doctors as specialists are concentrated around three main strategies: 1) end-of-training examination 2) recognition on behalf of demonstrated clinical experience and years in training; and 3) in-training evaluation reports from the trainers. ${ }^{7}$ Over time and jurisdictions these strategies have been more or less formalised and applied either singularly or in various combinations. However, these strategies are now being questioned as to whether they are sufficient in 
assuring trainees' competence according to society"s needs, and new assessment strategies applied in the in-training contex are requested. 1.8

Internationally, professional bodies are increasingly responding to society's needs and warious models specify the roles of future doctors and the expected leaming outcomes. In essence these models are quite similar, see Table 1. 12

Table 1 . Prevaling models applying to a broad context-based concept of competence

\begin{tabular}{|c|c|c|c|c|}
\hline & $\begin{array}{l}\text { Marden, Crosby } \\
\text { and Davisi } \\
12 \text { learning out } \\
\text { comes for a compe- } \\
\text { lent doctor }\end{array}$ & $\begin{array}{l}\text { JCHMT } \\
12 \text { generic aspects } \\
\text { of the role of the } \\
\text { consultant }\end{array}$ & $\begin{array}{l}\text { RCPSCe } \\
7 \text { roles of the } \\
\text { future speciall } \\
\text { ist }\end{array}$ & $\begin{array}{l}\text { ACGMEd } \\
6 \text { general } \\
\text { competencies } \\
\text { rot residents }\end{array}$ \\
\hline $\begin{array}{l}\text { Performance } \\
\text { of the talsk }\end{array}$ & $\begin{array}{l}\text { 1. Clinicall skils } \\
\text { 2. Practical proce- } \\
\text { dures } \\
\text { 3. Patient investiga- } \\
\text { tion } \\
\text { 4. Patient manage- } \\
\text { ment } \\
\text { 5. Heatth promo- } \\
\text { hon } \\
\text { 6. Communication } \\
\text { 7. Information } \\
\text { handling skils }\end{array}$ & $\begin{array}{l}\text { 2. Communication } \\
\text { skills } \\
\text { 3. Information use } \\
\text { and management } \\
\text { 4. Cross specialty } \\
\text { skills }\end{array}$ & $\begin{array}{l}\text { 1. Medical } \\
\text { expet } \\
\text { 2. Heath } \\
\text { promoter }\end{array}$ & $\begin{array}{l}\text { 1. Patient care } \\
\text { 2. Medical } \\
\text { knowledge }\end{array}$ \\
\hline $\begin{array}{l}\text { Approach } \\
\text { to the task }\end{array}$ & $\begin{array}{l}\text { 8. Understanding of } \\
\text { social, basic and } \\
\text { clinical sciences } \\
\text { 9. Decision-making } \\
\text { and clinical reason- } \\
\text { ing and judgentent } \\
10 \text {. Approprate } \\
\text { attitudes, ethoat } \\
\text { and legal responsi- } \\
\text { bilitios }\end{array}$ & $\begin{array}{l}\text { 5. Working with } \\
\text { colleagues } \\
\text { 6. Team working } \\
\text { and leadership } \\
\text { stkils } \\
\text { 7. Structure and } \\
\text { principles of } \\
\text { management } \\
\text { 8. Teaching } \\
\text { 9. Researdh } \\
\text { 10. Clinical gov- } \\
\text { ernance }\end{array}$ & $\begin{array}{l}\text { 5. Manager } \\
\text { 6. Scholar }\end{array}$ & $\begin{array}{l}\text { 4. Practice- } \\
\text { based learming } \\
\text { and improve- } \\
\text { ment }\end{array}$ \\
\hline $\begin{array}{l}\text { The profes- } \\
\text { sional in } \\
\text { context }\end{array}$ & $\begin{array}{l}\text { 11. Role within the } \\
\text { bealth servics } \\
\text { 12. Personal devel- } \\
\text { opment }\end{array}$ & $\begin{array}{l}\text { 11. Maintaning } \\
\text { 1rust } \\
\text { 12. Maintaining } \\
\text { good pratioe }\end{array}$ & 7. Professional & $\begin{array}{l}\text { 5. Profession- } \\
\text { alism } \\
6 . \text { System- } \\
\text { based practice }\end{array}$ \\
\hline
\end{tabular}


Harden et al. pictures a model of an outcome-based curriculum as three layers in a circle. The core represents the doctor"s knowledge and skills, the middle layer the doctor's approach to the task, and the outer layer the doctor's role within a wider health service context and the continuing professional development., In Canada a model of seven roles for the future specialist emerged,$^{\prime \prime}$ in USA a model of 6 general competences," and in UK a model of 12 generic aspects of the role as a consultant. ${ }^{12}$ Postgraduate training programmes are now requested to define learning outcomes within these broad aspects of roles and elaborate assessment programmes accordingly. ${ }^{11,12,14}$

This introduction describes the rationale for in-training assessment (ITA) strategies in postgraduate education in light of the shifting concepts and strategies in medical education and the challenges of constructing ITA in a postgraduate work-based medical education context. In the first part the evolution of the concept of competence is described and why that calls for new assessment strategies. The second part addresses the problems of the prevailing strategies and why there is a need for effective in-training assessment strategies. The third part discusses the challenge of constructing in-training assessment programmes for a postgraduate work-based context. These challenges are seen from three different, but inter-related perspectives: the programme, the trainees, and the teachers.

In this thesis the term in-training assessment refers to various assessment instruments applied systematically in real clinical settings during training based on direct evidence such as observation or judgment of specific tasks completed by the trainee. ${ }^{15}$ The term in-training examination refers to a knowledge test usually taken once or more during the training period and used formatively in contrast to the summative end-of training specialist exam. in The expression in-training exoluation is used here to refer to trainers' global rating of the trainees on various facets of clinical competence, which is usually applied by the end of defined period of time during the training. . $^{\text {th }}$

\section{Shifting concepts and strategies}

The concept of medical competence has evolved over the years from a narrow focus on only cognitive knowledge to also include skills and finally into the application of both in actual practice., ${ }^{8,17}$ In undergraduate medical education the evolution of the concept of competence is reflected in the development of assessment strategies as pictured by an upward escalation in four layers of Miller's pyramid, "' Figure 1. 
Figure 1. Millers pyramid of aspects of competence and assessment.

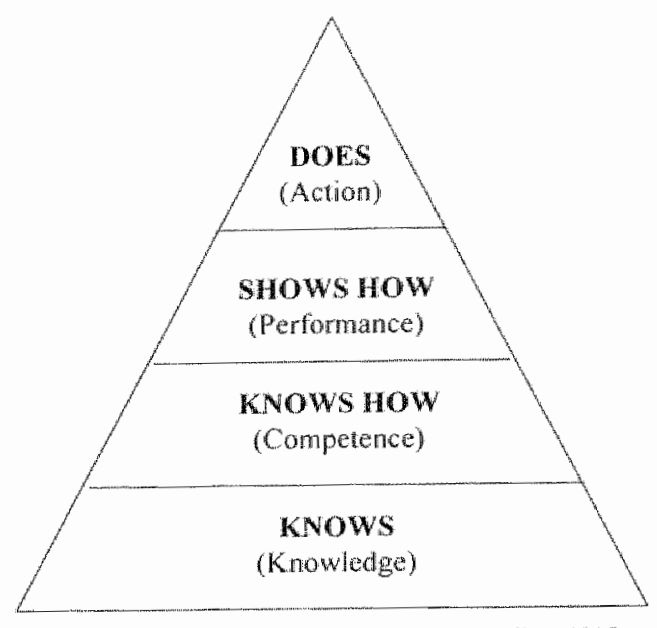

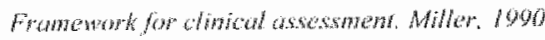

The bottom of the pyramid is 'Knows=knowledge', and for centuries that was the definition of professional competence as reflected in most examinations in the medical profession. ${ }^{17}$ In undergraduate medical education the biggest innovation in assessment strategies in the last century was the introduction of the OSCE in 1975, which moved the monocular focus on competence as a cognitive function to also including rule-based skills. ${ }^{19}$

The second layer in the pyramid is 'Knows how=competence', and according to Miller this is 'the skill of acquiring information from a variety of sources, to analyse and interpret these data, and finally to translate such findings into a rational diagnostic or management plan'. The third layer is 'Shows how=performance in the artificial examination setting demonstrating the process through which conclusions are reached and not only the accuracy of diagnosis. The distinction between competence and performance has been subject to some confusion and the terms are ambiguous. ${ }^{17}$ Some authors define competence as what doctors know and can do under ideal circumstances, whereas performance refers to what is actually done under existing circumstances. ${ }^{7,20}$ Others use the term performance about what is directly observable, whereas competence refers to something that is not directly observable, but inferred from performance. ${ }^{21}$ In American literature the term competence is given a generic or holistic meaning and refers to an overall capacity, whereas the term competency refers to specific capabilities. ${ }^{17}$ The holistic and generic aspect of competence is sometimes referred to as meta-competencies or general competencies. "1? The top layer in the pyramid 'Does=action' is 
defined by Miller as 'the functioning independently in clinical practice'. Postgraduate education is work-based, which implies a lot of 'does=action'. In line with the future expectations of a wide variety of specialists' roles, Epstein and Hundert ${ }^{22}$ define competence as "the habitual and judicious use of communication, knowledge, technical skills, clinical reasoning, emotions, values, and reflection in daily practice for the benefit of the individual and the community being served".

Irrespective of distinctions between competence and performance, the focus of postgraduate education is on the top layers of Miller's pyramid. Nevertheless, the prevailing formal assessment strategies in postgraduate education have been testing cognitive abilities applied as end-of training examinations, Figure 2. The recognition of a broad and context-based concept of competence implies that assessment of cognitive abilities is not enough and supplementation with assessment in real practice is recommended. ${ }^{8,21,23,24}$ The mission of postgraduate education is to structure the development of the individual learner through increasingly complex contexts in order to progressively become an independent competent practitioner. ${ }^{25-27}$ Accorclingly, there is a need for in-training assessment strategies with emphasis on learning through assessment and on-the-job learning, assessment of progression towards defined outcomes, assessment of integrated abilities, assessment of different forms of medical knowledge, and assessment of self-directed learning skills. 23,28,29

Figure 2. Miller's framework for assessment in undergraduate education as it applies to postgraduate education.

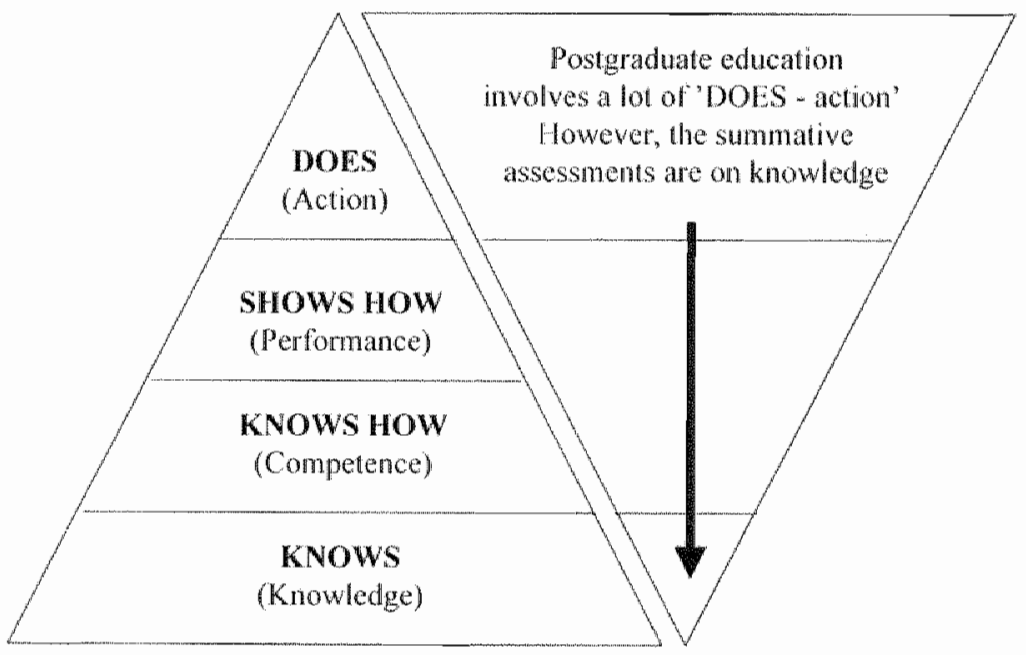

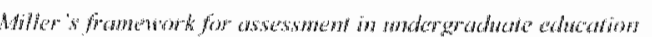




\section{Prewailing strategies}

The prevailing strategies to ensure the outcome of postgraduate education are end-of training examination, certification on behalf of years in training and clinical experience, and formal recognition of training programmes according to specified standards. The prevailing in training strategies used as indicators of clinical performance and monitoring progress are trainers' in-training evaluations and in-training examinations. This section addresses the validity of these strategies and some problems iclentified in previous research.

\section{Prewailing assessment strategies}

The prevailing assessment strategies in postgraduate education are testing cognitive abilities applied as end-of training examinations or intraining examinations, and using trainers' in-training evaluations as an indicator of performance in practice. The link between results on these strategies and more rigorous assessment of clinical performance is complex. In internal medicine results on multiple assessments of clinical encounters, the mini-CEX, demonstrate rather high correlations (from $r=0.59$ to $r=0.79$ ) with the corresponding scores on the ABIM evaluation form and with corresponding sub-sets of scorings on the in training examination ( $r=0.57$ to $r=0.47)$. ${ }^{30}$ The ABIM scores in turn are only modestly or poorly correlated (from 0.31 to 0.00 ) with the results on in-training examinations and certification exam. ${ }^{31}$ The poorest correlations are within aspects of procedural skills and interpersonal behaviour included in the evaluation form. In surgery the performance on examinations testing knowledge correlates poorly with assessments of technical skills and assessment of operative performance. ${ }^{32,33}$ Several studies from a variety of specialties have demonstrated that trainers' evaluations are poorly related to objective tests of clinical skills and knowledge ${ }^{3-41}$ and often these evaluations suffer from poor reliability. 42,43 This indicates that assessment strategies targeting performance in practice are necessary supplements to the cognitive tests.

In order to monitor the trainees progress during training and to identify trainees at risk mock examinations are offered to the trainees as intraining examination. The value of monitoring trainees' progress by use of in-training examinations of medical knowledge might be different across specialties. ${ }^{32,44}$ In internal medicine the most frequent reported difficulties with problem residents were insufficient knowledge $(48 \%)$, poor clinical judgement (44\%), and insufficient use of time (44\%) (Yao).45 In contrast a report from neurosurgery programmes indicate that problems were rarely attributed to cognitive or psychomotor deficits, rather dismissals were more often due to issues of professionalism, ethics, and 
interpersonal skills and behaviours. ${ }^{4 / 6}$ Atrition from postgraduate medical programmes remains a small but persistent issue and problem residents are a significant challenge to programme directors within most programmes. $55,47,48$ IT A programmes with clear standards of performance within the wide aspects of competence and clear formulation of expected progress are suggested for the prevention, identification, management, and remediation of problem trainees. ${ }^{45,49,50}$

Certification examinations serve to ensure that doctors provide high quality of practice to the public. The link between certification and performance in practice varies considerably across studies. ${ }^{24,51.53} \mathrm{~A}$ review of the literature from USA summarises the validity of certification in this respect. ${ }^{24}$ In 1.6 out of 33 studies a positive association between certification status and clinical outcomes was demonstrated, 14 revealed no association, and three studies showed worse outcomes for certified doctors. ${ }^{24}$ Several of the studies were problematic due to differences in case-mix among certified and non-certified doctors and various other contributors to the outcomes, which were not controlled for in the studies. In surgical specialties examinations focusing on knowledge cannot be expected to relate to technical ability. ${ }^{53}$. In other specialties a straightforward relationship between certification and performance in practice is more logical for some aspects of competence. For example in family medicine performance on diagnosis and management sub-scores on the certifying examination was associated with higher rates of diseasespecific relative to symptom-relief prescribing, and sub-scores on drug knowledge in the licensing examination were associated with a lower risk of contraindicated prescribing. ${ }^{54}$ How recently doctors have graduated predicts performance in certain aspects of practice ${ }^{55-57}$ indicating a need for continuous professional development after certification as a specialist. $5 \$$ Doctors must acquire the skills and attitudes towards continuously assessing and up-dating their own knowledge and skills according to the development of new medical technology as well as other aspects of competence. ${ }^{5 \mathrm{k}-60}$ Merely attending courses might not be sufficient in changing physicians' practice. ${ }^{61}$ ITA programmes might contribute to fostering self-directed learning skills and attitudes, ${ }^{23,28,24}$

\section{Clinical experience}

In many countries and jurisdictions for example in Europe the $^{\text {C the are no }}$ end-of training specialist exams. In these countries certification is usually granted in recognition of training in formal programmes or documentation of years spent in specified positions. Internationally there are various policies and guidelines concerning clinical experience and formal training. ${ }^{11,12,14,63,64}$ 
The designated number of years is quite arbitrary and varies considerably between jurisdictions as does the amount of working hours. An example from anaesthesiology is given in Table 2 .

Table2 Minimum requirements of clinical experience in Denmark (DK), European Lnion (EU), United Kingdom (UK), and United States of America (USA)

\begin{tabular}{|c|c|c|c|c|}
\hline & $\mathrm{DK}$ & EUc & UK: & USA \\
\hline Working hours per week & $371 / 2$ hours & $48-56$ hours & 72 hours & 80 hours \\
\hline Total length of training & $81 / 2$ years & & 8 years & 4 years \\
\hline Internship & Why years & & 1 year & 1 year \\
\hline Anaesthesiology, in total & 7 years'b & 5 years & 7 years & 3 years \\
\hline Basic anaesthesiology & 12 months & & 24 months & 12 months \\
\hline Electives, other specialties & 6 months & & 12 months & \\
\hline \multicolumn{5}{|l|}{ Rotation requirements } \\
\hline - Obstetric anaesthesia & 2 months & & 3 months & 1 month \\
\hline - Paediatric anaesthesia & 2 months & & 3 monthes & 1 month \\
\hline - Neuro-anaesthesia & 2 months & & 3 months & I month \\
\hline - Thoracic-anaesthesia & 2 months & & 3 months & 1 month \\
\hline $\begin{array}{l}\text { Andesthesia for vascular } \\
\text { surgery }\end{array}$ & 1 month & & 3 montlis & \\
\hline - Postoperative observation & & & & 2 werks \\
\hline - Intensive care medicine & 12 months & 6 months & 3 months & 2 months \\
\hline - Pain treatment & 3 months & 3 months & 3. months & 1 month \\
\hline $\begin{array}{l}\text { - Emergency medicine, trauma } \\
\text { - General anaes thesiology }\end{array}$ & 3 months & 3 months & 6 months & \\
\hline $\begin{array}{l}\text { Additional experience in } \\
\text { anaesthessology }\end{array}$ & 24 monthis & & & \\
\hline $\begin{array}{l}\text { DK and UK are both part of } \\
\text { hours. Wach country in EU may } \\
\text { working hours. Each country has } \\
\text { wive years formal training is requ } \\
\text { ywars experience in anaesthesiolog }\end{array}$ & $\begin{array}{l}\text { o indivi } \\
\text { ividual re } \\
\text { d to beco } \\
\text { requeste }\end{array}$ & $\begin{array}{l}\text { ons for } \\
\text { rtified a }\end{array}$ & $\begin{array}{l}\text { Farding } \\
\text { aduate } \\
\text { cialist an } \\
\text { to a con }\end{array}$ & $\begin{array}{l}\text { workin } \\
\text { al training. } \\
\text { dithonal tw } \\
\text { int position. }\end{array}$ \\
\hline
\end{tabular}

The actual time spent in training within each year ${ }^{65-67}$ is highly variable, and the proportion of time considered being of educational value in the residencies is between 11 and $76 \%$. ${ }^{6}$ Regulations that limit working hours of residents have globally been met with serious concerns about residents' clinical experience. ${ }^{62}, 69.74$ These aspects add to the reasons for 
constructing effective postgraduate training programmes that ensure educational objectives are met and ITA might be one of the means to reach that end. ${ }^{53}$ Long $^{75}$ demonstrated that structured ITA considerably increased the efficacy of postgraduate education with a $50 \%$ reduction in the time trainees' required to master procedures in neurosurgery.

Many specialties include a recommended caseload in their objectives. The recommended volume is not always in line with the learning curve for achieving competence. ${ }^{76-79}$ Clinical experience measured by number of patients seen or number of procedures performed varies considerably among trainees. ${ }^{80-82}$ In undergraduate education the amount of clinical experience is poorly related to results on either cognitive tests ${ }^{* 3}$ or objective skills tests. ${ }^{84,85}$ The benefit from clinical experience appears to be related to well-organised learning styles and the quality of teacher support. $52.84-89$ In postgraduate education the importance of clinical experience and volume has repeatedly been demonstrated. ${ }^{70,90 \%}$ However, learning curves seems to be rather individual and for several procedures and performances it is unknown how much experience is sufficient for trainees to become competent. Formal ITA with clear performance standards rather than quantitative measures might be of help in constructing efficient training strategies and ensuring effective outcomes. ${ }^{5.3}$

\section{Quality assurance of programmes}

More or less formal recognition or accreditation of postgraduate training programmes serve the purpose of ensuring the quality in the learning environment at the training sites. This includes standards for the sponsor institutions and standards of general educational principles. ${ }^{11,12,14,63,64}$ Historically these requirements were instituted when it became evident to the examiners that a substantial number of candidates coming up to final examinations had severe deficits in their clinical training. ${ }^{64}$ Nowadays accreditation includes a considerable number of standards that programmes are expected to meet, which for example in internal medicine amounts to $301{ }^{97}$ Among significant predictors of a programme's accreditation cycle length are total number of citations in the notification letter. percentage of trainees passing the certification exam, inadequate participation of trainees in teaching sessions and conferences, inadequate breadth in clinical experience, inadequate evaluation of trainees, and features of working conditions. ${ }^{97}$

A link between accreditation status and trainees' pass rates on end-of training examinations has been demonstrated. $27 \%$ Whether this is a causal relationship is a question as pass rates is one of the standards determining accreditation status. It has been demonstrated that doctors who have attended formal training programmes in internal medicine and in family medicine perform better on certifying exams and in prac- 
Hice. $40,56,57,96,99-103$ However, pass rates on certification examination might not be the best indicator of the effect of formal training due to the competitive selection of trainees to programmes. Performance on prior examinations is a major contributor to the variance in performance on certification examinations, 400 When statistically controlling for the effect of trainees' performance on previous examinations, educational characteristics, like faculty/student ratios, length of training, performance during training, and well-supervised educational experience account for only $10-$ $20 \%$ of the variance in scores on certification examination. $40,98,100$

Despite the emphasis accreditation bodies put on teaching sessions and conferences, the quality and effect of these activities on the learning outcome are questionable. Teaching sessions often fail to embrace standard educational principles such as needs assessment, program evaluation, and assessment of learning outcome. 104 Trainees" attendance does not correlate with scores on cognitive tests $105-107$ unless interactive teaching formats are used or intiatives supporting trainees' self-study are included. 10 int 110

Features of residents' working conditions such as service obligations or call-status do not significantly affect performance on in-training examinations.111112 Rather amount of study and learning style account for performance on cognitive tests. 109110 However, work place characteristics such as high intensity of workload and poor staff support have repeatedly been shown to increase junior doctors' stress levels, $65,113-115$ leading to a risk of getting into interpersonal conflicts and making serious medical errors. 65,16 Reforms in postgraduate education introducing formal requirements of structured programmes and teacher support may increase trainees' satisfaction with training and the likelihood of better induction, consultant supervision and feedback, and more hands on clinical experience 17 Whether this also means that trainees become more competent has been questioned. In a study from England trainees confidence in several procedures seemed to declme after the introduction of the Calman refom. 72

Demonstrating clinical learning outcomes and quality of chinical performance while in training could be of help in comparing the quality of programmes. Several accreditation bodies now request programmes to apply rigorous ITA of learning outcomes and performance while in training with assessment of broad aspects of competence including interpersonal skills and behaviour. 1.,12,1.4 


\section{ITA programmes}

The potential benefits of ITA in postgraduate education have been described and a wide variety of assessment instruments have been suggested for inclusion in comprehensive ITA programmes. 1,11,12,22 However, the literature on how ITA work in practice and what educational outcomes can actually be achieved is limited. $1 "$ Any assessment programme can only cover a sub-set of the entire curriculum. ${ }^{119,120}$ The challenge is to choose the important foci that cover the broad aspect of competence as it applies to each particular specialty and select appropriate assessment instruments that fit into a busy work-based postgraduate education context. $16,119,120$ Secondly, it is a challenge to introduce the new concepts of competence and assessment in practice. These challenges are seen from three different, but inter-related perspectives: the programme, the trainees, and the teachers.

\section{The programme}

The utility of an assessment programme is based on the inter-related aspects of the programmes' validity, reliability, feasibility, acceptability, and educational impact. 19,:2! The weight one should put on each of these aspects is often a trade-off and a compromise when keeping the overall purpose of the assessment programme in mind. In theory no assessment instrument can be valid unless it has sufficient reliability to be acceptable to the users and perceived as fair. 118,122 However, in the pursuit of reliable assessment instruments there is a risk of drawbacks concerning the validity, feasibility, acceptability, and effect on learning. 19,121 Having a reliable instrument that is not valid does not make sense. Strategic use of the integrated assessment programmes at the macro-level is recommended with an awareness of what educational impact it has as a total system. 119 Similarly studies of psychometric properties, feasibility, and acceptability must address the total system and not only the individual elements at the micro-level. ${ }^{11 \%}$ The psychometric properties of an assessment instrument can only be judged in terms of data collected from authentic application. ${ }^{123}$ Thus an instrument is not in itself reliable or valid, it's the application of the instrument in a particular context in practice and the interpretation of the results obtained that has these properties. ${ }^{123}$ Traditional strategies of psychometric judgment and standard setting apply to end-of training assessments with pooled data on groups of students, and usually expert assessors are involved. ${ }^{12 t}$ However, these strategies do not readily apply to progressive assessment of individual trainees' mastery in clinical practice. ${ }^{25}$ An ITA programme using mastery criteria for progress and the possibility of re-tests until mastery means that data would not include the variance traditionally used for psychometric analysis and 
standard setting. ${ }^{25}$ Therefore, the internal rational validation process becomes extremely important when constructing ITA programmes and introducing new and broader aspects of competence to be assessed.

In constructing an assessment programme definition of what is to be assessed is most important and the selection of appropriate methods comes second. ${ }^{123}$ Sampling across many observations and using multiple assessors over time is recomrnended in order to ensure reliability. ${ }^{42,119,111}$ Several instruments based on these principles have been suggested. However, very elaborate programmes bear the risk of bureaucratic overloading, ${ }^{47,120,26}$ which reduce their feasibility and acceptability, especially if they are not educational and beneficial. $122,126,127$ For example at least 30 report charts based on medical record audits are needed to achieve acceptable levels of generalisability. ${ }^{128}$ Disappointingly, such report charts may be ineffective in improving residents" practice performance. ${ }^{129}$ Another example is using peers and nurses to judge humanistic qualities, which requires sampling across 13 performance categories using 10-15 ratings from nurses or 11 ratings from peers. ${ }^{130-132}$ Further, $20-40$ patients" ratings of residents' communication skills on five to ten items have been shown to be sulficient for obtaining a reproducible, meaningful indicator. 13 Given the fact that all aspects of the future roles as a specialist should be covered in an assessment programme, instruments like these could add up to an immense workload on trainees, trainers and other health professionals. ${ }^{126,134}$

One problem with ITA is poor reliability when using clinicians as assessors. ${ }^{135-137}$ Using checklists with task specific items might improve accuracy of assessment ${ }^{435}$ and checklists might be seen as a help to the clinicians in making fair decisions on the trainees' performance. On the other hand checklists bear the risk of trivialising the content and global rating scales might be better in reproducibility as well as more efficient to develop and administer. ${ }^{138,13 \%}$ in standardised settings using expert assessors global rating scales has repeatedly been shown to have better psychometric properties than checklists. ${ }^{138}$-142 Whether these findings also apply in a real life postgraduate setting has not been shown. ${ }^{\text {is }}$ In postgraduate education, assessment instruments using general categories of competence have been shown to have sufficient reliability. $30,31,143$ However, some of these instruments fail to demonstrate increasing levels of competence over the time of training and might not be suitable for monitoring trainees' progress or serve as a tool for learning and feedback. ${ }^{3 t, 3,118,143}$ Thus, in designing ITA programmes the challenge is to strike the balance between too much and too little if they are to have sufficient utility and applicability in a postgraduate work-based context. ${ }^{16,119}$ 


\section{The leamer}

The leamers in postgraduate education desire training in reflective practice, increasing in complexity over the years of training through ongoing supervision and feedback and on-the-job discussions with consultants. ${ }^{1: 4}$ Furthermore they want algorithms for medical decision-making, regular sign-offs on a competencies logbook, effective and strategic use of annual assessment, and development of more objective instruments for use in psychomotor skills training and assessment. 144 In other words comprehensive assessment programmes that foster learning and the development of competence in increasingly complex contexts are requested. Elaborating and introducing assessment strategies is a delicate balance between too much structure and too little. Trainees in postgraduate education are highly independent adult learners with a high motivation to learn and function as individual practitioners. ${ }^{45}$ Too much rigor and structure might take away learners initiatives and responsibility for own learning, and too little will make the learning haphazard and ineffective. 117.146 Assessment has profound effects on both learning and teaching through its content, format, feedback, and programming. "1:3 However, these effects are unpredictable and can be both positive and negative. ${ }^{119,125}$

Another problem of introducing formal assessment procedures is avoiding a blame and shame culture. 122,147 Resistance to formal assessment procedures can be expected especially in postgraduate contexts where examinations are not the tradition. ${ }^{62}$ For example when formal assessment procedures were introduced for UK doctors, the attitude towards performance procedures changed in negative direction over time and experience with these. ${ }^{147}$ The negative attitudes included that the procedures were perceived to foster more defensive practice, making doctors vulnerable, being unfair to some doctors, impairing medical morale and teamwork, and being principally window-dressing. *t7 An ITA programme applied progressively through the training with adequate time to remediation in case of failures might overcome some of these barriers. 122

\section{The tenchers}

Apprenticeship learning and discussion with senior colleagues are major sources of learning in postgraduate education. However, the trainers might not always be up-to-date in knowledge and skills ${ }^{5 \%, 148}$ and in case of disagreements over patient management decisions, discussions might be hampered due to the perception of knowledge deficits from both sides. ${ }^{14 \%}, 150$ For better or for worse many of the medical and non-medical aspects of competence are learned through role modelling. ${ }^{151,152}$ For example doctors' team working skills have been questioned and deficien- 
cies in the collaboration with team members have been demonstrated in ward rounds, in the OR, and in the emergency room. ${ }^{153-157}$ However, structuring collaboration between team members can be of benefit to patient care in addition to improving staff satisfaction, team spirit and communication. ${ }^{155.156 .}$ Novices in a profession tend to mimic their role models and due to lack of experiential insight they might even misinterpret them. 158 Unfortunately this implicit learning is more memorable than the explicit curriculum. ${ }^{156}$ Hence, explicit instruments for work-based teaching and assessing of both medical and non-medical aspects of competence might be of benefit to all parties.

Teachers' skills in clinical teaching can be of significance to trainees' learning out-come. In a study by Anderson et al. ${ }^{15 \%}$ students' performance on objective clinical tests were significantly correlated to their perception of the quality of instruction. This included making goals and responsibilities clear, being flexible to meet needs, having reasonable expectations, being accessible for discussion, giving supervision and feedback, asking challenging questions, and demonstrating concern for progress. ITA programmes specifying standards of performance and progress might be of help to clinical teachers in carrying out their instructor responsibilities in a busy working context.

Training the teachers for the role as assessors is recommended in order to minimise the assessor bias in the results. ${ }^{113}$ ITA in practice is often opportunistic requiring almost any senior clinician to take on the role of being assessor. Elaborate ITA programmes might be of help to the programme managers in preparing the clinicians for the role as assessors. 118

\section{Summary of problem formulation}

The recognition of a broad and context-based concept of competence implies that assessment of cognitive abilities is not enough and supplementation with assessment in real practice is recommended. In order to ensure structured development of the trainees into competent individual practitioners there is a need for using assessment as an on-going part of the learning process, and ITA strategies seem to be a means to meet that end. The special conditions for postgraduate education being based in a busy working context and not a teaching institution offer some unique challenges to those who are responsible for constructing assessment programmes. These challenges include compiling a programme that sufficiently covers the content and at the same time is feasible in practice without bureaucratic overloading of the users. Despite evidence that instruments using global scoring of competence are more efficient to develop and administer, there is a need for sufficiently elaborate tools to support the learning process and be of help to the trainers in providing feedback and monitoring progress. Finally, the programme should aim at 
avoiding a blame and shame culture while serving its summative purpose of ensuring performance standards, quality of care and patient safety.

\section{Research questions}

This thesis focuses on the challenges of constructing and introducing an ITA programme, which is in accordance with the new concepts and methods introduced in medical education and applicable in a postgraduate work-based context. The overall research question of this dissertation is:

- How do theory on education and previous research outcomes inform the design and content of ITA in a work-based postgraduate medical education context and how does that apply to specific ITA programme in actual practice?

Six sub-questions were generated from the overall research question, which related to the aspects of design and content of an ITA programme, feasibility of ITA in a postgraduate context, and the educational impact of ITA. These research questions were applied to a specific context of $1^{\text {st }}$ year training in anaesthesiology

\section{Design and content of an ITA programme}

In developing ITA that address new concepts and aspects of competence in postgraduate medical education, a careful internal rational validation process based on existing literature and theory becomes extremely important. 8160 This process includes defining the content and selecting instruments that are supposedly applicable in a work-based context, and prospectively setting standards of performance and pass/fail criteria. ${ }^{8,120161}$ The first research question of the thesis addresses this aspect:

1. What is the internal rational validity of ITA in postgraduate education? How do theory on education and previous research outcomes inform the design and content of a specific ITA programme?

When new concepts and strategies are to be introduced, consensus on the content and the assessment protocol should be sought from content experts and those expected to be examiners. In ITA numerous clinicians will be the examiners. The second research question addresses this aspect of validation. 
2. What is the content validity of ITA addressing broad aspects of competence? Do clinical experts agree on the composite content and the pre-defined standards for making decisions about the trainees?

\section{Feasibility of an ITA programme}

It is difficult to decide whether task specific checklists or global scoring forms using categories of competence are most appropriate in the postgraduate clinical context. The third research question addresses this aspect.

3. What is the feasibility of scoring forms in postgraduate education? Do clinicians prefer task specific checklists or global scoring forms with categories of competence when assessing trainees' performance? Is clinicians' agreement on pass/fail decisions better when using checklists compared to global scoring forms?

No matter how extensive the internal rational validation process and the prospective consensus seeking, barriers to implementing new concepts and imposing ITA in a busy work-based environment can be expected. Research question four addresses the feasibility of the programme in practice.

4. To what extent can ITA be implemented? How well is ITA accepted by the trainees? What are the positive and negative aspects?

\section{Educational inupact}

The possible benefits and the educational impact of ITA are described in the literature. However, the literature on how ITA works in actual practice is sparse. Research question five addresses this aspect:

5. What is the educational impact of ITA in practice? How does it actually work in practice and how does that affect the training, teaching and learning?

Assessment drives learning and one of the stated aims of ITA is to increase trainees' clinical confidence. The last research question of this thesis address this aspect: 6. What is the effect of ITA in postgraduate education on trainees' clini-
cal confidence?

The six research questions in this thesis relate to the construction and introduction of an ITA programme, and the first experience with the 
programme. However, these studies are but a start and there are many other important questions related to ITA that have to be studied at a later stage. Those issues and future research questions are addressed in the concluding section of this thesis.

\section{Structure of the thesis}

The research questions in this thesis are addressed through six individual studies presented in each of six chapters. Chapter one deals with the internal rational validation process and how the theory on education and previous research outcomes informed the design and content of a specific ITA programme embracing broad aspects of competence. Chopter two presents the external validity of the programme, i.e. the clinical experts' opinion about the content of the programme and the pre-defined standards of performance and decisions that are to be made on behalf of the programme. Chapter three is a study of the feasibility of task specific checklists vs. global rating forms addressing general aspects of competence for the purpose of assessing trainees' clinical performance in postgraduate education. Chapter four is a study of the feasibility of the programme in practice, and preliminary data on the trainees' acceptance of ITA. Chapter fize is a qualitative study of how the programme works in actual practice and the effect on training, teaching and learning. Chroter six is a study of the effect of ITA on trainees' clinical confidence. Since this dissertation is based on journal articles some information pertaining to the ITA programme itself may be repetitive.

\section{References}

1. Murray E, Gruppen, L, Catton P, Hays R, Woolliscrot IO. The accountubility of climical kducation: its definition and assessment. Med Educ 2000; 34: 87l-9.

2. Kinminster SM, Jolly BC. Efective supervision in dinical practioe settings: aturatue review. Med Educ 2000; 34: $827-40$.

3. McCue. Addressing the service versus education conflicts created by residency training in ambulatory care settings. I Ambul Manage 1995; 18: $84-90$

4. Aitken RJ, Thompson MR, Smith JAE, Radcliffe AC, Stamatakis JD, Steele RJC. Thining in large bowel cancer surgery: obserwations from the prospective regilonal Unilted Kingdom audits. BMJ 1999; 318,702.3.

5. Baldwin PJ, Newton RW, Buckley G, Roberts MA, Dodd M. Senior house officers in medicine: postal survey of traning and work experience. BMJ 1997; 314: 740-3.

6. Freeman ML. Training and competence in gastrointestinal endoscopy. Rev Gastroenterol Disord 2002; $1: 73-86$.

7. Dauphinee WD, Licensure and certification. In: Norman, GR, Van der Vleuten, CPM, Nawble, DI, eds. International Handbook of Research in Medical Education, Dordrecht: Klawer Academic Publishers. Printed in Great Britain. 2002. 835-79. 
8. Tumbull J, Van Barneveld C. Assessment of clinical performance: In-training evaluation. In: Norman, GR, Van der Veuten, CPM, Newble, DI, eds. Intemational Handbook of Research in Medical Education, Dordrecht: Kuwer Academic Publishers. Printed in Great Britain 2002.793-810.

9. Hardan RM, Grosby JR, Davis MH. AMEF Guide No. 14: Outcomebased education: Part 1 - An introduchon lo outcome-based education: model for the specification of leaming, outcomes. Mud Teach 1999; $21: 7-14$.

10. CanMDDS 2000. Fxtract from the CanMEDS 2000 Project Societal Needs Working Group Report. Med Teach $2000 ; 22$ : 549-54.

11. ACGME Outcome project. Accreditation Council for Graduate Medical Education Web

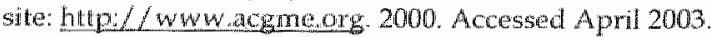

12. $\mathrm{CHA}$ : Higher medical training. Generic curriculum. Joint Commitee for Higher Medical "raming Web site htpL//Www Achmi org wh. 2003. Accessed April 2003.

13. Iarden RM, Crosby JR, Dawis MH, Fredman M. AMEE Guide No. 14: Outcome-based education: Part 5 - From competency to metacompetency; a model for the specificam tion of learing oulcomes. Med Teach $1999,21: 546-52$.

14. RCPSC General standards of accreditation. Royal College of Physicians and Surgeons in Canada Web site: htp//www ropscmedicalorg 2002 . Accessed April 2003.

15. Feleti $G$, Cameron D. Dawson-Samders B, Des Groseillers J. Dooley B, Farmen $E$, McAwoy $P$. In-training assessment. In: Newble $D$, lolly $B$, Wakeford $R$, eds. The certification and recertification of doctors: Issues in the assessment of chnol competence. Combridge Unversity Press 1994: 151-66.

16. Holmboe ES, Hawkins RE Methods for evaluating the clinical comperence of residents in internal medicine: a review. Ann lntern Med 1998; 129:42-8.

17. Eraut M. Concepts of competence and their implications. In: Fraut M, ed. Developing professional knowledge and competence. The Falmer press. London. 1999: 163-81.

18. Miller GE. The assessment of clinical skils/competence/performance. Acad Med 1990; 65 (Suppl): $563-7$.

19. Harden $R$, Gleeson $F$. Assessment of chiniont competence using an objective structured clinical examination (OSCE) Med Edwe 1979; 13:41-54.

20. Rethans IJ, Norcini J]. Barón-Maldonado M, Blackmore D, Jolly BC, LaDuna T. Lew S, Page $G$, Southgate $L M$. The relationship between competence and perfomance: implications for assessing practice performance. Med Educ 2002; 36: 901.9

21. Haeger P, Gonczi A. What is competence? Med Teach 1996; 18: 15 8

22. Fpstein RM, Hundert EM. Defining and assessing professional competernce. IAMA $2002 ; 287: 226 \% 35$

23. Friedman Ben-David M. The role of assessment in expanding professional horizons. Med Teach 2000; 22: $472-6$.

24. Sharp IK, Bashook PG, Lipsky MS, Horowitz SD, Miller SH. Specialty board centificathon and clindal outcomes: The missung link. Acad Med 2002; 77:53442.

25. deach DC. Comperence is a habit. JAM 2002, 287:243-4.

26. Ftaut $M$. Theories of professional expertise. In: Eraut $\mathrm{M}$, ed. Developing professional knowledge and competence. "The Falmer press. London. 1999: 12357.

27. Dreyfus HL, Dreyfis SE. Mind over machine: The power of human intuition and expertise in the en of the computer. Oxford, Basil Blakwell, 1986. 28. Dauphinee WD. Assessing clinical pertomance. Where do wie stand and what might
we expect? AMA 1995;274:741-3.

29. Shepard L. The role of assessment in a leaming culture Fduc Reseanch 2000; 29:4 14.

30. Duming SI. Lannie JC. Markert RJ, Pangaro LN. Assessing the reliability and validity of the mini-chical evaluation exercise for internal medicine resdency training. Acad

31. Dumning S1, Cation LJ, Jackson JL. The neliability and wality of the American Band of Internal Medicine monthly evaluntion form. Acad Med 2003; 78: 175-82. 
32. Scott DI, Valentire $\mathrm{E} I$, Bergen PC, Rege RV, Laycock R, Tesfay ST, Jones DB. Bvatuat ing surgical competency with the American Board of Surgery in-training examination, skill testing, and intraoperative assessment. Surgery 2000; 128:613-22.

33. Sloan DA, Donnelly MB, Schwartz RW, Strodel WR. The objective structured dinical examination. The new gold standard for etaluating postgraduate clinical performance. Ann Surg 1995; 222: 735-42.

34. Sloan DA, Donnelly MB, Johnson SB. Sclnwartz RW, Strodel WE. Use of an objective structured clinical examiration (OSCE) to measure improvenent in clinical compes tence during the surgical internship. Surgery $1993 ; 114: 343-51$.

35. Fox RA, Clark CLI, Scothand AD, Dacre JE. A study of pre-registration house officer's' clinical skills. Med Educ 2000, 34: 1007-12.

36. Dupras DM, Li JTC. Use of an objective structured cinical examination to determine chinical competence. Acad Med 1995; 70: 1029-34.

37. Kahn MJ, Mernill WW, Anderson DS, Szerlip HM. Residency program director waluations do not correlate with performance on a required 4thyear objective structured clinical examination. Teach Learn Med 2001; 13: 9-12.

38. Joorabchi $B$. Objective structured clinical examination in a pediatric residency program. ADDC 1991; 145: 757 $\times 62$

39. Hawkins RE, Sumption KF, Gaglione MM, Holmboe ES. The in-training examination in internal medicine: resident perceptions lack of correlation between resident scores and faculty predictions of resident performance. Am J Med 1999; 106: 206-10.

40. Norcini JJ, Grosso LI, Shea JA, Webster GD. The relationship between features of residency training and $\mathrm{ABIM}$ certifying examination performance. J Gen Intern Med $1987,2,330-6$.

41. Wise $S$, Stagg PL, Szues $\mathrm{R}_{s}$ Gay $\mathrm{S}$, Mauger D, Hartman D. Assessment of resident knowledge: subjective assessment versus performance on the ACR in-training examination. Acad Radiol 1999; 6: 66-71.

42. Kreiter CD, Ferguson $K_{r}$ Lee W-C, Brennan RL, Densen P. A generalizability study of a new standardized rating form used to evaluate students' clinical clerkship performances. Acad Med 1998; 73: 1294-8.

43. Gray JD. Global rating scales in residency education. Acad Med 1996; 71(Suppl): S5563.

44. Garibaldi RA, Subhyah $\mathbb{R}$, Moore ME, Waxman $H$. The in-training examination in internal medicine: an analysis of residents" performance over time. Ann Intern Med 2002: 137: $505-10$.

45. Yao DC. Wright SM. National surwey of internal medicine residency programme directors regarding problem residents. IAMA 2000; 284: 1099-1104.

46. Cusimano MD, Yonke AM, Tucker WS. An analysis of attrition from Canadian neurosurgery residency programs. Acad Med 1999; 74:925-31.

47. Beasley BW, Karn DE, Kolodner $K$. Job turnover and its correlates among residency program directors in internal medicine: a three-year cohort study. Acad Med 2001; 76: $1127-35$

48. Van Zanten: M, Boulet JR, McKinley D, Whelan GP. Attrition rates of residents in postgraduate training programs. Teach Learn Med 2002; 14; 175-7.

49. Short JP. The importance of strong evaluation standards and procedures in training residents. Acad Med 1993; 68: 522-5.

50. Bergen PC, Littlefield JH, OKeefe GE, Rege RV, Anthony TA, Kim LT, Tumage RH. Identification of high-risk residents. ) Surg Res 2000; 92: 239-44.

51. Kramer AW, Jansen IJ, Zuithoff P, Dusman H, Tan LH, Grol RP, van der Vleuten CP. Predictive validity of a written knowledge test of skills for an OSCE in postgraduate training for general practice. Med Educ 2002; 36: 812-9.

52. Hutchinson $\mathrm{L}_{\mathrm{r}}$ Aitken IJ, Hayes T. Are medical postgraduate certification processes valid? A systematic review of the published evidence. Med Ed uc 2002; 36: 73-91. 
33. Moothy K, Munz Y, Sarker SK, Dazi A. Objective assessment of technical skills in surgery, 8Ma) $2003 ; 327: 1032-7$

54. Tamblyn R, Abrahanowicz M, Dauphinee WD, Harley JA, Norcin J, Girard N. Grand'Maison P. Bralowsky C. Association between licensure examination scores and practice in primary care. JAMA 2002, 288:3019-26.

55. Spike NS, Veitch PC. Analysis of the RACGP mellowship examunation. Aust Family Physician 1990, 19: 767.75 .

56. Levy AR, Tamblyn RM, Mcleod PJ, Fitchet D, Abramawica M. The effect of physi. cians' traing on prescribing beta-blockers for secondary prevention of myocardial infarction in the elderly. Anu Epidemiol 2002; 12: 869 .

57. Norcini IJ, Kimball HR, Lipner $\mathbb{R S}$. Certhication and specialization: Do they matter in the outcome of acute myocardial marction? Acad Med 2000; $75 ; 1193-8$.

58. Rethans $J$-J Morcini IJ, Baron-Maldonado M, Blackmore D, Jolly BC, LaDuca J, Lew $S$, Page $G G$, Southgate $1 H$. The relationship between competence and performance: implications for assessing practice perfomance. Med Educ 2002; 36: 901-9.

50. Wernooij-Dassen MI, Ram PM, Brenninkmeijer WJ, Franssen LI, Bottema BJ, van der Veuten CP, Grol RP. Quality assessment in general practice trainers. Med Fduc 2000; 34: $1001-6$.

60. Guest $C B$, Regehr $G$, Tibenus RG. The life long challenge of expertise. Med Educ 2001: $35 ; 78-81$

61. Davis DA, Thompson MA, Oxman AD. Haynes $\mathbb{R} B$. Changing physician performance. A systematic rewew of the effects of continuing medical education strategies. IAMA 1995; $274: 700-5$.

62. Karle H, Nystrup I. Comprehensive evaluation of specialist trainimg an alternative to boand examinations in Europe? Med Educ 1995; 29:308-16.

63. Borman E, O'Grady P. Postgraduate training policy paper prepared by the subcommittee on postgaduate training: Permanent working group of European junior hospital doctors. Med Educ 1997; 31:338.

64. Cassie, IM, Armbruster IS, Bowmer MI, Leach DC. Accreditation of postgraduate medical education in the United State and Canata: a comparison of wo systems. Med Educ 1999:33:493-8.

65. Baldwin DC, Daugherty SR, Tsai R, Scotti MI. A netional survey of residents* selfreported wotk hours: Thinking beyond specialty. Acad Med 2003, 78: 1154-63.

66. Hoekelman RA, Parker RM. Variations in length of training among nesidents in paediatmics and internal medicine training programs. Acad Med 1990; 65: 257-66.

67. Thkersill T. The European wotking tome drective for doctors in traing. BMI 2001, 323: 1266

68. Boex $\mathrm{JR}_{\mathrm{R}}$ Leathy $\mathrm{P}$. Undersitatuding resikents' work: Mowing beyond counting hours to assessing oducational watue. Acad Med $2003 ; 78$ : 93944

69. Directive $2000 / 34 / \mathrm{EC}$ of the Eumopean Parliament and Conncil. Official Journat of the European Commanity $2000 ; 1.195: 41-45$

70. Johnson T. Limitarions on residents womking hours at New rork teaching hospitals: a status report. Acad Med 2003; 78:3-8.

7. Machellan A Residents ututy hours in the province of Quebec, Canada. Acad Med $2003 ; 78: 11-3$.

72. Gillat JH, Dent TH, Smyth-Pigott PI, Fatom I. Recent changes in the workload and clinical experience of preregistation house oftcens: experiences over four years in south-west Lngland. Med Edic 2000; 34:371-3.

73. Kapur N, House A. Working patterns and the quality of training of medical house ofticers: evaluating the tfect of the "new deal' Med Educ 1998; 32: $432-8$.

74. Urowitz M. Crescenzi A, Muharuma L. Residents duty hours in the province of Onknio, Conada. Acad Med 2003; $78 ; 9 \div 10$

75. Long DM. Compotency-based residency training: the next advance in graduate medical education. Acad Med 2000; $75: 1178-83$ 
76. Jowell PS, Baillie J, Branch S, Afront J, Browning CI, Bute BP. Quantitative assessment of procedural skills. A prospective study of training in endoscopic retrograde cholangiopancreatography. Amn Intern Med 1996; 125: 983-9.

77. Konrad $C_{r}$ Scüpfer $G$, Wietlishbach M, Gerber H. Leaming manual skills in anaesthesiology: Is there a recommended number of cases for anesthetic procedures? Anesth An$\operatorname{lig} 1998 ; 86: 635-9$.

78. Kopacz Df, Neal JM, Pollock J. The regional anaesthesia 'learning curve'. What is the minimum number of epidural and spinal blocks to reach consistency? Reg Anesth 1996;21:182-90.

79. Marshall J8. Technical proficiency of trainees performing colonoscopy: a learring curve. Gastraointest Endosc $1995_{*}$ 42: 287-91.

80. Sandermann J, Panduro JL. The Danish specialist training in vascular surgery. Eur J Vase Endocasc Surg 2002; 23:353-7.

81. Nixon MC. The anaesthetic logbook - a surrey. Anaesthesia 2000; 55: 1076-80.

82. Mangione S, Peitzman Sf. Revisiting physical diagnosis during the medical residency: It is time for a logbook - and more. Acad Med 1999; 74: 467-9.

83. Greenberg LW, Getson P. Clinical experienoes of medical students in pediatric derkship and performance on the NBME subject lest are they related? Med Teach 1999; 21: $420-3$

84. Martin $\mathbb{I G}_{2}$ Stark $\mathrm{P}$, Jolly $B$. Benefiting from clinical experience: the influence of learning style and clinical experience on performance in an undergraduate objective structured clinical examination. Med Educ 2000; $34: 530-4$.

85. Chatenay $M$, Maguire T, Skakun E, Chang $G$, Cook D, Warnock GL. Does volume of clinical experience affect performance of clinical clerks on surgery exit examinations? Am J Surg 1996; 172: 366-72.

86. Godellas CV, Huang R. Factors affecting performance on the American Board of Surgery in-training examination. Am J Surg 2001; 181: 294-6.

87. Marteau TM, Wyrne G, Kaye W, Evans TR. Resuscitation: experience without feedback increases confidence but not skill. BMJ 1990; 300: 849-50.

88. McManus IC, Richards P. Winder BC, Sproston KA. Clinical experience, performance in final examinations, and learning style in medical students: prospective study. BM] 1998; 316: 345-50.

89. Paice E, Moss F, West G, Grant I. Association of use of a logbook and experience as a preregistration house officer: interview survey. BMJ 1997; 31.4: 213-5.

90. Marting LA, Holm T, Rutquist L- IE, Moran BI, Heald RJ, Cedermark B, for the Stockholm Colorectal Cancer Study Gromp and the Basingstoke Bowel Cancer Research Prow ject. Lancet: 2000;356:93-6.

91. Martling $\mathrm{A}$, Cedermark $\mathrm{B}$, Johansson H, Rutquist LE, Holm T. The surgeon ats a prog nostic factor after the introduction of total mesorectal excision in the treatment of rectal cancer. Br] Surg 2002; 89: 1008-13.

92. Nowick RJ, Stitt LW. The leaming curve of an academic cardiac surgeon: Use of the CUSUM method. J Card Surg 1999; 14:312-20.

93. Norcini J]. Lipner RA. Recertification: is therg a link between take home and proctored examinations? Acad Med 1999; 74(Suppl); S27-30.

94. Norcini JI, Lipner RS. The relationship between the nature of practice and performance on a cognitive examination. Acad Med 2000; 75(Suppi): $568-70$.

95. Shea IA, Norcini JJ, Baranowski RA, Langdon LO, Popp RL. A comparison of video and print formats in the assessment of skill in interpreting cardiovascular motion studies. Eval Health Prof 1992; 15: 325-40.

96. Steel $K$, Norcini $J$, Brummel-Smith $K$, Erwin $D_{x}$ Markson L. The first certifying examination in geriatric medicine. I Am Geriatr Soc 1989; 37: 1188-91.

97. Beasley BW, Scrase DR, Schultz HJ. Determining the predictors of internal medicine residency accreditation. What they do (not what they say). Acad Med 2002; 77: 238-46. 
98. Wollstual SD, Beasley BVV, Kopelman R, Stickey W, Gabryel T, Kahn MU, Membership survey and scientific data commitee, the association of program directors of internal medicine. Benchmarks of suppon in intermal medicine residency traing programs. Acad Wed 2002; 77:506.

99. Noncini J, Shea JA, Langdon LO, Hudson LD. Firat American Board of Intermal Medicine crithal care examination process and results. Crit Care Med 1989; 17:695-8.

100. Norcin I. Indicators of educatiomal effectweness of subspecialty training programs in internal medicine. Acad Med 1995; 70: 512-6.

101. Nortini J], Lipner RS, Kimball HR. Certifying examination performance and patient outcomes following acute myocardial infarction. Med Educ 2002; $36: 853-9$

102. Pargiel AE, Willams II, Bass MI, Dumn EV, Evensen MK, Lamont CT, MacDonald PJ MeCoy JM, Spasofi RA. Quality of care in family practice: does residency training make a difference? CMAJ 1989; 140:1035-43.

103. Maheux B. Beaudoin C, Jacques A, Lambert $)$, Levesque A. Effect of residency iraning ir family medicine $v$. intemship traning on professional attitades and practice palLerns. CMAI 1992;146:901-7.

104. Habert $\mathrm{R} S$, Wright SMl. Re-examining the value of medical ground rounds. Acad Med $2003 ; 78: 1248-52$

105. TizGerald JD, Wenger NS. Didactic teaching conderence for M residents: who attends, and is attendance related to medical certifying examination scores? Acad Med 2003; 78 $34-9$

106. Peciano A, Winter $\mathrm{R}$, Ballan D, Bmberg B, Jacks M, Laing E. Resident acquistion of knowledge during a noontime tonference series. Fam Med $2003 ; 35,418-22$

107. Pollak R, Baker RJ. The acquistion of fachal knowledge and the role of the didactic confenence in a surgical tesidency program. Am Surg 1988; 54:531-4.

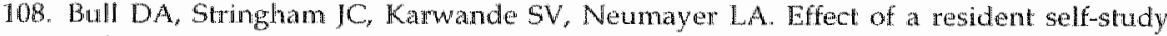
and presentation program on performance on the thowacic surgery inmaining examination. Am I Surg 2001; 181:142-4.

109. Hirvela ER. Becker DR. Impact of programmed reading on ABSITE performance. American Boand of Surgery In-Traming Txamination. Am J Surg 1991; 162: 487-90.

110. Itani KM, Miller CC, Church HM, MCCollum CH. Impact of a problem-based learning conference on surgery residents' in training exam (ABSITE) scores. American Boand of Surgery In Training Exam. I Surg Res 1997; 70: 66m.

111. Rjggs JW, Johnson $\mathrm{C}, \mathrm{O}$ Niel $\mathrm{P}^{*}$ Berens $\mathrm{P}$. Are tesidents work schedules related to their in traning examination scores? Obstek Gynecol 1996:88:891 4

112. Stone MD, Doyle J, Bosh RJ, Bothe $A$, stele G. Efrect of resident call status on $A B S T E$ perfomane. Surgery $2000 ; 128.463-71$

113. Willioms 5 , Dale J. Glthksman F, Wellestey A. Sentor house afticers work related stressors, psychological distress, and confidence in perfoming cinical taks in acident

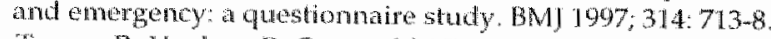

114. Tyssen $R$, Vagm $P$, Grenvold NT, Ekeberg $Q$. The impact of job stress and morking conditions on mental thealth problems among junor house officers. A nationwide Nomegan prospective colnot study. Med Educ 2000; 34:374-84.

115. Wace E, Rutkr H. Wetherell M, Whater B. McManus IC Stressful incidents, stress and coping strtegies in the pre-registration house officer year. Med Educ 2002; 36: 56 m 65

116. Gaba DM, Howard 5K. Fatigue anong clinicians and the satety of patients. N Engl J
Med 2002, $347,1249.55$.

117. Pace $F_{\text {, Aitken } M}$, Cowan $G$, Heard $s$. Tamee satistaction before and after the Calman reforms of specialist taring: questionatre survey. BM] 2000; 320 ; 832 6 .

128. Spike NS, Vaith PC. Analysis of the RACGP Fellowship exammation. Aust Family Physician 1990; 19:767-75.

119. Van dev Vleuten CPM. The assessment of professional competence developments, researdind pratical implications. Adv Health Sci Edur 1996: 1:41-67. 
120. Schuwirh LWT, Southgate L, Page GG, Paget NS, Lescop IM], Lew SR, Wade WB, Boron-Maldonado M. When enough is enough a conceptual basis for tair and defensible practice performance assessment. Med Educ 2002, 36:925.30.

121. Van der Vleuten CPM, Scherpbier AIIA, Dolmans DHIM, Schuwirth LWT, Verwijnen GM, Wolfhagen HAP. Clerksluip assessment assessed. Med Teach 2000; 22:592 600 .

122. Finucane PM, Barron SR, Davies HA, Hadheld-Jones RS, Kaigas TM. Towards an acceptance of performance assessment. Med Educ 2002; 36: 959-64.

123. Dauphinee WD, Blackmore DE. Assessing the assessors assessment. Med Educ 2001; 35: $317-8$.

124. Norcini I, Guille R. Combining tests and setting standards. In Noman GR, Van der Vleuten CPM, Newble DI, eds. International Handbook of Research in Medical Education, Dordrecht: Kluwer Academic Publishers. Printed in Great Britain. 2002: $811-34$.

125. Petrusa ER. Clinical performance assessments. Im. Norman GR, Van der Vleuten CPM, Newble DI, eds. International Handbook of Research in Medical Education. Kluwer Academic Publishers, 2002: 673-709.

126. Leung W-C. Competency based medical training: review. BMI 2002; 325; 693-6.

127. Hauer KE, Teherani A, Wese J. Fenton CL. A strategy to standardize the learning of core clerkship objectives. Adv Health Sci Educ 2003; 8:213-21.

128. Norcini IJ Jr. Standards and reliability in evaluation: When rulles of thumb don't apply. Acad Med 1999; 74: 1088-90.

129. Kogan JR, Reynolds EE, Shea IA. Effectiveness of report cards based on chart audits of residents" adherence to practice guidelines on practice performance: A randomized controlled trial. Teach Learn Med 2003, 15: 25-30.

130. Ramsey PG, wenrich MD, Carline JD, Irnui TS, Larson EB, LoGerto JP. Use of peer ratings to evaluate physician performance. JAMA $1993 ; 269 ; 1655-60$.

131. Ramsey PG, Carline JD, Blank LL, Wenrich MD. Feasibility of hospital-based use of peer ratings to evaluate the performances of practicing plyysicians. Acad Med 1996; 71 : $364-70$.

132. Wenrich MD, Carline JD, Giles LM, Ramsey PG. Ratings of the performances of practicing internists by hospital-based registered nurses. Acad Med 1993;68;680-7.

133. Swanson, DB, Webster GD, Norcini IJ. Precision of patient ratings of residents' humanistic qualities: how many itenns and patients are enough? In: Bender $W$, Hiemstra RJ, Scherpbier AJJA, Zwierstra IRP, (Eds.) Teaching and Assessing Clinical Competence. Groningen: BoekWerk Publications, 1990: 424-31.

134. Dunnington GL, Williams RG. Addressing the new competencies for residents' surgical training Acad Med 2003; 78 : 14-21.

135. Noel GL, Herbers JE, Caplow MP, Cooper GS, Pangaro JN, Harvey J. How well do internal medicine faculty members evaluate the clinical skills of residents? Ann Int Med 1992; 117: 757-65.

136. Herbers [E, Noel GL, Cooper GS, Harvey J, Pangaro LN, Weaver MJ. How accurate are faculy ewaluations of clinical competence? I Gen Intern Med 1989; 4: 202-8.

137. Kroboth FJ, Hanusa BH, Parker S, Coulehan J.., Kapoor WN, Brown FH, Karpl M, Levey GS. The inter-rater reliability and internal consistency of a clinical evaluation exercise. J Gen Int Med 1992;7:174:9.

138. Gowaerts MJB, Van der Vleuten CPM, Schuwirth LWT. Optimising the reproducibility of a performance-based assessment test in midwifery education. Adv Health Sci Educ 2002; 7: 133-45.

139. Regehr G, Mackae H, Reznick RK, Szalay D. Comparing the psychometric properties of checklists and global rating scales for assessing performance on an OSCE-format examination. Acad Med 1998; 73: 993-7.

140. Hodges $B$, Regehr $\mathrm{G}$, Hanson M, McNaughton $N$. Validation of an objective structured clinical examination in psychiatry. Acad Med 1998; 73:910-2.

141. Hodges $\mathrm{R}$, Regehr $\mathrm{G}$, McNaughton N, Tiberius R, Hanson M. OSCE checklists do not capture increasing levels of expertise. Acad Med 1999; 74: 1129434. 
142. Daelmans HEM, Scherpbier AllA, Van der Veuten CPM, Konker AJM Reliability of cinical oral examinations re-examined. Med Teach 2001; $23: 422-4$.

143. Norcini Jf, Blank LL, Arnold CK, Kimball HR. Examuner differences in the Mini-Cex. Adw Health Sci wduc 1997; 2: 27-33.

144. Khera $N$, Stroobant J. Primhak RA, Gupta R, Davies H. Traiming the ideal hospital doctor, the specialist registrars' perspective. Med Educ 2001; 35: $957-66$.

145. Creaves $\int D_{x}$ Grant J. Watching anaesthetists work using the professional judgement of conisultants to assess the developing clinical competence of tranees. Br I Anaesth 2000; 84: 525-33.

146. Calman KC, Temple JG, Naysmith R, Caimcross RG, Bennett SI. Reforming higher specialist training in the United Kingdom - a step along the continuum of medical education Med Educ 1999; 33: 28-33.

147. MoManus 1C, Winder BC, Gordon D. UK doctors attitudes to the General Medical Council's performance procedures, 1997-99. Med Educ 2001; 35(Suppl.1): 60-9.

148. Iirola T, Lund VE, Katila A], Mattila-Vuori A, Pälve $\mathrm{H}$. Teaching hospital physicians' skills and knowledge of resuscitation algorithms are deficient. Acta Andesthesiol Scand 2002: 46: 1150-4.

149. Coats RD, Burd RS. Intraoperative communication of residents with faculty: perception versus reality. I Surg Res 2002; 104: 40-5.

150. Shreves JG. Moss AH. Resident's athical disagreenents with attending physicians: an unrecognized problem. Acad Med 1996; 71 : 1103-5.

151. Paice $\mathrm{E}$, Heard $\mathrm{S}$, Moss F. How important are role models in making good doctors? BMJ 2002; 325:707-10.

152. Prideaux D, Alexander H, Bower A, Dacre I, Haist $S$, Jolly B, Norcini J, Roberts T, Rothman $A$, Rowe $\mathbb{R}$, Tallett $S$. Clinical teaching: maintaining an educational role for doctors in the new heall thare environment. Med Educ 2000; 34: 820-6.

153. Lindgard L, Reznick R, DeVito I, Espin S. Forming professional identities on the health care team: discursive constructions of the "other" in the operating room. Med Educ $2002 ; 36: 728-34$.

154. Elliot DL, Hickam DH. Attending ward rounds on in-patient units: differences between medical and non-medical serwices. Med Educ 1993; 27:503-8.

155. Zwarenstein M, Bryant $W$. Interwentions to promote collaboration between nurses and doctors (Cochrane Review). In: The Cochrane Library, Issue 4. Oxford: Update Softward; 2001.

156. Risser D, Simon R, Rice M, Salisbury M. The potential for improved teamwark to reduce medical errors in the emergency department. Ann Emergency Med 1999; 34: $373-83$. 157. Busby A, Gilchrist B. The role of the nurse in the medical ward round. I Adv Nurs
$1992 ; 17: 339-46$.

158. Lindgard L, Reznick R, Espin $S_{*}$ Regehr C. DeVito I. Team communications in the operating room: talk patterns, sites of tension, and implications for novices. Acad Med $2002 ; 77 ; 37-42$.

159. Anderson DC, Harris $\llbracket B$, Allen S, Satran $L_{\text {, }}$ Btand $\mathrm{Cl}$, Davis-Feickert JA, Poland CA, Miller WJ. Comparing students feedlack about clinical instruction with their perfornances. Acad Med 1991; 66:29-34. 160. Fowell SL, Bligh $1 \mathrm{G}$. Recent developments in assessing medical students. Postgrad
Med $1998 ; 74: 18-24$.

161. Hays RB, Davies HA, Beard JD, Caldon LJM, Farmer EA, Finucane PM, McCrorie P, Newble DI, Schuwirth LWT, Sibbald GR. Selecting performance assessment methods for experienced physicians. Med Educ 2002; 36: 910-7. 


\section{CHAPTER 1}

\section{Designing an in-training assessment (ITA) programme}

Published in Medical Teacher 2003; 25: 54-62. http:/tnndf.co.uk/journals

Embracing the new paradigm of assessment in residency training. An assessment programme for first year residency training in anaesthesiology

C. Ringsted, D. Østergaard, and A. Scherpbier 


\begin{abstract}
Assessment of clinical competence is facing a paradigm shift in more than one sense. The shift relates to test content, which increasingly covers a broader spectrum of competencies than mere medical expertise and to test methods, with an increasing focus on testing performance in realistic settings. Also there is a shift in the concept of assessment in that instruction and assessment are no longer seen as being separate in time and purpose, but as integral parts of the learning process. The nature of the new paradigm for assessment is well described, but the challenge to programme directors is to specify the evaluation situations and develop appropriate methods. This paper describes the intrinsic rational validation process in outlining an assessment programme for first year anaesthesiology residency training according to the new paradigm. The applicability to other residency programmes and higher-level training in anaesthesiology is discussed.
\end{abstract}

\title{
Introduction
}

Postgraduate assessment of clinical competence is facing a paradigm shift due to changes in the roles of physicians and of assessment. First, the content of assessment covers an increasingly broader spectrum of competencies than mere medical expertise. The Report of the CanMEDs 2000 project, for example, defines seven roles and competencies for future specialists: medical expert, scholar, communicator, health advocate, manager, collaborator and professional. ${ }^{1}$ Similarly, The Accreditation Council for Graduate Medical Education in the United States has defined the following six general competencies: patient care, medical knowledge, practice-based learning and improvement, interpersonal and communication skills, professionalism, and system-based practice. ${ }^{2}$ The challenges are to define and specify the evaluation situations and train the evaluators. ${ }^{3}$ Second, the paradigm shift manifests itself in the assessment methods, which are targeting higher levels of Miller's pyramid.4 From a previous focus on the lower levels of the pyramid, i.e. 'knows' and 'knows how', the emphasis is shifting to performance assessment where a candidate must 'show how' and/or be observed 'doing' the tasks reflecting the competencies at stake. ${ }^{5}$ Considerable experience and high psychometric quality have been achieved in assessment at the level of "shows how', with standardised formats like the observed structured clinical examination (OSCE) and simulated patients., 7 At the 'does' level the prevailing method in residency assessment has been in-training observation with scoring on rating scales. There have been serious problems identified in 
the reliability of this approach. "Finally, there is a marked shift in the concept of assessment. Whereas instruction and assessment used to be separated in time and purpose, the current trend is towards assessment as an integral part of the learning process. If If we want to ensure that assessment does indeed drive learning and constitutes a learning experience, a variety of assessment methods is needed along with continuous documentation of the learning of the resident. The challenge in this area has been summarised by M Friedman Ben-David" as: "how to assess progression towards defined outcomes, integrated abilities, different forms of medical knowledge, on-the-job learning, learning through assessment, error management, and portfolio evidence".

These new perspectives on assessment have been translated by the Danish National Board of Health into new guidelines for postgraduate medical education.11, 12 In the future, residency programmes must address a broad spectrum of competencies in their objectives, learning strategies, and assessment. The broad spectrum of competencies included in the guidelines is derived from the seven roles and competencies defined by the CanMEDS 2000 Project. The guidelines stipulate that the objectives must represent an acceptable minimum standard of performance, the assessment must be criterion referenced, and it must be implemented as an on-going process rather than an end-of-training examination. Although the guidelines include suggestions for several assessment methods that may be used, they do not provide any further description, references or examples. Therefore, implementing the new guidelines poses a huge challenge, the more so because residency programmes in Denmark have not previously included specific assessment of trainees or specialist examinations. Until now, residency evaluation has consisted of at least three appraisal consultations of the trainee with a supervisor during each post and the trainee's evaluation of the programme.

This paper describes the intrinsic rational validation process, i.e. the reasons for particular decisions in test development, used in outlining an assessment programme for the first year of residency in anaesthesiology according to the new guidelines. ${ }^{3}$ The description of that process may be helpful to educators and programme directors in meeting the challenges. of the new paradigm. Also discussed is the applicability of the process to other residency programmes and higher-level training in anaesthesiology. 


\section{Method}

A project supported by the Danish Society of Anaesthesiology and Intensive Care Medicine (DASAIM) was set up to develop the assessment programme for anaesthesiology residency year 1 . The nationwide project was a joint venture with Copenhagen Hospital Corporation Postgraduate Medical Institute and was carried out by a working group of 20 people including members of DASAIM's board of education, consultants from various parts of the country and trainees. The authors of this article and the working group drafted an outline for the objectives and the assessment programme, based on a number of seminars, workshops and literature studies. The structure of the outline of the assessment programme was provided by five central questions with respect to residency assessment: Why, What, When, How and Who. Also taken into account was the programme's usability, defined as a function of the presumed validity, reliability, acceptability, effect on learning and costs as described by Van der Vleuten et $1{ }^{14}{ }^{14}$ Finally, a key principle was to design an assessment programme that fitted in the context of daily practice in anaesthesiology departments and took account of the fact that trainees are perceived as part of the workforce. Between the seminars parts of the assessment programme were tried out in practice. On the basis of these experiences the assessment programme was continuously adjusted, especially its practicability and acceptability. All decisions were made by consensus and a draft was distributed to core faculty for review. The final curriculum, including the assessment programme, was implemented in all. first year residency programmes in May 2001. The curriculum has been published in a book entitled 'The Education Book for 1st year training in Anaesthesiology'15, which was sent out to all anaesthetists in Denmark. It is also available on the Internet, www.dasaim.dk.

\section{Results}

Examples of the key competences and objectives are listed in Table 1. The seven roles and competences have been reduced to six by integrating the role of 'health advocate' with that of 'medical expert', which includes identification of determinants of health and preventive measures that are important to risk and outcome in anaesthesia. The objectives include a list of procedures to be mastered by trainees at the end of the first year of
training. 
Table 1. Examples of key objectives in a first-year residency in anaesthesiology related to the new roles and competences

\begin{tabular}{|c|c|}
\hline Rale & Objectioes of some of the key commetences \\
\hline 1. Medical expert* & $\begin{array}{l}\text { - Manage ASA group 1-2 patients for anaesthesia as a team leader } \\
\text { and ASA group } 3-5 \text { as a team member } \\
\text { - Manage simple intensive care patients } \\
\text { - Manage simple emergencies including CPR as atean leader and } \\
\text { initiate and sustain resuscitation of complicated patients and chil- } \\
\text { dren until more experienced staff arrives } \\
\text { - Manage procedures acording to procedure list }\end{array}$ \\
\hline 2. Communicator & $\begin{array}{l}\text { - Establish relations with patients and relatives characterised by } \\
\text { understanding respect, empathy and confidence. } \\
\text { - Communicate effectively and encourage patient participation in } \\
\text { decision making when appropriate } \\
\text { - Recognize ethical and attitudinal dilemmas and discuss these with } \\
\text { respect for patients' integrity, wishes and rights regarding infor- } \\
\text { mation and participation in decisions }\end{array}$ \\
\hline 3. Collaborator & $\begin{array}{l}\text { - Demonstrates effective communication with the multi- } \\
\text { - Wrofessional team } \\
\text { and ability to take either the role as team leader or team member } \\
\text { when appropriate } \\
\text { - Respect the skills of other team members and their specific roles in } \\
\text { different situations. Contribute to making the team appear ho- } \\
\text { mogenous and professional to the patients and relatives, and con- } \\
\text { tribute to effective and consistent information to patients and rela- } \\
\text { tives }\end{array}$ \\
\hline 4. Manager & $\begin{array}{l}\text { - Is organised in his/her work, demonstrates planning, considera- } \\
\text { tion, precaution, and responsibility. Works systematically and } \\
\text { properly in a way that demonstrates a generall overview of situa- } \\
\text { tions } \\
\text { - Sets proper priorities among tasks and patients on the acute list } \\
\text { according to patients" needs and the availability of staff and re- } \\
\text { sources, and uses resources effectively }\end{array}$ \\
\hline 5. Scholar & $\begin{array}{l}\text { - Can perform a critical analysis of a patient course using the litert- } \\
\text { ture and guidelines and reflect critically on ow practice and that } \\
\text { of the department ingeneral } \\
\text { - Is able to identify a clinical problem and reformulate it ats a re- } \\
\text { search question that can be answered through al literature search. } \\
\text { Can perform afocused literature search, a critical appraisal of the } \\
\text { literature, discuss the results and the implications for the specific } \\
\text { clinical problem. Is able to present this in a short written report }\end{array}$ \\
\hline 6. Professional & $\begin{array}{l}\text { - Recognize the importance of knowing own limitations, express } \\
\text { this openly and call for timely assistance from more experienced } \\
\text { colleagues when appropriate } \\
\text { - Understands the importance of proper recording and registration } \\
\text { of data and demonstrates this in written and oral communica- } \\
\text { tionDemonstrates respect for effective patient management and } \\
\text { management of the operating list. Demonstrates punctuality. }\end{array}$ \\
\hline
\end{tabular}

Note: "The list of objectives for this role is more elaborate than shown here. 


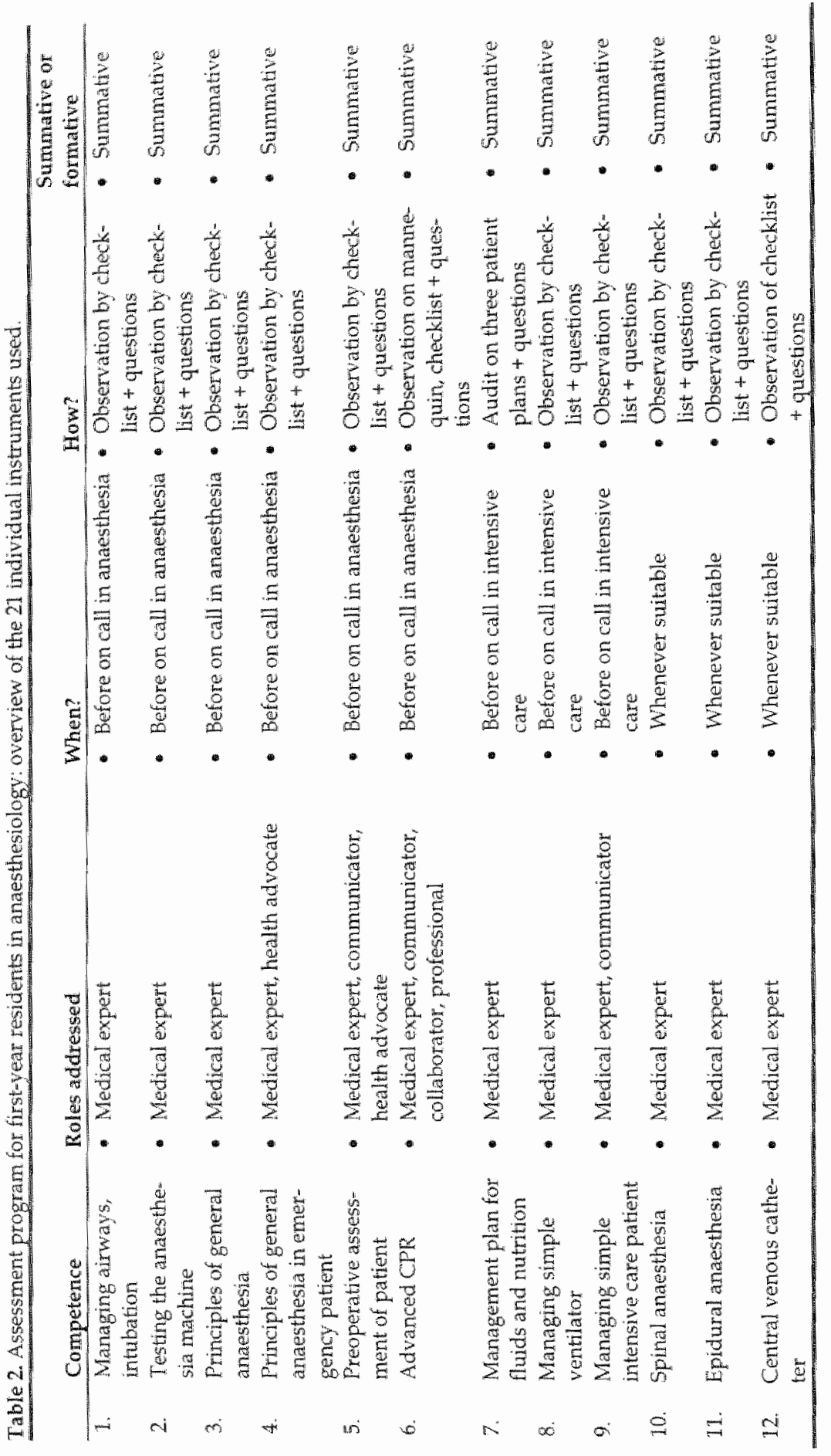




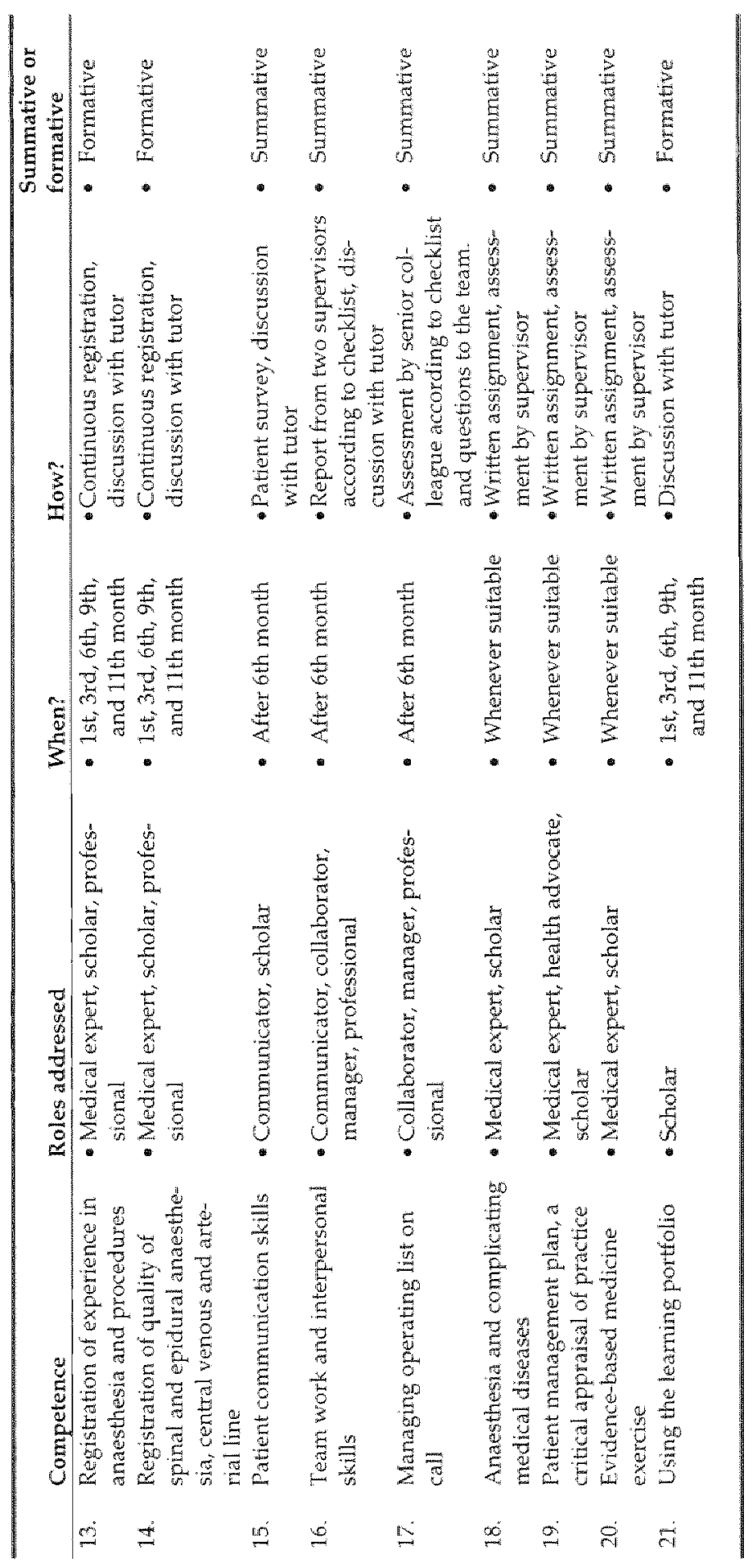


'The Education Book' contains a list of key textbooks and other references relevant to first year residents. Each anaesthesiology department designs it's own training programme targeted at the stated objectives. In addition, the departments in each of the three geographical regions in Denmark, North, South and East, collaborates on designing 10 one-day seminars to be attended by the residents. Issues of basic scientific knowledge and anaesthesia knowledge are addressed in the training programmes and the seminars. The resulting assessment programme consists of 21 specific tests or assessment strategies (Table 2). A few examples of the assessment formats are given in the Appendix. The programme is presented below under the headings why, what, when, how and who.

\section{Why?}

The basic question to be answered before an assessment programme can be designed asks about the purpose of the programme. The working group identified several purposes of assessment of first year residents. Assessment assures trainees and stakeholders that minimum standards are met. The assessment programme also serves as an aid to the educational programme. One of the main purposes is to reduce trainees" stress levels in emergency situations by increasing their confidence in their own abilities. Another purpose is to take advantage of the fact that assessment drives learning and that trainees can learn through assessment. The assessment programme is also aimed at fostering a positive attitude towards systematic collection of data and information on quality of care and a continuous and systematic review of and reflection on clinical practice. Finally, assessment is used for a summative purpose that is the selection of trainees for higher-level residency training in anaesthesiology. The assessment programme was constructed to meet all these purposes.

\section{What?}

This question refers to the content of assessment. What do we need to evaluate to ensure that assessment fulfils the purposes we have identified? Table 2 lists the 21 competencies that comprise the assessment programme. The assessment programme should reflect the objectives including the wide spectrum of roles and competences. Being aware that only a sample of the learning of residents can be tested, the group aimed at constructing a programme focused on competences and procedures that were perceived to be of major importance or more complex. The first twelve competences are related to procedural skills and standard patient management skills. It was decided to assess managing airways and intubation skills because of the potential risk of life threatening complications. In Checking the anaesthetic machine was selected because this is often neglected by physicians, ${ }^{7}$ and basic life support skills because an- 
aesthesiology residents have been shown to be unable to perform these skills properly even while in training and without recognizing this themselves. ${ }^{18}$ Skills such as spinal and epidural anaesthesia and central venous line were included because of uncertainties regarding the learning curves and the relation between experience and complications. 19.30 In item 14 these skills are assessed from the perspective of other roles. Other procedures such as laryngeal mask and peripheral venous catheter were perceived as more simple and therefore not requiring the same attention. Item 13 consists of continuous documentation of trainees' experiences during the year. A special log (item 14) tests four procedures: spinal and epidural anaesthesia, central venous line, and arterial catheter. Patient communication skills (item 15) are assessed by a patient survey and items 16 and 17 address managerial, collaboration, and professional competences. Items 18-20 assess reflection on practice and academic competence in three areas. Item 18, 'anaesthesia and complicating diseases' evaluates the choice of anaesthetic practice for a standard case and changes of practice related to various complicating conditions, item 19 requires the trainee to write a management plan and reflections on the actual perioperative course, and item 20 addresses the trainee's performance in applying the principles of evidence-based-medicine. Finally, the trainees" competence in self-directed learning is assessed (item no 21).

\section{How?}

One of the aims of the assessment programme is to facilitate learning through assessment. Hence both trainees and assessors are informed of the assessment programme and its content. If a trainee fails a test, the general rule is that proper remediation is instituted and the assessment procedure repeated. A handbook for assessors contains guidelines on how to handle situations where trainees do not pass a test and other potential problems, for instance difficulties arising from the conflicting roles of preceptor and assessor being combined in one person at the same time.

How the 21 competencies are assessed is shown in Table 2. For the first twelve competences direct observation is used with scoring on a checklist, which also includes some standard questions on, for example indications, contra-indications, risk of complications, their treatment and preventive measures, drug choice and dose, ethical considerations, etc. The scoring on the checklist is binary, yes/no, and all items on the checklist must be correct for the performance of the skill to be approved. These tests are summative and at the 'shows how' level. They must be passed before the trainee is allowed to perform without close supervision or assigned to be on call.

The assessment method used in item 13 is documentation of the trainee's experiences over the course of the year. The data to be entered 
are related to patient cases, procedures and complications. This method tests at the "does" level and is used for formative assessment. The database is reviewed regularly with the trainee's tutor and helps direct the trainee's activities or indicates when remediation is needed. At the same time the database serves as documentation of whether objectives of procedurall skills have been met.

The four procedures of item 14 are tested by means of a $\log$, which monitors the quality of the procedures, by use of the Cusum technique.2" The principle in the Cusum technique is that every time the procedure is performed, the trainee records success or failure by a specific scoring system, which takes the failure rate of experienced anaesthetists into account. This instrument tests at the 'does' level and over time the scoring provides a learning curve identifying trainees in need of remediation.

Patient communication skills (item 15) are assessed by a patient survey including 10 questions and 25 patients. The questionnaine is predesigned and included in 'The Education Book'. The trainee is responsible for carrying out the survey and for reporting the results to the tutor. This is also a test at the "does' level. If the results of the survey do not meet the set criterion, the trainee will be observed in at least five patient encounters. Performance is scored on a checklist that is similar to the questions in the survey.

Managerial, collaboration and professional competences (items 16 and 17) are assessed by two individual senior staff members for day time performance and by one senior on call. The competences are scored on specified rating scales. For the on call assessment the rating scales include questions about the organisation and function of the anaesthetic team and the hospital organisation, and about procedures in emergencies and catastrophes.

Reflection on practice and academic competence (items 18-20) are assessed by three written assignments. 'Anaesthesia and complicating diseases ${ }^{*}$ requires the trainee to discuss the choice of anaesthetic practice for a standard case and changes of practice related to various complicating conditions. The written assignment on the patient management plan (item 19) requires the resident to describe a management plan for a patient of his or her own choice, followed by reflections on the actual perioperative course. A third written assignment (item 20) is an exercise in evidence-based-medicine relating to a case selected by the trainee. Supervisors assess the assignments using standard review formats.

Finally, the trainees" competence in self-directed learning (item 21) is assessed by use of a learning portfolio. An outline and examples of the principles of the learning portfolio are specified to trainees and tutors. The leaming portfolio is used for formative evaluation and as subject of discussion at regular meetings of tutor and resident. 
When?

The timing of the individual tests is in principle left to the initiative of the trainees. A resident has to notify a senior staff member that he or she feels ready to be assessed. The assessment programme is designed to ensure that individual tests are timed in accordance with the aim of the assessment and the competence at stake. Thus assessment of procedural skills is mainly placed at the beginning of the year and assessment of academic competencies and reflection on practice in the second half of the training year, when the trainees have gained some experience in various procedures and patients. Assessment at the 'does level' through continuous collection of data and assessment of self-directed learning abilities is an ongoing activity throughout the year.

\section{Who?}

The assessment programme is designed in such detail that any specialist in anaesthesiology can function as an assessor. In each department one consultant is responsible for resident education and each resident is assigned a tutor, who sees to it that tests are taken in due time and that the trainee returns the signed forms to document satisfactory performance of competencies. The consultant responsible for education approves by signature a final list of the summative assessments.

\section{Discussion}

This paper describes how an assessment programme was designed according to the new paradigm that is facing residency education. The assessment programme does not include a national, uniform end-oftraining examination. It is entirely based on timely assessment in clinical practice in the individual departments. Nevertheless the programme is implemented nationwide and the detailed outline of the assessment programme, which includes the checklists to be used, ensures that all trainees are assessed by the same methods and standards. "The programme has several advantages. Its independence of time and place is an advantage in a system where not all trainee posts in all hospitals start at the same time. Furthermore, the programme is proactive in that trainees' performance on procedures is assessed at the time when they are actually expected to perform the procedures in clinical practice, which seems logicall from a quality of care point of view. This approach may speed up the learning process as was demonstrated by Long in a neurosurgery residency. ${ }^{22}$ Another advantage is the opportunity for timely remediation. Finally, as expressed by working group members who piloted the indi- 
vidual tests, "one positive side effect is that as an assessor you have to keep up to the standards". The disadvantages that were foreseen are the conflict inherent in combining the roles of appraiser and assessor in the same person and the problem of educating the assessors."

Any assessment programme will have to meet requirements of reliability, validity, feasibility, acceptability, and effect on learning and we are currently investigating these issues. ${ }^{23,}{ }^{24}$ In the following we discuss these issues and how they have influenced our choice of design and methods.

Regarding the reliability of observations in residency assessment Noel ct al 25 revealed serious problems in internal medicine and showed that facullty in university hospitals were more accurate than staff in community hospitals. They demonstrated that accuracy was improved by the use of checklists. Whether the content of the items in our assessment programme is sufficiently detailed in this respect remains to be shown. The reliability of logbook data and learning portfolios is problematic ${ }^{26,27}$ and we are currently using these methods for formative assessment only. Patient ratings of communication skills from 20-40 patients on 5 to 10 items have been shown to be sufficient for obtaining a reproducible, meaningful indicator of residents' skills, ${ }^{2.8}$

In order to be valid the assessment programme should reflect the stated objectives including the wide spectrum of roles and competences. Being aware that any assessment programme can only test a sample from the entire domain, the group aimed to construct a programme that focused on competences and procedures that were considered to be of major importance or more conplex.

One important question is whether introducing this assessment system compared to the previous system, which has with no assessment, will result in more competent residents by the end of the first year of anaesthesiology residency. There are reasons to believe that introducing assessment will have a positive effect on learning as well as on teaching in the clinical setting. ${ }^{29}$ In dealing with many concerns regarding feasibility, acceptability, and cost, the working group worked hard to narrow down the programme. The somewhat limited number of observed tests may have a negative effect on learning and limit trainees' experiences as a result of the steering effect of assessment on trainees behaviour. ${ }^{30}$ This negative effect may be counterbalanced, however, by the positive effect of the continuous log on behaviour, which it is hoped will direct training to the entire set of objectives. Hunskaar \& Seim ${ }^{31}$ demonstrated such an effect when they introduced a list of objectives for procedures in an undergraduate curriculum without any other educational intervention. The positive as well as negative effects on learning will have to be studied 
further and the implementation of this assessment programme will be followed by an extensive evaluation.

An important question about an assessment programme is whether there are better ways to do the same thing. ${ }^{32}$ A final examination including an OSCE is a well-described alternative. ${ }^{33}$ A knowledge-of-skills test has been shown to correlate well with performance-based testing, and applied as a progress test would emphasise the effect on learning. ${ }^{34}$ Nevertheless, this kind of test cannot replace observation in practice and would not be appropriate for testing the broad spectrum of competences as required by the new paradigm.

Hays \& Wellard ${ }^{35}$ presented a model of an in-training assessment programme in postgraduate training for general practice. The main difference from our programme is that theirs is aimed at formative assessment and that the summative part is a final certification examination." Hays \& Wellard ${ }^{35}$ emphasised the problem of designing an assessment programme that is congruent with the values and tradition of the speciality. Family Medicine in Australia traditionally has a strong focus on adult learning principles and self-directed learning with feedback being regarded as a vital part of these principles. This means that formative intraining assessment is acceptable, whereas summative in-training assessment is perceived as incongruent with these principles. Interestingly, summative assessment is accepted in the form of a certificate examination. End-of-training examinations are not highly valued in some parts of Europe. Karle \& Nystrup ${ }^{36}$ summarised how pedagogical, methodological, legal and resource problems influence these aspects. They proposed a better alternative a comprehensive formative evaluation involving both trainees and institutions.

One of the controversial elements of the programme described in this article is that it does not test cognitive knowledge to the extent that traditional board examinations do.37 Board examinations include a comprehensive test of knowledge and they are generally perceived as the "gold standard'. Slogoff et al. ${ }^{38}$ studied the relation between good clinical performance and results on a board examination in anaesthesiology. They found a strong relation between clinical skills ratings and certification success rates. Clinical skills ratings consisted of the consultant's judgement whether he/she would permit the anaesthetist to provide anaesthesia care for him/her in three increasingly complex scenarios. Reich et al. ${ }^{34}$ demonstrated that tests in the academic domain administered within the first month of anaesthesiology residency were mildlly predictive of clinical performance whereas tests administered after 6 and 13 months were not. McLeskey \& Ward ${ }^{40}$ found that senior residents appeared to perform worse on written examinations compared to junior residents with less than 2 years of training. The question is whether there is a causal rela- 
thonship between board certification and good clinical pertormance or whether it is a matter of comexisting phenomena. Friedman Ben-David 3 addressed the question of the relation between practice and knowledge in a paper on the future role of assessment and stated that: "Core knowledge may take on a completely different meaning when decisions are made as to what forms of knowledge should be separated from action and which forms of knowledge should be inferred from action.". According to Rasmussent the first step in practice leaming is the acquisition of skills, and this can be achieved before the full theoretical knowledge for their application has been acquired. 42 As skills are acquired, trainees learn to follow rules that constilute appropriate responses to most situations most of the time. At higher levels solutions are derived from broad experience and not directly related exclusively to the specific information that is available in the current situation. Our assessment programme is designed for firstyear anaesthesiology residency training, and assessment of procedural skills by observation and checklists corresponds to the lower levels of practice learning, whereas the written assignments and the leaming portfolio target the more experienced level in the latter half of the year. In that sense the design of our programme seems appropriate for first year residents.

One aim of our assessment programme is to decide whether trainees can move on to higher-level residency training. An important issue in this respect is to assess whether trainees are able to perform basic tasks relevant to anaesthesiology by testing the 'shows how' level. It is also important to test whether the trainees are able to accommodate to the speciality"s standards of professionalism. Slogoff et als found that consultants' indications of trainees' professional competence were strongly linked to chinical skills ratings. Cusimano et a th $^{\text {th }}$ showed in neurosurgery residencies that reasons for dismissals were issues of protessionalism and not cognitive deficits. Also in that sense it appears rational that our assessment programme should include aspects of professionalism.

The design and methods used in our assessment programme may not be suitable for higher levels of training or other specialities. The use of checklists, for example, has been shown to be inappropriate in higher levels of experience and more complex skills. In anaesthesiology highstakes simulators are likely to be used in the future for testing complex skills and integrated abilities. 3

Different specialities have different values, traits and preferred leaming styles and the education and assessment strategies will have to be in keeping with those.45 Baker ot al. 4 identified a predominance of the 'Accommodator learning style' emphasising clinical experience in anaesthesiology and the authors point to the importance of assignments in mon-dominant areas such as conceptual knowledge, writing and research. 
In our assessment programme the academic activities in the three written assignments are in accordance with this perspective. The emphasis on various domains may be different for other spectalities.

\section{Conclusion}

We believe that the process and considerations involved in outlining the assessment programme for the first year of andesthesiology residency training may serve as a template for those who wish to design similar programmes for other specialities. The specific design and the methods will probably have to be adapted if they are to be used in higher levels of training in anaesthesiology and in other specialities.

Acknowledgements: The working group that compiled "The education book for first year residency in anaesthesiology included: Andersen $N$, Berlac PA, Bested $K$, Callesen T, Christensen P, Jensen E, Jensen IW, Lemholt $K$, Lund J, Malling B, Mandøe $H$, Norregaard O, Pedersen BD, Petersen JA, Ravlo O, Ravn L, Ringsted C, Skjelsager K, Sprehn M, Ostergaard D.

\section{References}

1. CanMEDS 2000: Extract from the CanMEDS 2000 Project Societal Needs Working Group Report. Med Teach 2000; 22: 549-54.

2. Accreditation Council for Graduate Medical Education. Outcome project (http://WwW ACGME.org), 2000.

3. Friedman Ben-David $M$. The rote of assessment in expanding professional homizons. Med Teach $2000,22,472-7$.

4. Miller G. Conterence summary. Acad Med 1993;68:471-4

5. Dauphinee WD. Assessing dinical performance. Where do we stand and what migit we expect? JAMA 1995; 274:741-3.

6. Harden R, Gleeson $\mathrm{F}$. Assessment of chinical competence using an objective structured clinical examination (OSCF). Med Educ 1979; 13:41-54.

7. Van der Veuten CPM, Swanson DB. Assessment of chinical skills with standardized patients: state of the art. Teach Learn Med 1990; 2: $58-76$.

8. Gray ID. Global rating scales in residency education. Acad Med 1996:71:555-63.

9. Feletli $G$, Cameron D, Dawson-Saunders B, Des Groseilliers J, Dooley B, Farmer D, McAvoy $P$. In-training assessment. In: Newble D, Jolly $B$, Wakeford $R_{2}$, ats. The certification and recertification of doctors: Issues in the assessment of clinical competence. Cambridge University Press. 1994: 151 -66.

10. Shepard 1.A. The role of assessment in a leaming culture. Educ Research 2000; 29:4-14.

11. Ministry of Health. The Future specialist. Roport from the Specialist Commission. Report no. 1384. Copenhagen Statens Information, 2000.

12. National Board of Heallh. Guidelines for Curriculum of Specialist Education. Copenhagen: National Board of Health, 2001. 
13. Ebel RL Frisbie DA. Esentials of educational meashrement In: Ebel RL, Frisbie DA, eds. 5h edr. Englewood Clifs, New Jersey: Premtice Hall, 1991: $102-5$.

14. Van der VEuten CPM, Scherpbier AJA, Dolmans DHIM, Schuwirth LWT, Verwinen CM, Wolluagn MAP. Clerkship assessment assessed. Med Teach 2000, 22. 592-600.

15. Ringsted C, Ostergard D. The aducation book for 1 st year training in anawthesology [Uddandsesbog. Introdukionsuddannelsen i anzestesiologi, ISSPM] (htp:/ /www dasam dk and htp//wwwhspmidk), Copenhagen, Denmark: CHC Pustgraduate Medical lnstitute, 2001 .

16. Crosby ET, Cooper RM, Doughas M], Doyle DI, Hung OR, Labrecque P, Muir H, Mur phy MF Preston RP, Rose DK, Roy L. The unanticipated difficult arway with recommendations for management. Can J of Anaesth 1998; 45:757-76.

17. Kloptenstein CE, van Gesgel E, Forster A. Checking the anaesthetic machine: selfreponted assessment in a unversity hosptal. Eur of Anaesth 1998; 15: 314-9.

18. Noordergraaf GJ, Be WK, Sabbe M, Diets RF, Noondergraaf A, van Hemelnijck J. Training needs and qualifications of anaesthesiologists not exposed to ALS. Resuscitation $1999: 40: 147-60$.

19. Kopacz DI. Neal IM, Pollock]. The regional anaesthesia Jearning curve' What is the minimum number of epidural and spinal blocks to reach consistency? Regional Anesthesia $1996,21: 182-90$.

20. Konnad $\mathrm{C}$, Scupfer $\mathrm{G}$, Wiethishbach M, Gerber M. Learning manual skills in anesthesiology. Is thene a recommendad number of cases for anesthestic procedunes? Anesth Analg 1998; $86: 635-9$

21. Kestin IC. A statistical approach to rueasuring the competence of anaesthetic tranees at practical procedures. Bry Anaesth1 $1995 ; 75: 805-9$.

22. Long DM. Competency based residency training: the next advance in graduate medical education. Acad Med 2000; 75: 1178-83

23. Van der Weuten CPM. The assessment of professional competence developments, research and practical implications. Adv Health sci Educ 1996; 1: 41-67.

24. Fowell St, Southgate L.,. Bligh JG. Evaluating assessment: the missing link? Med Educ $1999 ; 33 \cdot 276-81$

25. Noel GL, Herbers IE, Caplow MP, Cooper GS, Pangaro JN, Harvey J. How well do internal medicine faculty members evaluate the clinical skills of residents? Ann Int Med 1992;117:757-65. 26. Pits 1. Coles C, Thomas IP. Enhancing reliability in portfolio assessment. 'shaping' the
portfolio. Med Teach 2001: $23: 351-6$.

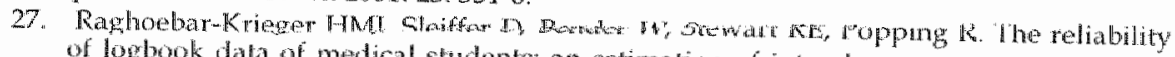
of logbook data of medical students: an estimation of interobserver ageement, sensi-
tiwity and specificity. Med Rduc $2001 ; 35: 624-31$.

28. Swanson, DF, Wobster GD, Norcini J]. Precision of patient ratings of residents' human-

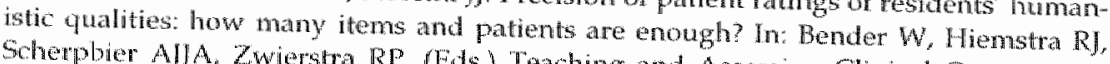

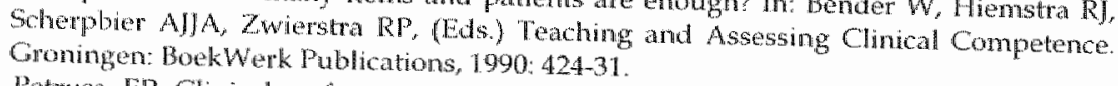

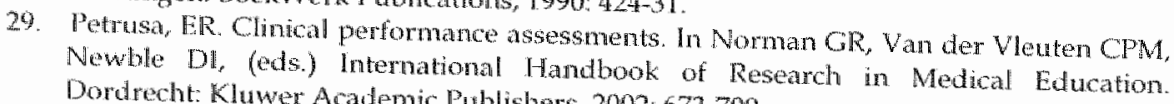
Dordrecht: Kluwar. Acatemic Publishers, 2002: 673-709

30. Waketord $\mathbb{R E}$, southgate L. Postgraduate medical education. Changing trainees" study approachos by changing the examination. Teach Leam Med 1992; $4: 210 \mathrm{~m}$.

31. Hurskad $A$ Seim AH. The effect of a checkist on pratical skills. Med Educ 1984: 18:439-42. Scthriven. M. The nature of evaluation part I: Relation to psychology Practical Assess1999.

33. Siker $\mathrm{BS}$. Assessment of cinical competence. Cument Opinion in Anaesthesiology,
$1999 ; 2: 677-84$. 


\section{Designing an in-training assessment (TTA) programme}

34. Ram P, wan der Vleuten $C$, Rethans II. Schouten B. Hobma S, Grol R. Assessment in general practice: the predictive value of written-knowledge tests and a multiple-station examination for actual medical performance in daily practice. Med Edur 1999; 33:197. 203.

35. Hays $\mathbb{R}$, Wellard $\mathrm{R}$. In-training assessment in postgraduate twaning for general practice Med Educ 1998; 32: 507-13.

36. Karle H, Nystrup J. Comprehensive evaluation of specialist training: an alternative to Board examinations in Europe? Med Educ 1995; 29, 308-16.

37. Zorab JSM. The educational activities of the European Acatemy of Anaesthesiology. Minerva Anestesiologica 1998; 64: 477-82.

38. Slogoff $S_{n}$ Hughes FP, Hug CC, Longnecker DE, Saidman LI. A denonstration of validity for certification by the American Board of Anesthesiology. Acad Med 1994,69:740-6.

39. Reich DL. Uysal S, Bodian CA, Gabriele S, Hibbard M Gordon W, Sliwinki M, Kayne RD. The relationship of cognitive, personality, and academic measure to anesthesiology resident clinical performance. Anesth Analg 1999; 88: 1092-1100.

40. McLeskey $\mathrm{CH}$, Ward R]. Validity of written examination. Anesthesiology 1978, $49: 224$

41. Rasmussen. J. Skills, rules, knowledge, signalls, signs and symbols and other distimcthons in human performance models. IEEE Transactions Systems, Man and Cybernetics $1983,123: 257-66$.

42. Rasmussen $\mathrm{J}$, Lind $\mathrm{M}$. A model of human decision making in complex systens and its use for design of system controll strategies. Riso National Laboratory Report. (Riso-M2349, Roskilde, Denmark), 1982.

43. Cusimano MD, Yonke AM, Tucker WS. An analysis of attrition from Canadian neurosurgery residency programs. Acad Med 1999; 74: 925-31.

44. Hodges B, Regelur G, McNaughton N, Tiberius R, Hanson M. OSCE checklists do not capture increasing levels of expertise. Acad Med 1999: 74: 1129-34

45. Baker $\mathrm{JD}$, Cooke $\rrbracket \mathrm{E}$, Contoy JM, Bromley HR, Hollon MF, Alpert CC. Beyond career choice: the role of learning style analysis in residency training. Med Educ 1988,22:52732.

46. Merril JM, Camacho Z, Laux LF, Lorimor B, Thomby J1, Vallbona C. Uncertaintes and ambiguities: measuring how medical students cope. Med Educ $1994 ; 28: 316-22$.

47. Stilwell NA, Wallick MM, Thal SE, Burleson JA. Myers-Briggs type and medical specialty choice: a new look at an old question. Teach Learn Med, 2000; 12: 14-20. 


\section{Appendix: Examples of checklists/assessment forms}

Example of checklist used for observing a procedure - conduct of a spinal anaesthesia

The resident indicates when the/ she is ready for assessment and finds a senior colleague that can superwise him/ her according to this checklist. All items on the checklist should be correct in ordter to approve the competence.

- Outlines plan for anaesthesia including description of indication of proper effect, acceptable blood pressure values, plan for mananging side-effects or unwanted effects

- Makes proper preparations in the artaesthetic and operating rooms

- Can explain choice of anaesthetic and dose related to the planned surgery

- Informs and instructs patient properly regarding the procedure

- Performs proper sterile preparation; check medicine and instruments

- Makes correct positioning of patient in collaboration with assistant

- Indicates correct site of needle prick

- Uses proper strerile technique

- Uses correct needle technique and assures correct needle position before injecting anaesthetic

- Performs proper observation and monitoring of patient after injection of local anaesthetic

- Initiates proper measures to support cardiovascular function

- Makes proper test of the analgesia and indicate segnental levet correctly

- Can mame indications and contra-indication to spinal anaesthesia

- Can name al least three complications and risks of spinal anaesthesia; can describe precautions regarding prevention and describe proper managenent of these complications.

Kes No

This competence is acceptable

Name of supervisor:

Name of resident:

Date: 


\section{Designing an in-training assessment (IT A) programme}

Example of assessment form used for assessing organisattonal skills and collaboration in the anaesthetic deparment.

Two senior colleagues independently assess this competence using this form. On behalf of these two assessments the tutor makes an overall assessment. Mean score from the two seniors should be $\geq 3$ in order to approve the competence

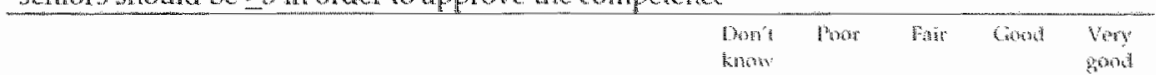

\section{Organizing own work}

- Demonstrates proper planning and orcer of prior ity of work

- Shows thoughtrulness and vigilance during work and management of the situations

- Demonstrates tidiness and structured approach to pracise

- Demonstrates punctuality in appearance and gives information on whereabouts and how he/she can be contacted or called

\section{Professional appearance}

- Knows his/her own limits of competence

- Demonstrates responsibility towards work assignments.

- Demonstrates ability to critical assessment of quality of practice

- Demonstrates ability to handle critical incidents and mistakes

- Shows respect towands demands for effective management of the operating list

\section{Team collaboration and communication}

- Works effectively in a team and assumes equally well the role as team member and team leader when appropriate

- Demonstrates understanding and respect for other taram members, their professional competence and situation-specific roles and assignnents

- Is receptive and apen, respects other people's opinion and contributes with own expertise when

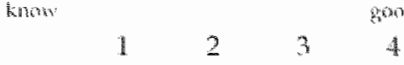

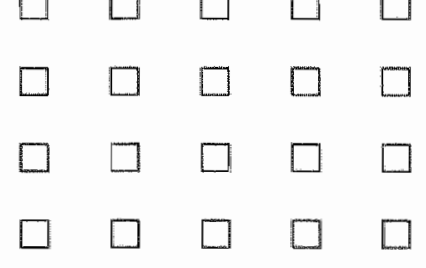
appropriate

Overall assessment by the tutor on behalf of the scoring of two assessors
The resident has been assessed by two senior colleagues:
Organization of own work is acceptable
Professional appearance is acceptable
Collaboration with the team is acceptable 


\section{Chapter1}

Example of assessment: profescional development and the use of the learning portfolio

This form is used at the regular meetings between tutor and resident

- Has the resident followed the learning plan from the last meeting?

- Has the objectives been met, i.e. can the resident describe what he/she has learned?

- If the objective has not been met - can the resident give a reasonable explanation?

- Has the learning portfolio been useful to the resident?

- Has the resident any suggestions regarding things that could be done differently in planning the next period?

- Has the mandatory assessments been completed according to the plan?

- Has the resident completed the logbook of experience and the Cusum scoring?

- Does the logbook shows proper breadth in experience?

- Does the Cusuri scoring shows proper development in the resident routine regarding the procedures?

- Has the resident accomplished the issues in the programme appropriately according to this stage of his/her education?

The professional development is acceptable

Yes No

No

口 $\square$

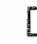
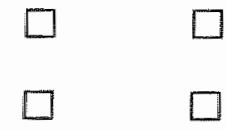

$\square$

(




\section{CHAPTER 2}

\section{Content validity of ITA}

Published in Acta Anaesthesiologica Scandinavica 2002; 46: 1119-23

Consultants' opinion on a new practice based assessment programme for first year residents in anaesthesiology.

C Ringsted, D Østergaard, and A. Scherpbier 


\section{Abstract}

Background: Assessment in postgraduate education is moving towards using a broad spectrum of practice-based assessment methods. This approach was recently introduced in first-year residency in anaesthesiology in Denmark. The new assessment programme covers: clinical skills, communication skills, organisational skills and collaborative skills, scholarly proficiencies, and professionalism. Eighteen out of a total of 21 assessment instruments are used for pass/fail decisions. The aim of this study was to survey consultants opinion of the programme in terms of the representativeness of competencies tested, the suitability of the programme as a basis for pass/fail decisions and the relevance and sufficiency of the content of the different assessment instruments.

Mefhods: A description of the assessment programme and a questionnaire were sent to all consultants in anaesthesiology in Denmark. The questionmaire consisted of items, to be answered on a five-point scale, asking the consultants' opinions about representativeness, suitability, and content of the programme.

Results: The response rate was $251 / 382(66 \%)$. More than $75 \%$ of the respondents agreed that the assessment programme offered adequate coverage of the competencies of a first-year resident and was appropriate for making pass/fail decisions. There was strong agreement that the content of the 18 tests used for pass/fail decisions was relevant and sufficient for pass/fail decisions.

Conclusion: Judging from the consultants opinions, the assessment programme for the first-year residency in anaesthesiology appears to be appropriate regarding the range of competencies assessed, the appropriateness as a basis for pass/fail decisions, and regarding of the content of tests used for pass/fail decisions. Further studies are needed to assess the feasibility and acceptability of the programme in practice.

\section{Introduction}

Assessment in postgraduate medical education is changing regarding content, methods and concept. A broader spectum of knowledge and skills are requited and this must be reflected in the assessment. "2 There is a move towards assessment by observation of residents performance in real practice and collection of information about performance from different sources. ${ }^{3}$. Furthermore, the concept of assessment as an end of training activity is increasingly being replaced by the view that assessment is an integral part of the leaming process." 
These ideas are reflected in the new guidelines for specialist training issued by the Danish National Board of Health. ${ }^{5}$ According to the guidelines, the objectives of residency programmes must cover a broad spectrum of competencies. Furthermore the new guidelines request the specialties to outline a formal assessment programme that must be implemented as an on-going process rather than an end-of-training examination. Although the guidelines include suggestions for several assessment methods that may be used, they do not provide any further description, references or examples.

A new curriculum for the first year of residency training in anaesthesiology was developed by a group of anaesthetists according to the new guidelines and introduced in the spring of 2001. "The assessment programme is practice-based and consists of 21 different instruments and methods, with tests being spread over the year. Implementing the new programme poses a huge challenge, the more so because residency programmes in Denmark have not previously included formal clinical assessment of residents or specialist examinations. Until now, residency evaluation has consisted of three appraisal consultations of the resident with a supervisor during each post, and the resident's evaluation of the programme.

Our assessment programme will be used by consultants nation wide. Specialist training in anaesthesiology in Denmark lasts 5 years of which 6 months are supplementary training in another speciality relevant to anaesthesiology. The first and final year of residency training can take place in general hospitals, whereas years 2 and 3 are performed in highly specialized university hospitals. The aim of this study was to survey consultants' opinion of the new assessment programme in terms of the representativeness of competencies tested, the suitability of the programme as a basis for pass/fail decisions and the relevance and sufficiency of the content of the different assessment instruments. At the same time we wanted to investigate if there was a relationship between the consultants' opinions and their having teaching responsibilities towards first-year versus second-and third-year residents.

\section{Method}

\section{Assessment progrmmme}

The assessment programme comprises 21 different assessments in which various instruments and methods are used. An overview of the programme is presented in Appendix 1. It lists for each of the 21 assessments: the competency to be assessed, when the assessment is to be scheduled, the method used, who performs the assessment, and whether 
it is summative or formative. Summative assessment means that the results are used for pass/fail decisions and formative assessment aims at providing feedback to the resident to guide further learning.

Eighteen of the 21. assessments are used for pass/fail decisions. Of these 18 assessments, 11 tests addressed procedural skills. Patient management plans, communication skills, collaborative skills and managerial skills were each assessed by one test, and three assessments dealt with theoretical reflection on practice. Observation in practice with scoring on detailed checklists was the method used for the assessment of procedural skills. Patient management plans regarding fluids and nutrition were assessed by a review of the resident's patient records. A patient survey was used to assess the resident's communication skills. Supervisors rated collaborative and managerial skills using a detailed checklist. There were three written assignments, which assessed theoretical reflection on practice. Items in the various instruments were scored dichotomously: yes or no. Residents had to obtain a pass on all test items. There were three instruments used for formative purposes: two logbooks in which the resident's clinical experiences with patients and procedures were recorded, and a learning portfolio for individual learning plans and reflection on learning. These instruments were discussed during regular meetings of resident and tutor.

\section{Consultants' opinions}

A questionnaire was sent out to all consultant anaesthetists in Denmark together with the curriculum and the assessment programme. The respondents were asked whether in their opinion 1) the range of competences of the assessment programme was representative of the competencies of first-year residents, 2) the assessment programme was appropriate for reaching a pass/fail decision about the first year, and 3) the assessment programme was appropriate to determine if the resident is ready to move on to the second year. For each of the 18 tests used for summative purposes the respondents were asked to indicate whether 4) the competency addressed was important 5) the content of the test was relevant, and 6$)$ the content of the test was sufficient for an adequate assessment of competence. The respondents were asked whether they had first or second/third-year residents in their department. Finally they were invited to add comments.

Respondents were asked to indicate their answers to questions 1-6 on a five-point scale, where $1=$ not at all and $5=$ to a high degree. A score at or above 4 from over $75 \%$ of respondents was considered an indication of strong agreement among consultants. Results are reported as medians (25-75 quartiles). Data were analysed using median test for comparison
between groups (SPS 10.0). 


\section{Results}

The questionnaires were sent out to 382 consultants and $251(66 \%) \mathrm{re}-$ sponded. The responses showed that $89(36 \%)$ consultants had firstyear residents in their departments, 114 (45\%) had second/third year and occasionally first year residents, and the remaining $48(19 \%)$ had no residents in years $1-3$ in their department.

The questions about the scope of the tests being representative of first year competence (question 1) and the appropriateness of the test as a basis for pass/fail decisions (questions 2 and 3) yielded scores of 4 or 5 from more than $75 \%$ of the respondents (Table 1). There were no statistically significant differences in responses between the groups of consultants.

Table 1. Consultants median ratings on a scale from $1=$ not at all to $5=$ to a high alegtee in response to questions about the assessment programme. The $25-75$ percentiles are given in brackets.

Median

Quentions (25-75 percentiles)

Is the range of competencies in the assessment programme representative of the competencies expected of a first: yedr resident?

Is the assessment programme appropriate as a basis for pass/fail decisions regarding the first-year of residercy training?

Is the assessment programme appropriate for decisions regarding residents competency to move to the second year of residency training?

Responses to the questions about each of the 18 tests used for pass/fail decisions are shown in Table 2. The median of the responses to the questions about the importance or the competency reflected in the test was 4 or 5 for each of the 18 tests. The lower quartile was 4 in 16 of the tests and 3 in two of the tests. The latter two were "Managing operating list on call' $(23 \%$ of responses $=3 ; 3 \%<3)$ and 'Evidence-based-niedicine exercise' $(26 \%$ of responses $=3,7 \%<3)$. The scores of the consultants with first-year residents in their departments were significantly lower (median 4) (3-4) compared with those of consultants with second and third year residents: median 4 (3-5), $P=0.000$.

The questions about the relevance and sufficiency of test content yielded median responses of 4 or 5 for all tests with the lower quartile always at or above 4 . There were no significant differences between the groups of consultants in their answers to these two questions. 
Table 2 . Consultants $(n=251)$ median responses on a scale from $1=$ not at all to $5=$ to a thigh degree to questions regarding the content of 18 tests used for pass/fail decisions. In brackets are the 25 and 75 percentiles.

$\begin{array}{lll}\text { How impor- Is the } & \text { Is the content } \\ \text { tant is this } & \begin{array}{l}\text { content of of this test } \\ \text { this test sufficiert? } \\ \text { competence? }\end{array}\end{array}$

\begin{tabular}{|c|c|c|c|}
\hline Managing arways and intubation & $5(5-5)$ & $5(5-5)$ & $4(4-5)$ \\
\hline Testing anaesthesia machine & $5(5-5)$ & $5(4-5)$ & $4(4-5)$ \\
\hline Principles of standard general anaesthesia & $5(5-5)$ & $5(5-5)$ & $5(4-5)$ \\
\hline $\begin{array}{l}\text { Principles of standard general anaesthesia } \\
\text { in emergency patient }\end{array}$ & $5(5-5)$ & $5(4-5)$ & $5(4-5)$ \\
\hline Preoperative assessment of patient & $5(5-5)$ & $5(4.25 \sim 5)$ & $5(4-5)$ \\
\hline Advanced CPR skills & $5(5-5)$ & $5(5-5)$ & $5(4-5)$ \\
\hline Managernent plan for fluids and nutrition & $4(4-5)$ & $5(4-5)$ & $5(4-5)$ \\
\hline Managing simple ventilator & $5(4-5)$ & $5(4-5)$ & $5(4-5)$ \\
\hline Managing simple intensive care patient & $4(4-5)$ & $5(4-5)$ & $5(4-5)$ \\
\hline Spinal anaesthesian & $5(4-5)$ & $5(5-5)$ & $5(4-5)$ \\
\hline Epidtural anaesthesia & 4. (4-5) & $5(4-5)$ & $5(4-5)$ \\
\hline Central venous catheter & $4(4-5)$ & $5(4-5)$ & $5(4-5)$ \\
\hline Patient communication skills & $5(4-5)$ & $5(4-5)$ & $5(4-5)$ \\
\hline Team work and interpersonal skills & $5(4-5)$ & $5(4-5)$ & $4(4-5)$ \\
\hline Monaging operating list on call & $4(3-5)$ & $5(4-5)$ & $5(4-5)$ \\
\hline $\begin{array}{l}\text { Anaesthesia and complicating medical } \\
\text { discases: Written assignment }\end{array}$ & $4(4-5)$ & $5(4.5)$ & $4(4-5)$ \\
\hline $\begin{array}{l}\text { Patient management plan: Written as } \\
\text { signment }\end{array}$ & $4(4-5)$ & $5(4-5)$ & $5(4-5)$ \\
\hline $\begin{array}{l}\text { Fividence-based medicine exercise: Written } \\
\text { assignment }\end{array}$ & $4(3-5)^{x}$ & $4(4-5)$ & $5(4-5)$ \\
\hline
\end{tabular}

One hundred and wenty-eight consultants commented on the assessment programme. In summary, 58 consultants praised the initiative. They used words like 'excellent' or 'brilliant' and thought that the assessment programme would improve specialist education. Fourteen consultants mentioned problems related to the implementation of the programme or thought that the programme or part of it was too ambitious. There were a number of comments about the wording of items. A few 
consultants mentioned the absence of specific skils, such as laryngeal mask and pain treatment.

\section{Discussion}

The consultants' opinion of the new assessment programme is important for various reasons. External opinion about the representativeness and the content of an assessment programme is essential before implenentation of any new assessment programme? "second, the introduction of fomal clinical assessment is new and controversial in Denmark, where the prevailing assessment method in residency training has been formative with no end-of-training examination.?

There was strong agreement regarding the representativeness of the tests incladed in the assessment programme. Any assessment programme will only be testing a subset of all the expected skills and competences. Surprisingly few consultants mentioned skills or competencies that they missed in the programme. The questionnaire did not include any specific test of how careful the consultants evaluated the different proposals. The number of comments about the wording of items and spelling errors indicate that the consultants actually wene very careful. The fact that the assessment programme is practice-based and will be used by consultants nationwide also gives us reason to believe that they were rather careful.

Strong agreement was observed regarding the content of most of the tests. In two tests the lower quartile was 3. One was the test mmaging operations list on call. The other test reflecting this competency, temwork and interpersonnl skils, showed strong agreement, which indicates that the perceived importance of this competency is not the problem. It is more likely that the variance reflects differences in work organisation in individual departments, with differences in the amount of responsibility given to first-year residents while on call. The other test, Evidence-brsedmedicine exercise", where the lower quartile was 3 , had a tendency to be rated as being of lower importance by the consultants from general hospitals than by those from university hospitals. This is not surprising as research activities are more prevailing among consultants at university hospitals, and hence this competency is likely to be more familiar. "Consultants at general hospitals may have doubts concerning the presence in their deparments of adequately qualified supervisors and assessors for these assignments. Although this concern was not expressed in the respondents' comments, there may be a need for training of trainers.

There was surprisingly positive attitude towards the programme. Denmark has previously resisted implementing the European Board Ex- 
amination in Anaesthesiology or a similar examination despite their use in several European countries.11, 12 The reason for the high degree of acceptance of our programme may be due to it being perceived as an appealing alternative to traditional final examination formats.

This study is limited to consultants" opinions on the outline of the assessment programme and not on actual experience with the programme. Further studies are needed to assess the feasibility of the programme and its acceptance in practice by both consultants and residents.

\section{Conclusion}

Judging from the consultants' opinions, the assessment programme for the first-year residency in anaesthesiology appears to be appropriate regarding the range of competencies assessed, the appropriateness of the tests for making pass/fail decisions and regarding the relevance and sufficiency of the content of each of the 18 tests used for pass/fail decisions.

Acknowledgements: The working group that compiled the curricullum and the assessment programme for first-year residency in anaesthesiology included: Andersen N, Berlac PA, Bested K, Callesen T, Christensen $P$, Jensen $E$, Jensen JW, Lemholt $K$, Lund I, Malling $B$, Mandøe H, Norregaard O, Pedersen BD, Petersen JA, Ravlo O, Ravn L, Ringsted C, Skjelsager K, Sprehn M, Østergaard D. We want to thank the consultants in anaesthesiology for answering the questionnaire and their constructive comments. 


\section{References}

1. Friedman Ben-David $M$. The role of assessment in expanding professional horizons. Med Teach $2000 ; 22: 472-7$.

2. CanMEDS 2000: Exiract from the CanMEDS 2000 Project Societal Needs Working Group Report. Med Teach 2000; 22:549-54.

3. Van der Vleuten CPM. The assessment of professional competence: developments, research and practical implications. Adv Health Sci Educ 1995; 1:41-67.

4. Shepard LA. The role of assessment in a learning culture. Educ Research 2000; $29: 4:-14$.

5. The National Board of Health. Guidelines for Curriculum or Specialist Galucation. Copenhagen: The National Board of Health, 2001.

6. Ringsted $C$, ostergaard $D$. The education book for first year residency in anaesthesiology. [Uddannelsesbog. Introduktionsuddannelsen i anestesiologi, HS Postgraduate Medicinske lnstitut] (www dasaim dk and www hspmi.dk). CHC Postgraduate Medical Institute, Copenhagen, 2001.

7. Ebel RL, Frisbie DA. Essentials of educational measurement. In: Ebel RL. Frisbie DA, eds. 5th edn. Englewood Clifts, New lersey: Prentice Hall, 1991: 102-5.

8. Fowell SL, Sonthgate LJ, Bligh JG. Evaluating assessment: the missing link? Med Educ $1999 ; 33: 276-81$.

9. Karle $\mathrm{H}$. Nystrup f. Comprehensive evaluation of specialist training: an altemative to Board examinations in Europe? Med Educ 1995; 29:308-16.

10. Nielsen $L B$, Jensen TUS, Skovgaard $L T_{r}$ Viby-Mogensen J. Research in Danish departments of anaesthesiology at the turn of the century: A biblometric analysis. Ugeskr Laeger $2001 ; 163: 6121-7$.

11. Wiklund $L$. Education of specialists in anaesthesia and intensive care in Europe - A Swedish perspective. Ann Acad Med Singapore 1994; 23: 623.9.

12. Zorab JS. The European Diploma in Anaesthesiology and Intensiwe Care of the Eurom pean Academy of Anaesthesiology. Acta Anaesthesiol Scand 1995; 39: 579.81. 


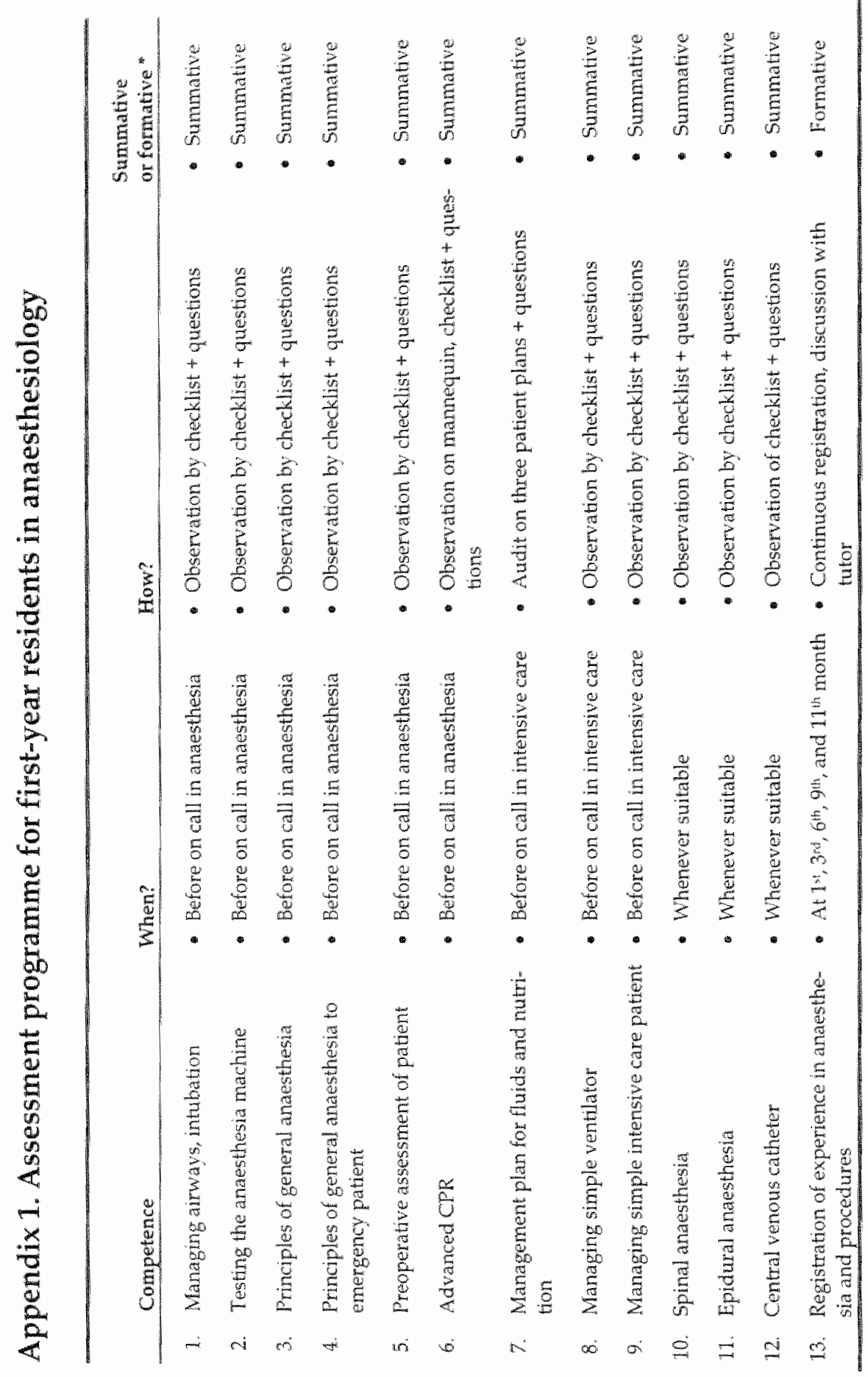




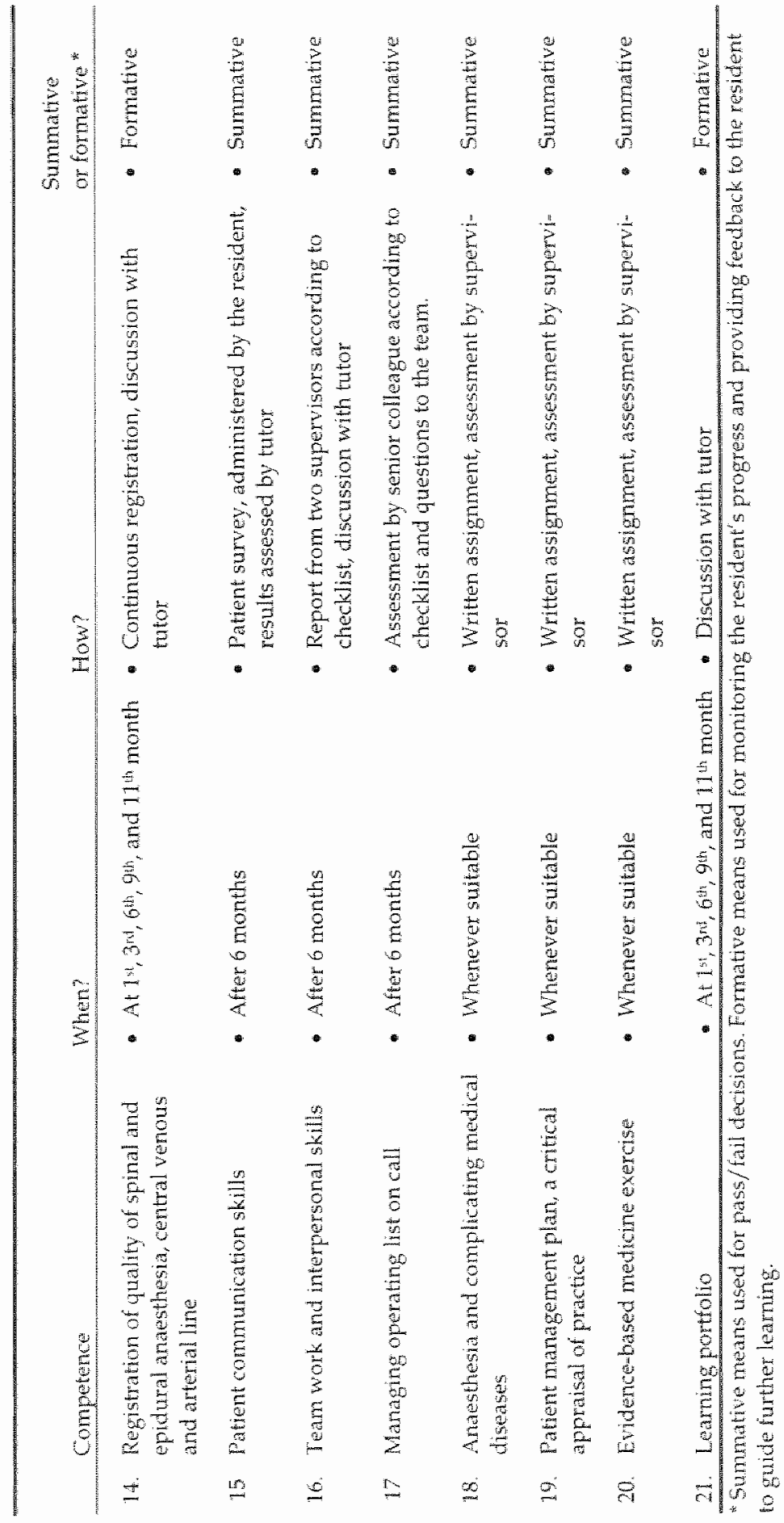


. 


\section{CHAPTER 3}

\section{Feasibility of scoring forms}

Published in Medical Teacher 2003; 25: 654-8. htw:/trmaf.co mkjoumnls

A feasibility study comparing checklists and global rating forms to assess resident performance in clinical skills.

C Ringsted, D Østergaard, L Ravn, JA Petersen, PA Berlac, CPM van der Vleuten 


\section{Abstract}

This study evaluated the feasibility of two different scoring forms for assessing the clinical performance of residents in anaesthesiology. One of the forms had a checklist format including task specific items and the other was a global rating form with general dimensions of competence including 'clinical skills', 'communication skills', and 'knowledge'. Thirty-two clinicians representing 25 (83\%) of the 30 training hospitals in the country participated in the study. The clinicians were randomised into two groups each of which used one of the scoring formats to assess a resident's performance in four simulated clinical scenarios on videotape. Clinicians' opinions about the appropriateness of the scoring forms were rated on a scale of $1-5$. The checklist format was rated significantly higher compared with the global rating form (mean 4.6 SD 0.5 vs. mean 3.5 SD $1.4, \mathrm{p}<0.001$ ). The inter-rater agreement regarding pass/fail decisions was poor irrespective of the scoring form used. This was explained by clinicians' leniency as assessors rather than by lack of vigilance in the observations or disagreements on standards for good performance.

\section{Introduction}

The introduction of in-training assessment using clinicians to assess the performance of residents is a challenge. The assessment method must be easy to both use and understand and must also provide reliable results. For technical skills task specific checklists have been shown to be reliable measurement tools in standardised settings. ' For complex tasks in clinical settings checklists tend to be too elaborate to cover all subsets of the task. For example Sivarajan et al. ${ }^{2}$ used 61 items in a checklist for epidural anaesthesia. This might not be a feasible instrument in a clinical setting and it is a lot of work to design if several different tasks are to be observed. One alternative to the use of checklists could be a rating form with general dimensions of competence such as those used for clinical observation of residents ${ }^{\prime}$ patient encounters in internal medicine. ${ }^{3}$ The advantage of such a form is that it adapts to a broad range of clinical situations.

The aim of this study was to evaluate the feasibility of two structured scoring formats, that is, checklists including task specific items versus global rating forms with general dimensions of competence including clinical skills, communication skills and knowledge. We wanted to study whether checklists were superior to global forms for observation of more technically oriented clinical tasks with respect to acceptability and interrater agreement on pass/fail decisions. 


\section{Context of the study}

A working group under the Danish Society of Anaesthesiology and Intensive Care Medicine had developed a new nationwide in-trainingassessment programme for first year residency of anaesthesiology ${ }^{4}$ The programme included twenty-one individual tests on various clinical tasks and the tests were spread out over the entire first year of residency. The programme was to be administered at the individual departments using clinicians as assessors for the individual tests. The working group, before introduction of the programme, established a consensus standard for pass/fail decisions implying that all specific tests must be passed in order for the resident to pass the entire programme. For each of the individual test the criteria for passing a resident was mastery meaning that all elements of the performance must be correct. The standard and the criteria were confirmed in a survey among consultants in anaesthesiology. ${ }^{5}$ The design of the program includes provisions so that if a resident fails a test, proper remediation is instituted and the assessment repeated in due time. The final report on each resident should only include the tests passed successfully. Hence study of test reliability using residents' actual test results was not feasible. We therefore designed an experimental study where clinicians score simulated videotaped scenarios rather than actual test situations.

\section{Methods}

Four: different test scenarios were simulated and videotaped. Each scenario demonstrated a resident performing a clinical task and a supervisor observing and questioning the resident. The scenarios included insertion of an epidural catheter for anaesthesia, a preoperative anaesthesia consultation, an emergency induction of general anaesthesia, and a round on a patient in the intensive care unit. A group of expert consultants were asked to define two mistakes in each of the first three scenarios that included one 'sloppiness' and one 'serious error' in each scenario, which to the experts opinion should result in a clear fail of the resident. In each of the first three scenarios the simulated resident was instructed to make these two specific mistakes. For example, in the epidural scenario this was being sloppy with the skin disinfection and withdrawal of the epidural catheter while still inside the needle. In the preoperative consultation scenario the mistakes were not questioning about status of teeth and not performing the relevant physical examination of the patient. In the emergency induction scenario the resident did not check appropriately for patient identification and second, did not perform crash induction cor- 
rectly. The intensive care scenario did not include any deliberate mistakes.

Two different scoring forms were elaborated for assessing the four different clinical tasks. One was a task specific checklist including fron nine to 14 items with a dichotomous scoring of each item, yes/no, and an overall dichotomous scoring of pass/fail. All checklists included items on communication skills, technical performance and some theoretical questions related to the task. An example of a checklist is shown in Appendix 1. The second scoring form was a global form that included three general aspects of competence to be assessed: communication skills, clinical skills and cognitive knowledge. The form contained for each of these categories a five point scoring, $1=$ clear fail, $2=$ borderline fail, $3=$ borderline pass, $4=$ clear pass, $5=$ excellent. This form included an overall dichotomous scoring of pass/fail. The global form is shown in Appendix 2.

A letter was sent to the anaesthetic department at each of the 30 training hospitals across the country inviting the educational responsible consultant at the department and/or one of the clinical supervisors to participate in a two-hour study about assessment of residents performance. The participants were instructed to use their professional expertise and judgement in evaluation of the resident's performance depicted in each of the four video taped scenarios. The assessors were also instructed to make an overall decision regarding pass or fail of the resident according to the assessment protocol. According to the protocol the criteria for passing a residents' performance on each scenario was mastery meaning that all elements of the performance must be correct.

The participants were randomised into two groups. Group one used checklists specific to the tasks in each of the four scenarios. Group two used identical global scoring forms for each scenario. For each scenario the participants were asked to indicate the appropriateness of the scoring form they had used for assessment of resident performance. Appropriateness was indicated on a scale 1 to 5 (1=not at all appropriate, 5=very appropriate). Also on each form the participants were invited to give written comments. The participants were not asked specifically to indicate observed mistakes. Each video lasted from ten to fifteen minutes. Time was given between each of the four scenarios to fill in comments.

\section{Statistical amalysis}

For each examiner and scenario an arbitrary index of the resident's mean performance score was calculated as a percentage of correct items on the checklists and as a percentage of the total rating of the three dimensions of competence on the global forms. Comparisons between groups were made using Kruscal-Wallis test for comparing data of mean performance score and appropriateness of scoring form. The chi-squared test was used 
for comparison of categorical data, p-values below 0.05 were considened statistically significant.

\section{Results}

Fourteen educational responsible consultants and eighteen clinical supervisors representing $25(83 \%)$ of the 30 teaching hospitals accepted the invitation. There was an equal representation of consultants and supervisors and an equal geographical representation in the two groups.

The appropriateness of the checklists was rated statistically significantly higher than the global format in each of the four scenarios (Table 1), (overall mean 4.6 SD 0.5 vs. mean $3.5 \mathrm{SD} \mathrm{1.4.} \mathrm{p}<0.001$ ). Several participants commented that a checklist is of great help when assessing a resident.

The pass/fail decisions on each of the four scenarios are shown for the two groups of assessors in Table 1 . In all of the first three scenarios where the resident makes two deliberate mistakes there was no statistical significant difference in number of clinicians passing or failing the resident in either of the two groups. In the fourth scenario where the resident was not instructed to make mistakes all assessors in both groups passed the resident. There were no significant differences between groups in the calculated mean performance score of any of the four scenarios.

The majority of assessors using checklists registered one or both of the mistakes in the first three scenarios, $94 \%(15 / 16), 100 \%(16 / 16)$, and $81 \%$ $(13 / 16)$ and several assessors using the global format indicated the mistakes in the commentaries, $69 \%(11 / 16), 38 \%(6 / 16)$, and $25 \%(4 / 14)$. Several assessors in both groups passed the resident despite noticing the mistakes as indicated either in the scoring of the items of the checklist or in the commentaries. On 10 occasions the assessors indicated that they passed the resident despite mistakes, but that they would give some conrections to the resident if this were a real life situation. 


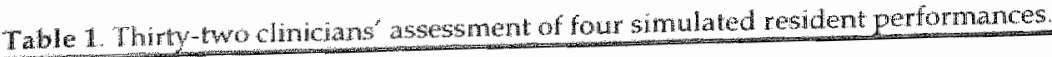

$\begin{array}{lcc} & \\ \text { Scenario } & \text { Group 1 Troup 2 } & \text { Grol } \\ & \text { Checklist } & \text { General } \\ \text { form } & \text { format }\end{array}$

Epidural anaesthesia

Number of clinicians passing the resident

Number of clinicians failmg the resident

Total

$\begin{array}{lcc}6 & 7 & 13 \\ 10 & 9 & 19 \\ 16 & 16 & 32\end{array}$

Calculated mean performance score (SD), per $72.2(14.0) \quad 679(6.2)$

centage

Appropriateness of scoring form.

$4.6(0.5) \quad 3.6(1.4)^{*}$

Premperative consultation

Number of clinicians passing the resident

Number of chicians fating the resident

Total

$8 \quad 6 \quad 14$

16

16

32

Calculated mean performance score (SD), perm centage

Appropriateness of scoring form

$4.5(0.6) \quad 3.3(1.3)^{*}$

General anaesthesia

Number of clinicians passing the resident

Number of clinicians failing the resident

Total

$\begin{array}{ccc}10 & 10 & 20 \\ 6 & 4 & 10 \\ 16 & 14 & 30\end{array}$

Calculated mean performance score (SD), percentage

Appropriateness of scoring form

$4.6(0.5) \quad 3.4(1.4)^{*}$

Intensive care patient

Number of chincians passing the resident

Number of clinicians failing the resident

Total

16

$16-32$
$0 \div \quad 0$
16
32

Calculated man performance score (SD), perm centage

Appropriateness of seming form

$4.9(0.4) \quad 3.2(1.2)^{*}$

Nok Growp one used a checklist with task specific items and group two used al form with genow atimensions of competence for the assessment. The table show the number of assessom in each group and that that passed or falled the resident, the calculated mean per formance score (SD), and the chichans mean rathg of approprateness, "Checklist form rated signifontly higher than general fomat, p<0.01. Two assessors in the general format group did not make an overall decsion of pass/failin scenario thres. 


\section{Discussion}

This study demonstrates that the clinicians found checklists more appropriate than global rating forms with categories of competence when scoring residents' performance on complex clinical tasks. This finding was consistent across all four clinical scenarios, although checklists could have been expected to be more appropriate for technically oriented tasks and general scoring forms more appropriate for patient encounters. In OSCE-examinations and standardised assessment using trained expert examiners several studies have shown that global rating might be a better alternative to checklists in terms of reproducibility and efficiency in test development and administration. 1, bo However, for in-training assessment, checklists might be a better choice because they can help make the program's learning objectives more explicit to both residents and supervisors.

The study showed a poor agreement among clinicians regarding pass/fail decisions inrespective of scoring form used. This poor agreement was probably not a problem of accuracy in observation of the resident's performance. The fact that the mean score in any of the scenarios was not significantly different between the two groups and that a number of clinicians in both groups noticed the deliberate mistakes even among those who passed the resident, indicates that the vigilance was equally high in both groups. Furthermore that all clinicians passed the resident in the last scenario without deliberate mistakes supports the validity of the videos. The contradiction of passing a resident performing incorrectly was probably not a question of underestimating the mistakes as several assessors emphasized the severity of the mistakes in their comments and indicated that they would address this in real life situations and instruct the resident to correct the performance. Thus irrespective of scoring form this study indicates a problem with assessors consistency and compliance with assessment protocol. The study of Wilkinson et $a l .{ }^{9}$ who found that station construction and mark sheets contributed $1.0 .1 \%$ and the examiner $89.9 \%$ to the variation in inter-rater reliability. This is in accordance with our findings and similar results of disagreement on pass/fail decisions in other studies using clinicians as assessors. "17, "Noel et al." demonstrated that the accuracy in evaluating residents' clinical performance by direct observation could be enhanced if assessors used a structured form, but still they found profound disagreement regarding overall pass/fail decisions. Kroboth ot al. ${ }^{3}$ performed an extensive reliability study on scoring forms with categories of competence and also found low inter-rater reliability.

Our study was performed at the initial introduction of formal assessment in postgraduate education in the country and unfamiliarity with the 
concept might in part explain the results and point to the need to train the clinicians as assessors. However, Wilkinson et al. ${ }^{9}$ demonstrated that examiner experience as assessors was not associated with inter-rater reliability in OSCEs. It has previously been shown that training assessors is ineffective for inconsistent assessors and that simply removing these from the analysis of the results on OSCE exams will increase reliability.12

Due to problems of reliability in performance-based assessment it is recommended to have several different assessors and several observations with a least amount of structure in the test formats. ${ }^{13}$ Using these principles reliable instruments for assessing residents' performance in a clinical context has been elaborated. $14-1+$ However, these studies probably also have the problem of lenient assessors. In the studies on the MiniClinical evaluation exercise ( $\mathrm{MCEX}$ ) for internal medicine residents where several different attending physicians observe the residents on several different patient encounters using scoring forms with general aspects of competence, only small differences in ratings across examiners and seltings were found. ${ }^{14}$, ${ }^{5}$ Especially in the study by Durning et at..$^{14}$ the mean score on seven consecutive mCEX during the residents' first year were not significantly different and did not indicate progress in performance over the year as expected. As opposed to these two studies Yudkowsky'tir used an approach that demonstrated an incremental growth in residents' competence. Two things probably contributed to this. First, they used a developmentally-oriented rating scale emphasising the progress expected in terms of the amount of supervision required to perform the task. Second, the decision of satisfaction with performance was being left to an education committee and not to the clinician.

Although our assessment programme for first year residents in anaesthesiology is in accordance with the principles using multiple observations and assessorst the results of this study point to the need for further study on how an in-training assessment programme works in clinical practice. ${ }^{13,17}$

\section{Conclusion}

Clinicians found checklists with task specific items more appropriate than rating forms with general dimensions of competence for the purpose of scoring residents" clinical performance. Consistency of pass/fail decisions was equally poor for checklists compared to global scoring forms. This was explained by clinicians' leniency as assessors rather than by lack of vigilance in the observations or disagreements on standards for good performance 
Acknowledgements: This study was supported in part by a grant from the Ministry of Health, Denmark. The authors wish to thank the clinicians for taking time to participate in this study.

\section{References}

1. Morgan P. Cleave- Yoss D, Guest CB. A comparison of global ratingent ahecklist scores from an undergraduate assessment using an anesthesia simulator. Acat Med $2001 ; 76 ; 1053-5$

2. Sivarajan M, Miler E, Hardy C, Herr G, Liu P, Willenkin R, Cullen B, Objective walua tron of chnical performance and correlation with knowledge. Anesth Anagr $1984: 63:$ $603-7$.

3. Kroboth F, Hanusa BII, Parker S, Coulehan IL, Kapoor WN, Brown FH, Kanpf M, Levey GS. "The inter-rater reliability and internal comsistency of a chinical valuation exercise II Gen [nt Med 1992; 7: 174.9.

4. Ringsted C, Ostergand D, Scherpbier A. Embracing the new paradigm of assessmert in residency training: an assessment programme for first-year residency traning in anaesthesiology. Med Teach 2003; 25:54-62.

5. Ringsted C. Ostergaard D, Scherpbier A. Consultants opinion on a new practice based assessment programme for first year residents in anaesthesiology. Acta Anawhesiol Scand 2002; $46: 1119-23$.

6. Govaerts MJB, Van der Vleuten CPM, Schwwinth LWT, Optimising the reproducibility of a performance-based assessment test in midwifery education. Adv in Heath Sci Fincic 2002; $7: 133 ; 45$.

7. Hodges B, Regehr G, MoNaughton N. Tiberius R, Hanson M. OSCE checklists do not capture increasing levels of expertise. Acad Med 1999,74:1129-34.

8. Regeh G, Mackae H, Reznick RK, Szalay D. Comparing the psychometric propenties of checklists and global rating scales for assessing performance on an OSCE-format examination. Acad Med 1998; 73: 993-7.

9. Wilkinson TJ, Frampton M, Thompson-Fawcett M, Fgan T. Objectivity in objective structured clinical examinations: Checklists are no substitute for examiner commitment. Acad Med 2003; $78,219 \times 23$

10. Eliot DL, Hokam DI1. Exaluation of physical examination sills. JMA 1987, 258: 3405.8 .

11. Noel GL, Herbers JE, Caplow MP, Copper GS, Hangaro IN, Marwey I. How wall do internal medicine faculy members evaluate the clinical skills of residents? Ann lut Med 1992;117:7 57-65.

12. Newble DI, Hoare ], Sheldrake PF. The selection and training of examiners for chincal xaminations. Med Educ 1980, 14:345-9.

13. Van der Vleuter CPM. The assessment of professional competence Developments, research and practical implications. Adv Healh Sci Educ 199\%; $1: 41 \ldots 7$

14. Durming S1. Cation LJ, Markert R Pangaro IN. Assessing the roliability and waldity of the Mini-clinical evaluation exercise for interal rodicine residency dranum. Acad Med 2002; 77:9004.

15. Norcini Id, Blank L. A, Anold GK, Kimball HIR. Examiner difterences in the Mini Cex. Adv Tealth Sci liduc 1997; $2 ; 27,33$.

16. Yudkowsky R. Can resident evaluatons demonstrate increases in restents skills over time? Acad Meel 1999; 74: 5106-10.

17. Fowell SL, Southgate L., Bligh JG. Evaluating assessment the missing link? Med Cduc $1999: 33: 276-81$ 


\section{Appendix 1. Example of checklist scoring form used for assessing a resident's performance.}

\section{Insertion of epidural catheter.}

Informs and guides patient appropriately regarding the procedure and positioning

Correct positioning of patient, sitting or prone position, with assis tance from staff

Correct preparation of utensils and check of drugs and instruments

Proper identification of insertion level appropriate for the planned operation.

Correct disinfection and sterile draping of skin

Discuss choice of local anaesthetic for skin and choice of median or parramedian approach

Correct insertion of needle

Correct identification of epidural space - loss of resistance

Correct insertion of epidural catheter

Test of catheter position - can explain the reason and procedure for testing

Discuss and tefend choice and alose of anaesthetic for the epidural black

Determines block level -with indication of dermatomes

Describes indications and contra-indications for epidural anaesthesia

Describes at least three important complications, describe how to prevent and treat these 


\section{Appendix 2. Example of global scoring form with general dimensions of competence used for assessing a resident's performance.}

Wrsertion of epidural cotheter

The resident's performance regarding parient communication is:

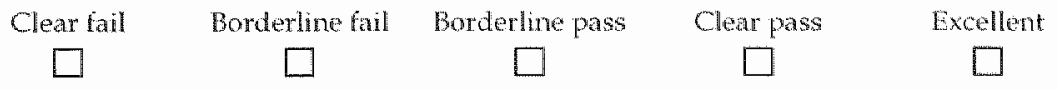

The resident's performance regarding dinical and technical skills is:

$\begin{array}{ccccc}\text { Clear fail } & \text { Borderline fail } & \text { Borderline pass } & \text { Clear pass } & \text { Excellent } \\ \square & \square & \square & \square & \square\end{array}$

The resident's performance reganding knowledge is:

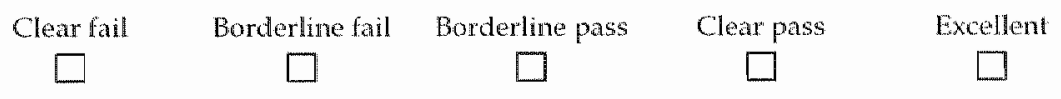

YES NO

I will pass the resident reganding this competency 



\section{CHAPTER 4}

\section{Implementation of ITA}

Published in Acta Anaesthesiologica Scandinavica 2003; 47: 1196-1203

Implementation of a formal in-training-assessment programme in anaesthesiology and preliminary results of acceptability.

C Ringsted, D Østergaard, CPM van der Vleuten 


\section{Abstract}

Background: A new reform on postgraduate education in Denmark requires formal in-training assessment in all specialties. The aim of this study was to survey the implementation and acceplability of the first example of a nation-wide in-training-assessment programme for first year trainees in anaesthesiology developed by a working group under the Danish Society of Anaesthesiology and Intensive Care Medicine.

Metrods: A questionnaire about the implementation of the programme in practice and the characteristics of trainees was sent to the educational responsible consultant (ERC) in each of the 26 anaesthetic deparments in the country with first year trainees in anaesthesiology. Standard evaluations of the assessment programme were regularly collected from trainees.

Results: "Wenty-five (96\%) departments returned the questionnaire. In total the departments reported on 100 trainees and 83 of these had been enrolled in the programme. Thirteen departments reported in total on 27 trainees who had completed their first year training and these departments had applied median 21 (range 17-21) of the 21 tests included in the entire programme. Time constraints and resistance among senior clinicians were the most frequently cited barriers to implementation. Evaluations from trainees showed a general positive attitude towards most of the programme. They especially praised the programme's effect on structuring training and having a positive effect on learning.

Conchusion: The in-training-assessment programme has been widely implemented across the country. The majority of the programme was acceptable to trainees and had a positive effect on structuring training and on fostering leaming.

\section{Introduction}

Since 2000 a new reform in postgraduate education in Denmark has been under way. ${ }^{\prime}, 2$ The new reform reflects the general paradigm shift towards concepts of outcome based education and comprehensive performance-based assessment as an on-going process rather than end-oftraining assessment. Apart from medical expertise this includes interpersonal, organisational, and academic competence and professionalism. ${ }^{25}$ The need for more structured training and assessment in all these aspects has repeatedly been demonstrated 70 Introducing a formal intraining assessment is an extra challenge in Denmaxk as until now there has been no formal clinical assessment of trainees and no specialist exams
in any specialties. 11,12 
This study deals with the implementation of the first example in Denmark of a nation-wide curriculum and in-training assessment programme complying with the new guidelines and the paradigm of practice-based assessment as an on-going process.t. it The programme was for first year trainees in anaesthesiology and was developed by a working group under the Danish Society of Anaesthesiology and Intensive Care Medicine (DASAIM). ${ }^{13}$ The working group of 20 people included members of the DASAIM's board of education, consultants from various parts of the country, and trainees. The programme was developed through several seminars and literature studies and all decisions were made by consensus in the working group. A draft was distributed to core faculty for review and a nation-wide survey on consultants' opinion showed high agreement regarding the scope, content, and importance of the elements of the programme.1:4

The aim of this study was to survey the implementation of the programme across the country and especially to identify any barriers to implementation. Also we wanted to obtain a first impression of the programme"s acceptability to trainees.

\section{Methods}

\section{The programme}

The assessment programme includes 21 individual elements spread out through the first year of training and tailored to practise and the trainee's professional development (Table 1). ${ }^{13}$ Eighteen of the elements are summative tests to which are associated pass/fail decisions. These include 12 observations of trainee performance on clinical tasks for which the supervisor uses a competence-card composed of a checklist of task specific items and some questions on related theory. One element is one a survey on the trainee's communication skills, distributed to 25 patients by the trainee during preoperative consultations. Two elements are structured reports from attending anaesthetists, one in daytime and one on-call, for assessment of the trainee's organisational and interpersonal behaviour. Three instruments are reflective written assignments on patient cases, one being an exercise of evidence-based medicine. 


\section{Chapter 4}

Table 1 . Specification of 21 elements included in the assessment programme for first year trainees in anaesthesiology.

\begin{tabular}{|c|c|}
\hline $\begin{array}{l}\text { Climical skills } \\
\text { 1. Managing airways } \\
\text { 2. Testing anaesthesia machine } \\
\text { 3. General anaesthesia } \\
\text { 4. Energency induction of anaesthesia } \\
\text { 5. Preoperative consultation } \\
\text { 6. Advanced resuscitation } \\
\text { 7. Pan for fluid and nutrition } \\
\text { 8. Function of standard respirator } \\
\text { 9. Managing intensive care patient } \\
\text { 10. Spinal anaesthesia } \\
\text { 11. Epidural anaesthesia } \\
\text { 12. Central venous catheter }\end{array}$ & $\begin{array}{l}\text { These tests are performed by having a supervi- } \\
\text { sor observe the trainee in practice and score the } \\
\text { performance by use of a competency-card with } \\
\text { task specific items regarding performance and } \\
\text { some questions about theory. Each test includes } \\
\text { an overall decision regarding pass/fail. }\end{array}$ \\
\hline $\begin{array}{l}\text { Experience } \\
\text { 13. Reconding of experience } \\
\text { 14. Cusum-scoring }\end{array}$ & $\begin{array}{l}\text { Recording of experience includes various kinds } \\
\text { of patients and procedures. An electronic data- } \\
\text { base was available on the Internet. } \\
\text { Cusum-scoring is registration of success or } \\
\text { failure rate each time a procedure is performed. } \\
\text { Four procedures were planned for Cusum- } \\
\text { scoring, spinal anaesthesia, epidural anaesthesia, } \\
\text { arterial catheter, and central venous catheter. } \\
\text { Success and failure rate is specified taking into } \\
\text { account the 'normal failure rate for expert an- } \\
\text { aesthetists. Flectronic database available. }\end{array}$ \\
\hline $\begin{array}{l}\text { Communication } \\
\text { 15. Survey on patient communication }\end{array}$ & $\begin{array}{l}\text { The trainee hands out a questionnaire to } 25 \\
\text { patients regarding the preoperative consultation } \\
\text { and elaborates a critical report on the results. } \\
\text { The supervisor assesses the report and makes a } \\
\text { pass/fail decision. }\end{array}$ \\
\hline $\begin{array}{l}\text { Managerial and collabotative skills } \\
16 . \text { Organisation, collaboration, pro- } \\
\text { fessionalisman call } \\
\text { 17. Organisation, collatwotion, pro- } \\
\text { fessionalism in OR }\end{array}$ & $\begin{array}{l}\text { Sevior clinicians, that have worked closely with } \\
\text { the tramee, rate the trainee on a structured form, } \\
\text { one consultant's rating in test no } 16 \text { and two in } \\
\text { test no } 17 \text {. The mainees clinical supervisor } \\
\text { makes an overall decision on behalf of the rat- } \\
\text { ings regarding pass/fail on each of two tests. }\end{array}$ \\
\hline $\begin{array}{l}\text { Written assigmments } \\
\text { 18. Choice of anaesthetics } \\
\text { 19. Reflection on case } \\
\text { 20. Evidence based medicine }\end{array}$ & $\begin{array}{l}\text { Writter assignments are scored according to } \\
\text { specified criterian and an overall pass/fail deci- } \\
\text { sion ts made for each test. }\end{array}$ \\
\hline $\begin{array}{l}\text { Self-directed llearning } \\
\text { 21. Learning portolio }\end{array}$ & $\begin{array}{l}\text { The trainee identifies individual leaming objec- } \\
\text { tives, means to reach the goals and reports on } \\
\text { the leaming. The supervisor monitors the pro- } \\
\text { gress of the trainee s leaming and gives an over- } \\
\text { all mark on the professional development ac- } \\
\text { conding to specified criteria on a checklist. }\end{array}$ \\
\hline
\end{tabular}


For each of these 18 summative elements the supervisor makes an overall decision regarding pass or fail. In case the trainee fails, proper remediation should be instituted and the test repeated in due time. All 18 elements must be successfully passed in order to have the first year training approved. The last three instruments had a formative purpose aiming at guiding training and learning. Two of these are continuous recording of experience in logs and the third is a learning portfolio. One of the logs is recording of experience with patients and procedures. The other one specifically monitors the quality of the performance of four technicall procedures, by use of the Cusum technique. ${ }^{15}$ The principle in the Cusum technique is that every time the procedure is performed, the trainee records success or failure by a specific scoring system, which takes the failure rate of experienced anaesthetists into account.

\section{General implementation strategy}

The curriculum and the assessment programme were issued in a booklet and sent to all anaesthetists in the country. A questionnaire accompanied the booklet to all consultants asking for their opinion about the content of the programme in general and of the content of each competence-card.4 A handbook on assessment protocols was elaborated and sent to all departments. The working group ran several information meetings across the country inviting all departments to participate. Barriers to implementation of the written assignments in the programme were foreseen 13,14 and hence special workshops for supervisors were conducted on how to manage the written assignment and principles of evidence based medicine. Finally the programme was introduced to the trainees at the regional mandatory seminars that accompanied the clinical training programme and special emphasis was put on how to perform assignments on evidence-based medicine.

\section{Survey on the implementation in practice}

This study was performed 1.5 years after the introduction of the programme. A questionnaire about the implementation of the programme in the departments was sent to the educational responsible consultant (ERC) in each of the 26 anaesthetic departments with first year trainees. Departments were asked to report the number of trainees and to indicate dates of employment for each trainee, and to what extent they had been enrolled in the assessment programme: completely, partly or not at all. Further each department was asked to tick off, which of the 21 elements in the assessment programme they had applied. The departments were asked to indicate reasons for not applying specific elements of the programme or the entire assessment programme if that was the case. Finally, departments were invited to give comments of any kind. 


\section{Tranees evaluation}

An evaluation form regarding trainees" opinion about the assessment programme was included in the booklet about the programme. The form included ratings of specific aspects of the programme on a scale of 1-9, $1=$ not at all/very bad and $9=$ very much/very good. The form also included open questions regarding positive and negative aspects of the programme. The trainees were asked to fill in the evaluation forms after termination of the entire assessment programme and send it to the authors. Trainees' identity were not known to the authors or included in any common database and hence personal reminder procedures were not possible. A general reminder was sent twice to the departments.

\section{Results}

\section{Implementation}

The questionnaire was returned by 25 (96\%) of the 26 departments. Four departments reported not having any trainees. In total, 21 departments reported on 100 trainees. Twenty-seven trainees had completed the first year training and all of these had been enrolled in the assessment programme. Fifty-one trainees had only had part of their training during the survey period and 49 of these had been enrolled in the programme. Finally there were 22 trainees who had only had short-term employments either as a vacancy or as a supplementary training for another specialty, typically for 3-6 months. Seven trainees in this group had been enrolled in parts of the assessment programme. In total, 83 trainees had been enrolled in the programme.

One of the 21 departments with only one recently started resident did not report on application of the elements of the assessment programme. Twenty departments reported on their application of the 21 elements of the entire assessment programme (Table 2). Thirteen departments reported on trainees who had completed their training and these departments had applied median 21 (range 17-21) of the individual 21 elements included in the entire programme. Seven departments reported on only having trainees who had had part of the training and these departments had applied median 12 (range 6-20) of 21 elements. The twelve clinical skills tests were the most widely implemented elements of the programme. The two least implemented elements of the programme were the test on communications skills and the learning portfolio. 
Table 2. Application of the 21 individual elements included in the assessment programme for first year trainees in anaesthesiology in departments with trainees who hat completed the programme and departments only having trainees who had had part of their training. Questionnaire returned from 25 of 26 departments in Denmuts. *

Number of departments reporting on applying the individuat elements of the prosramme

The 21 elements included

in the assessment, programme

\section{Clinical skills}

1. Managing airways

2. Testing anaesthesia machine

3. General anaesthesia

4. Emergency induction of anaesthesia

5. Preoperative consultation

6. Advanced resuscitation.

7. P. an for fluid and nutrition

8. Function of standard respirator

9. Managing intensive care patient

10. Spinal anaesthesia

11. Epidural anaes thesia

12. Central venous catheter

Experience

13. Continuous registration of experience

14. Cusum-scoring

Communication

15. Survey on patient communication

Managing and collaborative skills

16. Organisation/collaboration on call

17. Organisation/collabotation in oR

Academic competence

18. Written assignment, choice of anaesthetic

19. Written assignment, reffection on case

20. Written assignment, evidence based medicines
Departments with tranees who had completed their training $(\mathrm{N}=13)$
Departments only having trainees who had had part of their training. $(N=7)$

\section{Self-directed learning}

21. Learning portfolio 10

Four departments had no trainees in the period. One department with one recently started resident did not report on application of the individual elements of the assessment programme. 


\section{Deparments comments in the questionnaines}

Six departments praised the programme on several aspects: for making goals and objectives clear to both trainees and trainers; for being of help in structuring the training; for emphasising responsibility of both the trainee and the supervisor; and for documentation of competence and monitoring progress. One deparment used this documentation to reward the trainees with greater responsibilities in practice. The departments commented that the trainees were enthusiastic about the programme. One department reported on having been awarded the county's anmual "Education reward" with special praise to the programme.

One of the barriers to implementation was difficulty in motivating the senior clinicians to engage in the assessment of trainees and five departments mentioned that. Also, five departments commented on the conflict of service demands and time needed for the assessments. Specific reasons for not applying the survey of trainee ${ }^{x}$ communication skills included not finding it worthwhile considering the efforts. One department found the two tests on organisational skills/ collaboration to be a duplicate and had gathered them in one. Several departments reported that senior clinicians found the written assignments a big challenge and one department used the principles but with oral presentations and discussions instead of writing. Recording of experience was problematic due to technical problems with the electronic database. Some departments did not use the learning portfolio as intended and one department commented that the assessment progranme in itself was some sort of a portfolio.

\section{Traineses eanluations}

Fifteen trainees from eight different departments had completed and returned the evaluation form (Table 3). Results showed that, in general, the booklet and the assessment programme were rated high (median at or above 7 on a scale of 1-9). The recording of experience, the survey on communication skills, and the learning portfolio, were less popular instruments compared to the tests on clinical skills, the test on organisational and collaborative skills, and the written assignments. 
Table 3. 'Trainees' evaluation of an in-traimingassessment programme for firsty year training in anaesthesiology. Rating of items on a scale 1-9, 1=not at all/very bad and $9=$ very mach/very good. Results are given as median (range).

Residents

$(N=15)$

\section{General opinion about the booklet}

Did the booklet on the curriculum and the assessment programme in gen- 8(6-9) eral include sufficient information?

Was the booklet easy to understand and well structured?

Were the booklet and the assessment useful for the appraisal meetings with $7(3-9)$ the supervisor?

Gemeral opinion about the assessment programme

Did you use the competency-cards in griding your learning?

In general has the assessment programme been useful? ing your competence?

Specific opinion about the individual tests

Were the tests on clinical skills (no 1-12) an acceptable way to be assessed?

Was the registration of experience (no 13) useful considering the effort put into it?

Was Cusum-scoring (no. 14) useful considering the effort putt into it?

Was the survey on communication skills (no 15) an efficient learning experience?

Were the tests on organisational skills/collaboration (no 16-17) an acceptable way to be assessed?

Were the written reflective assignments (no 18-20) a worthwhile learning experience considering the effort?

Was the learning portfolio (no 21) useful in structuring the training and $5(1-9)^{*}$ leakning?

\footnotetext{
"Item scored statistically significant lower compared to 'clinical skills test' "tests on organisational skills/collaboration, and the 'written ansiguments', Wilcoxon signed ranks test, $p<0.05$
}

Trainees" responses to the open-ended questions (Table 4) showed that the positive aspects of the programme were making goals and objectives very clear and broadening the aspects of competence: "the ndonntrge of the details in the cands are that they point to aspects that would probubly wot howe been conered otherwise". "The programme helped in structuring training, for example, gaining access to experience in the intensive care unit. Also the programme fostered teaching and learning through the studying for the tests and through the feedback on performance during the observations. 
Table 4. Summary of responses to open-ended questions about positive and negative aspects of an in traning assessment programme for first year trainees in anaesthesiology from fifteen trainees. An $x$ indicates number of times a statement was found in the commentaries.

\begin{tabular}{|c|c|}
\hline \multicolumn{2}{|l|}{$\begin{array}{l}\text { Number of } \\
\text { stadeneentes }\end{array}$} \\
\hline & Positioe statements \\
\hline 16 & The programme in general \\
\hline $\operatorname{cox} x$ & Programme has high quality, well structured and easy to ase. \\
\hline$x \times x \times x \times$ & Programme makes goals and objectives very clear. \\
\hline$x \times x \times x \times$ & $\begin{array}{l}\text { Objectives are reasonable and relevant. Focus on quality of practice. Good } \\
\text { focus on 'soft competencies' also. }\end{array}$ \\
\hline 12 & Positive effect on training and teaching \\
\hline$x \times \times x$ & Good instrument for structuring training. \\
\hline$x \times x \times x \times x$ & Safoguard for training (ex intensive care) and for supervision. \\
\hline 20 & Positive effect on learning \\
\hline $\operatorname{xx} \times \times \times \times \times x \times$ & Ensures effective and efficient learning of both practice and theory. \\
\hline$x \times x \times x x$ & $\begin{array}{l}\text { Clinical tests motivate study of theory underlying practice. Good coupling } \\
\text { of theory and practice. }\end{array}$ \\
\hline$x \times x \times x$ & $\begin{array}{l}\text { Written assigrments good for reflection on practice. Good opporttunity for } \\
\text { studying literature in-depth. }\end{array}$ \\
\hline 7 & Visibility and documentation of competence \\
\hline$\times \times$ & Supervisors get to obserwe you and hear what you can. \\
\hline \multirow[t]{2}{*}{$x \times x x$} & $\begin{array}{l}\text { Nice to document competence and progress. Documentation good for } \\
\text { guidance and appraisal. }\end{array}$ \\
\hline & Negative statements \\
\hline 4 & Tests in practice \\
\hline$x \times x \times$ & $\begin{array}{l}\text { Supervisors should be better prepared for the programme and the individ- } \\
\text { ual tests. Tests are time-consuming if supervisors are not well prepared }\end{array}$ \\
\hline $\mathbb{1}$ & Time and planning \\
\hline$x \times x \times x \times$ & Conflict with servicedemands. Needs better planning. \\
\hline$x \times x \times x$ & Writhen assignments time-consuming Four assignments ton mach. \\
\hline 6 & Negative alfect of structure \\
\hline$x \times x$ & $\begin{array}{l}\text { Risk of focus on the tests. Might narrow teaching and learning in other } \\
\text { aspects. }\end{array}$ \\
\hline$x x$ & $\begin{array}{l}\text { Too much structure might take away trainee initiative. Written assignments } \\
\text { could be a hindrance to engage in research activities due to time. } \\
\text { constraints. }\end{array}$ \\
\hline$x$ & $\begin{array}{l}\text { Difficult to adapt to structure, control and assessment when you are used } \\
\text { to be independent. }\end{array}$ \\
\hline
\end{tabular}


Finally documentation of competence and monitoring progress were listed as positive aspects. Negative aspects included mainly problems of time-constraints, and supervisors who were ill prepared for the assessment procedures. One trainee stated that 'when the superisor is wot frmiliar with the content of the competence-card and the theory coupled to the individual tests the assessment procedure inkes too long and obstructs efficient service.' Only one trainee commented that it could be 'difficult to adnt to structure, control and assessment when you are used to being independent".

\section{Discussion}

The response rate to the survey on the implementation of the programme was high, $25(96 \%)$ of 26 departments, and the results showed that the intraining assessment programme for first year residents in anaesthesiology was widely implemented across the country. Departments with trainees who had completed the entire first year training had implemented most of the training programme and the vast majority of trainees who had only had part of their training were enrolled in the assessment programme. Unfortunately, the trainees' response rate about the evaluation of the programme was only $56 \%(15 / 27)$. However, the responders had a very consistent message about how the programme fostered structuring of the training and had a positive effect on learning. The trainees' ratings of the individual elements of the programme are in accordance with the data from the departments showing that three elements were less popular than others, namely the recording of experience, the survey on communication skills, and the learning portfolio.

The problems with implementing the recording of experience could be due to technical problems. But another problem is that formative evaluation tends to be difficult to implement if there is no statement of quality measured against defined criteria. ${ }^{16.18}$ The Cusum-scoring where a quality standard was included tended to be rated higher than the recording of experience. However, this was not statistically significant and the opinion on the Cusum-scoring showed large variances. It has been shown that although formative student logs do provide insight into the nature of students' learning experiences, they do not have the effect of engaging students, teachers or programme directors in structuring training. ${ }^{19}$ Logbooks might not be regularly analysed or attended to by trainees and supervisors and are not perceived as a valuable contribution to assessment of competence. ${ }^{20}$

The survey on communication skills was not considered worth the effort without further explanations and this aspect will have to be studied further. The less optimal implementation of the learning portfolio could 
be explained by lack of appreciation of the concept. Although the learning portfolios apply to theories of self-directed reflective learning, trainees may find them lacking relevance and not worth the effort. ${ }^{14}$, 15 Our highly structured assessment programme, including documentation of procedural performance as well as reflective written assignments, could have contributed to not finding the individual learning portfolios worthwhile.

One concem raised about our programme was that of ill prepared supervisors. The problem of clinicians preparedness for the assessment protocols and instruments used in in-training assessment has been demonstrated in other programmes. ${ }^{16,21}$ Our results point to the need for better introduction of the supervisors and formal training in assessment protocols; in that respect from the current study, our information meetings and the handbook on assessment appear to have been insufficient. The implementation of the written assignments in general and the trainees' ratings of these were surprisingly high. In a previously conducted nation-wide survey among consultants the test evidence-based medicine' was rated significantly lower regarding importance by consultants from departments with first-year trainees compared to other consultants. ${ }^{4}$ Due to the awareness of this, special workshops had been run for preparing the supervisors and the trainees and this probably contributed to the better than anticipated implementation.

The summative aspects of the major parts of our programme may well account for the implementation as well as the positive effects on training and learning. Several studies have shown that assessment is a strong incentive to both learners and the clinical departments to engage in learning activities and to structure the training. ${ }^{22,23}$ Time constraints as a barrier to implementation was stated by 5 of the 26 departments and this was less than expected. The programme's effect on structuring training might have been perceived as an advantage that counterbalances the investment of time. A study by Long24 demonstrated in a neurosurgery residency programme that structuring training through in-training assessment could considerably reduce the time required by trainees to acquire competence. Similar effects of our programme might have played a role in the results of our study. However, this was only vaguely stated in the commentaries and further studies are needed on how the programme works in practice.

Our in-training assessment programme focuses on firstyear trainees and on assessing trainees' performance in real life setting. However, other strategies might be necessary for higher levels of experience and management of more complex situations. Advanced simulators are now available for training and assessment of complex skills and situations 
rarely occurring ${ }^{25,20}$ and might be a valuable supplement to in-training strategies.

\section{Conclusion}

This study shows that the in-training-assessment programme for first year residents in anaesthesiology has been widely implemented across the country. Preliminary data on the evaluations from tramees indicate that the majority of the programme is highly acceptable and has a positive effect on structuring the training and on promoting leaning.

Acknowledgements: This study was supported in part by grants from the Ministry of Health in Denmark. The authors wish to thank all the anaesthetists who took time to fill in the forms and for their willingness to share information about their experiences with the implementation process and for their constructive criticism and suggestions for improvement of the assessment programme. We wish to thank the working group behind the assessment programme for their enthusiasm and efforts in lostering the implementation of the programme. The working group that compiled the curriculum and the assessment programme for first year residency in anaesthesiology included: Andersen $N$, Berlac PA, Bested $K$, Callesen $T$, Christensen $P$, Jensen $E$, Jensen JW, Lemholt $K$, Lund I, Malling B, Mandøe H, Nørregaard O, Pedersen BD, Petersen JA, Ravlo O, Ravn L, Ringsted C, Skjelsager K, Sprehn M, Ostergaard D. Finally we wish to thank Deborat? Davis for her editorial assistance.

\section{References}

1. The Mintstry of Heath. The future specialist. Report from the specialist conmission. Report no 1385. Copenhagen Statens Information 2000.

2. The National Boand of Health. Gudelines for curriculum of specialist aducaton The National Board of Mealth, Copendagen, 2001.

3. CanMDOS 2000: Extract from the CanMEDS 2009 Project Societal Nabds Working Group Report. Med Trach 2000; 22 . 549-54.

4. Accreditation Coumil for Graduate Medical Education Outrome project. 2000 WWW ACGME Org.

5. Friedman Ben-David M. The role of assessment in expanding professonal horizons. Med "leach 2000; 22:472-7.

6. Shepard $L$. The role of assessment in a learming culture Euture $2000,29: 4-14$

7. Lirola T, Lund VE, Katila Al, Mattia-Nuori A, Palve H Teaching hospital physiciane skills and knowledge of resuscitation algorilloms are deficient. Acta Anowhesiol Scand $2002 ; 46: 11504$. 
8. Skrifvars $\mathrm{MB}_{\text {, }}$ Castren $\mathrm{M}$, Kuroloa J, Rosenberg PH. In-hospital cardiopulmonary resuscitation. Organization, mangement and training in hospitals of different levels of care Acta Anaesthesiol Scand 2002; $46: 458-63$.

9. Schmid $A$, Akeson J. Practice and knowledge of cricoid pressure in southern Swaden. Acta Anaesthesiol Scand 2001; 45: 1210-4.

10. Rosenstock C. Meller J, Hauberg A. Complaints related to respiratory ewents in anaesthesioa and intensive care medicine from 1994 to 1998 in Denmark. Acta Anaesthesiol Scand 2001: 45: 53-8.

11. Karle $\mathrm{H}$, Nystrup ]. Comprehensive evaluation of specialist training: an alternative to Board examinations in Europe? Med Educ 1995; 29:308-16.

12. Zorab J5M. The educational activities of the European Academy of Anaesthesiology. Minerva Anesthesiologica 1998; $64: 477-82$.

13. Ringsted $C, \varnothing$ stergaard D, Scherpbier A Embracing the new paradigm of assessment in residency training. An assessment programme for first year residency training in andesthesiology. Med Teach 2003; 25: 54-62.

14. Ringsted $C$, Ostergaard $D$, Scherpbier $A$. Consultants' opinion on a new practice based assessment programme for first year trainees in anaesthesiology. Acta Anaesthesiol Scand $2002 ; 46: 1119-23$.

15. Kestin IC A statistical approach to measuring the competence of anaesthetic trainees at practical procedures. Br J of Anaesth 1995; 75: 805-9.

16. Morris ZS, Bullock AD, Belfield CR, Butterfield S, Frame JW. Assessment in postgraduate dental education: an evaluation of strengths and weaknesses. Med Educ $2001 ; 35: 537-43$.

17. Kelly OR, Murray TS. The development and evaluation of a personal learning log for Senior House Orficers. Med Educ 1999; 33: 260-6.

18. Mangione S, Peitman SI. Revisiting physical diagnosis during the medical residency: It is time for al logbook - and more. Acad Med 1999; 74: 467.9.

19. Dolmans D, Shmidt $A$, van der Beeck J, Beintema M, Gerver WJ. Does a student log provide a means to better structure clinical education? Med Educ 1999; 33: 89-94.

20. Nixon MC. The andesthetic logbook - a survey. Anaesthesia 2000; 55: 1076-80.

21. Noel GL, Herbers JE, Caplow MP, Cooper GS, Pangaro JN, Harvey J. How well do internal medicine faculty members evaluate the clinical skills of residents? Ann Int Med 1992; 117: 757-65

22. Petrusat ER. Clinical performance assessments. In: Norman GR, Van der Vleuten CPM, Newble DI, eds International Handbook of Research in Medical Education. Kluwer Acatemic Publishers, 2002:67:-709.

23. Van der Veuten CPM. The asscssment of professional competence developments, reseach and practicat implications. Adv Health So Educ, 1996: 1: 41-67.

24. Long DM. Competency-based residency training: the next advance in graduate medical educiation. Acad Med 2000; $75: 1178-83$.

25. Jacobsen 1, Lindekaer AL, Ostergaard HT, Nielsen K, Ostergaard D, Laub M, Jensen Pr, Joharnesen $N$. Management of andphylactic shock evaluated using a full-scale anaesthesia simulator. Acta Anaesthesiol Scand 2001; 45:315-9.

26. : Gardi T, CImistensen UC, Jacobsen I. Jensen PF, Ording H. How do anaes thesiologists treal matignant hyperthermia in a full-scale anaesthesia simulator? Acta Anaesthesiol Scand $200 \%$; $45: 1032-5$. 


\section{CHAPTER 5}

\section{Educational impact of ITA}

Published in Medical Education (in press)

Educational impact of in-training assessment (ITA) in postgraduate education. A qualitative study of an ITA programme in actual practice.

C Ringsted, A-H Henriksen, AM Skaarup, CPM van der Vleuten 


\section{Abstract}

Objectives To investigate experiences and thoughts of programme directors, clinical supervisors, and trainees about an in-training assessment (ITA) programme on a broad spectrum of competence for first year training in anaesthesiology: how does the programme work in practice and what are the benefits and barriers; what are the users' experiences and thoughts about the effect on training, teaching and learning; what are their attitudes towards this concept of assessment.

Methods Semi-structured interviews were conducted with programme directors, supervisors, and trainees from three departments. Interviews were audio taped and transcribed. Content of the interviews was analysed in a consensus process among the authors.

Results The programme was of benefit in making goals and objectives clear, in structuring training, teaching and learning, and in monitoring progress and managing problem trainees. There was a general positive attitude towards assessment. Trainees especially appreciated the coupling of theory to practice and in general the programme inspired an academic dialogue. Issues of uncertainties regarding standards of performance and conflict with service declined over time and experience with the programme, and departments tended to solve practical problems through structured planning.

Discussion Three inter-related factors appeared to influence the perceived value of assessment in postgraduate education. 1) The link to patient safely and individual practice using assessment as a licence to practice un-supervised rather than end of training examination, 2) the benefits to educators and learners in the educational process rather than mere documentation of competence, and 3) the attitude and rigour of assessment practice.

\section{Key learning points}

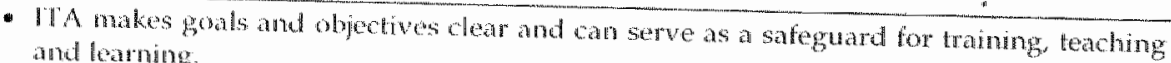
and tharning.

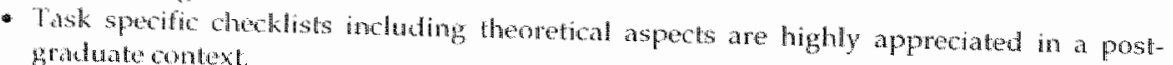
grathate context.

- ITA should be linked to practice and patient safery with progressive limely assessment instean of end 0 fraining assessment.

- TA is of help in identification, diagnosing and lemediation of probiem trainees at an
Qanty stare

- Th ingtruments are well received by the asers as far as they are eductional benelicial tather then mere tocumentation of compatence 


\section{Introduction}

The current literature on in-training assessment (ITA) indicates the potential benefits to the leamer, the teacher, and the programme . $^{-5} \mathrm{By}$ emphasizing broader aspects of the future roles of doctors such as communicator, health advocate, collaborator, manager, scholar, and issues of professionalism the development of appropriate ITA models becomes increasingly important. ${ }^{6}$ Postgraduate education consists mainly of progression through workplace experience. In developing ITA instruments, the emphasis should be on residents' progression towards defined standards of performance, assessment of professional. knowledge as well as assessment of core knowledge, assessment of on-the-job-learning and learning through assessment rather than assessment of learning by the end of training. ${ }^{3,7-9}$

Medical curricula embracing broader aspects of competence have been described together with the principle of using $\mathbb{\text { ITA }}$ as an on-going process rather than an end of training activity. ${ }^{1615}$ In order for any assessment programme to be accepted by the users the majority must feel that the process is fair and educationally beneficial. ${ }^{13},{ }^{16}$ Several studies have dealt with the psychometric properties of ITA and demonstrated that sampling across several observations and using several assessors can ameliorate problems of reliability, ${ }^{2}, 9,14,17-19$ However, there is currently little research on how ITA programmes in postgraduate education work in practice and what impact they have on the educational process. 7.20

The aim of this study was to investigate the experiences and thoughts of the programme directors, the assessors, and the trainees about a recently introduced IT A programme. Firstly we wanted to explore thow the programme works in actual practice: how the administration of the ITA programme was organised, how the individual assessments were administered, and what benefits or barriers the users had experienced. Secondly, we wanted to explore what impact the introduction of ITA had on the educational process: what was the effect on training, teaching and learning, and what were the users' experiences and thoughts about the benefits and drawbacks. Finally we wanted to investigate the users' attitudes towards the concept of assessment.

\section{The ITA progrannule}

A working group under the Danish Society of Anaesthesiology and Intensive Care Medicine developed a new nationwide in-trainingassessment programme for first year residency of anaesthesiology. ${ }^{10,21}$ The programme included twenty-one individual elements that were sequentially dispersed over the entire first year training (see Table 1), ${ }^{22}$ The programme was tailored to the professional development of the trainees 
over the year with a focus on clinical skills in the beginning of the programme and on reflection on practice at a later stage of the programme..$^{23}$ In the ITA programme standards of performance were elaborated in task specific competence cards that included a checklist and some theoretical questions applying to the procedure (see Table 2). Each card also included a global pass/fail decision on the specific task. The trainee had to pass all elements of the programme in order to have the entire $1^{\text {st }}$ year training approved.

The ITA programme was developed through an internal rational validation process through literature studies, expert group discussions and piloting of parts of the programme. Content validity had been assured by a survey among consultants. ${ }^{21}$ Another nation-wide survey revealed that the programme was widely implemented. ${ }^{24}$

\section{Method}

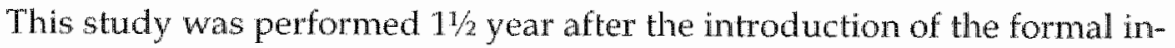
training assessment programme. Three departments of anaesthesiology at different hospitals were chosen to participate in the study of which we knew they had implemented the programme. Individual interviews were made with the three programme directors (PD), nine supervisors, and fourteen trainees. The interviews were semi-structured and included questions about the organisation of the ITA programme and how it works in practice, and about positive as well as negative experiences and thoughts of the programme.

Two of the authors (AH and AS) who were not doctors and who had not taken part in the design, development or implementation of the ITA programme performed the interviews. All interviews were audio taped and transcribed. Content was coded and analysed according to the questions and organised into a tramework of categories. The general categories include issues of the ITA programme in practice, the educational impact, and the attitude towards assessment. Results are presented according to these general categories with specification of sub-categories. Emergent themes were identified in a consensus process among the first three authors (CR, AH, AS). The team then discussed the summaries of the data and consistency in interpretation. 
Table 1 Specification of 21 elements included in the assessment programme for firt year trainees in anaesthesiology.

\section{Clinical skills \\ 1. Managing airways \\ 2. Testing anaesthesia machine \\ 3. General anaesthesia \\ 4. Emergency induction of anaesthesia \\ 5. Preoperative consultation. \\ 6. Advanced resuscitation \\ 7. Plan for flud and nutrition \\ 8. Function of standard respi- rator \\ 9. Manazing intensive care patient \\ 10. Spinal anaesthesia \\ 11. Epidural anaesthesia \\ 12. Central venous catheter}

\section{Experience}

13. Recording of experience

14. Cusum-scoring
These assessments are performed by having a supervisor observe the trainee in practice and score the performance by use of a competency ward with task specific items regarding performance and some questions about theory. Each assessment includes an overall decision regarding pass/fail.

The first six elements are supposed to be passed within the first three months of training and before the trainet is assigned to onwall duty.
15. Survey on patient communication

\section{Communication}

Recording of experience includes various kinds of patients and procedures. An electromic dabbase was avail able on the Internet.

Cusum-scoring is registration of success or failure rate each time a procedure is perfomed. Four procedures were planned for Cusum-scoring, spinal anaesthesia, epidural anaesthesia, arterial catheter, and central venous catheter. Success and failure rate is specified taking, into account the 'normal' fallure rate for expert anasthetists (see ref. no 22). Llectronic database available.

The trainee hands out a questionnaire to 25 patients regarding the preoperative consultation and elaborates a critical report on the results. The supervisor assesses the report and makes a pass/ fail decision.

Managerial and collaborative skills

16. Organisation, collaboration, professionalism on call.

17. Organisation, collaboration, professionalism in $O R$

Writtern assignments

18. Choice of anaesthetics

19. Reflection on case

20. Evidence based medicine

Self-directed learning

21. Fearning portfolio
A senior colleague that have worked closely with the trainee rate the trainee on a structured form, one senior colleague rates for assessment no 16, and two for assessment no 17. The tranees climical superwisor makex an overall decision regarding pass/fail on behalf of the ratings on each of two assessiments.

Written assignments are scored awcording to specifed criteria and an overall pass/fail decision is made for each of them. These assignments are supposed to bo placed in the second half of the training period.

The trainee identifies individual leaming objectives, means to reach the goals and reports on the learning. The supervisor monitors the progress of the trainees learning and gives an overall mark on the professional development according to specified criteria on a checklist. 


\section{Chapter 5}

Table 2 Example of checklist used for assessment

\section{Conduct of a spinal anaesthesia}

The tranee indicates when he/she is ready for assessment and finds a senior colleague that can assess him/her according to this checklist. All items on the checklist must be correct in order to approwe the competence.

Yes No

- Outine plan for anaesthesia induding description of indication of proper effect, acceptable blood pressure values, plan for managing side-effects or unwanted effects.

- Make proper preparations in the anaesthetic and operating rooms

- Can explain choice of anaesthetic and dosie related to the planned surgery

- Inform and instruct patient properly regarding the procedure

- Perform proper sterile preparation; check medicine and instruinents

- Make correct positioning of patient in collaboration with assistant

- Indicate correct site of needlle prick

- Use proper sterille technique

- Use correct needle technique and assures correct needle position before injecting anaesthetic

- Perform proper observation and monitoring of patient after injection of local anaesthetic

- Initiate proper measures to support cardiovascular function

- Make proper test of the analgesia and indicate segmental level correctly

- Can name indications and contra-indication to spirabl anaesthesia

- Can narne at least three complications and risks of spinal anaesthesia; can describe precautions regarding prevention and describe proper management of these complications.

This competence is acceptable

Name of supervisor:

Name of trainee:

Date: 


\section{Results}

\section{The ITA programme in practice}

\section{Key persons and responsibilities}

The PDs had the overall. responsibility of the programme. The responsibilities of the personal supervisors included introduction of the trainees to the department and the training, guidance and follow-up on the trainees' progress, and examining trainees, at their request, on any of the individual assessments in the programme. Any other senior colleague in the department was also expected to examine trainees at their request. The PDs had introduced and discussed the ITA programme and the assessment protocol with the staff at several meetings within the departments emphasizing the responsibilities that each individual had towards making this programme work. Assessment protocol and practical problems were addressed regularly at staff-meetings. PDs had briefly introduced the personal supervisors to their assignments, but apart from the staff-meetings, they had not discussed the assessment protocols in detail with the supervisors. Most supervisors reported that they had prepared for the assessments and studied the basic textbook of anaesthesiology in order to capture the level of requirements for first year trainees and review topics that were not within their main area of academic interest.

In principle the trainees had the responsibility to indicate when they wanted to be assessed and to find a senior colleague who was willing to do so. Often that was most feasible when on call. The written assignments were prepared by the trainees at home and assessed by the supervisor and the PD together. One department requested oral presentation and discussion rather than writing.

\section{Problens and barriers}

A few commented that the ITA programme was extensive, but at the same time that all elements were very relevant. Issues of time and conflict with service demands were addressed by the interviewees to a minor extent. A few supervisors indicated that they found it difficult in the beginning and that more instruction in the assessment protocol would have been appropriate.

[S6] "Time is a problem especially at the start. It's better now that we" re more used to it, and we know the standards and so on. And somehow we seem to make it work."

Both supervisors and trainees appreciated that trainees had the initiative to undergo assessment. Some trainees found it rather stressful to find a willing assessor and tended to be reluctant to ask for assessment, which resulted in lagging behind the programme"s schedule. 
[T7]: "The benefit is that you're forced to be active and be aware of your own progress. The drawback is the barrier to approach a supervisor. Perhaps some more intiative from the supervisors would be good, but it is difficult to strike the balance between taking way our responsibility and on the other hand not feel too pushy."

[T14]: "You're reluctant because you are asking another person for some of his time - and that's easy if it's something you cannot do, but it's difficult to ask for supervision on something that you can do."

\section{Administration of the indioidual assessments}

Some supervisors adhered strictly to the protocol, i.e. observed the trainee, asked the questions, and checked on the card. Others split the individual assessments in a practical and a theoretical part. A few took it rather leniently and checked the card on behalf of a general impression of the trainee. The trainees pointed to the importance that supervisors take it seriously and trainees tended to seek supervisors that were serious about the assessments, showed interest and were knowledgeable.

[T12] "You look for supervisors that you know are knowledgeable and where you get something out of it, a good dialogue or really learn something. Not just marks on a sheet of paper."

Several trainees and supervisors pointed to the importance of linking assessment to patient safety and using the assessments as a licence to engage in service and become more independent.

[T11]:" I didn't get the epidural right and I didn't pass. But it's ridiculous that I did 3 epidurals alone on the same call... you should not be allowed to do anything on your own before you have passed."

\section{Change in practice over time}

Over time and experience with the programme the recognition of some of these practical problems caused departments to schedule several of the first assessments during the day time within the first one or two months of the trainee's posts with specific appointment of assessors: This structured organisation of the programme was highly appreciated by the supervisors and trainees, who had experience with it.

[T3]: It's nice that they have approved that you can do such and such. You get confidence - I know I have been able to do this correctly."

\section{Educational impact}

The interviewees found that the ITA programme was good in making goals and objectives very clear and in drawing attention to other aspects of compretence than medical expertise.

[PD2]: "The advantage is that suddenly they can see the objectives. There are things that have been verbalised, which previously were tacit." 


\section{The effect on training, teaching and learning}

Some of the supervisors used the programme in structuring training activities and several. of the trainees used the programme for requesting training experience within specific categories of patients or procedures, for example getting allocated to service in intensive care. The programme was of help in planning and focusing teaching and learning and interviewees repeatedly indicated that the programme was a safeguard for training, teaching and learning.

[S3]: It gives you structure and is a useful tool in many aspects. You spend inordinately many resources when things are not structured."

The trainees indicated that the programme made learning more effective and efficient in assuring the breadth in the learning and in reaching the goals in a shorter time.

[T3]: "I would probably have studied the same, but it would have taken more time. It's very easy to see what you shall study next."

[T10]: "I had to pass certain things before I could move on. So I hurried to finish the various competencies and then asked for more and more."

The assessment scenarios fostered clinical teaching and discussion of clinical matters between supervisor and trainee also on issues not included in the checklists. Some supervisors returned later and gave further perspectives on the matter. Several interviewees expressed that the programme inspired an academic dialogue in the department in general and indicated that all learn more.

[PD3]: "It has made life easier - questioning has been legalised. You get closer and you're forced to supervise more. They get the breadth in cognitive knowledge and the assignments require that you dig deeper."

[S8]: "I find it beneficial to all of us. It is a little extra work, but it also gives some feedback and a dialogue in the daily work. So it's very positive for the department in general."

PDs and supervisors reported that the trainees studied more than previous trainees, and the trainees reported that the assessment programme made them study. Some trainees reported that they would study anyhow, but that the programme guided their studies and pointed to some aspects that they would probably not have focused on otherwise. The interviewees appreciated the programme's coupling of theory to practice and the details in the competence cards.

[PD2] "The ITA programme has made the trainees more active, they reflect more and transfer the concepts to other things. They critically appraise various things at our meetings."

[T6]: "Some of the cards make me study things that I would not have otherwise - you get around the stuff very well. It forces me to study and reflect on things at an early stage in my training year." 
[T11]: "The best part is not so much the practical part, but the theory in the cards, because - if you do a spinal it's more important that you know how to manage complications. It's important that you study the theory when you are supposed to use it."

Those trainees who had performed the written assignments in the end of the programme found them an enjoyable and valuable learning experience. They appreciated the way they made them go over some theory again and reflect on practice.

Negative aspects of the programme

Some interviewees indicated a potential risk of a highly structured programme in reducing initiatives on both sides and that trainees who had completed the programme could get a sense of emptiness.

[T10]: "When you've finished the whole programme its like the development stops. "That's bad."

Both trainees and supervisors emphasised that the assessments should foster learning. For example the communication skills survey was not appreciated as they only got positive reports from the patients and they did not learn from that. Another aspect of this survey and also of the assessment of collaborative skills was the lack of immediate feedback and dialogue with the assessor.

[T11]: "If you just get this information on paper - "you are good at this or you are not good at this', you can't use it. Perhaps you should make some sessions where you discuss how you act in various situations."

The written assignments were considered time consuming and both supervisors and trainees, who had not yet experienced that part of the programme considered it a big challenge.

[S8]: "I find it very ambitious and I tell the trainees that. The assignments require that you have scholarly competence."

\section{Monitoring progress and mannging problem trintes}

The programme helped in keeping track of trainees' progress and both trainees and supervisors expressed that the programme had added a meaningful content to the appraisal meetings, which previously or in other programmes tended to be loose talk. The ITA programme made the individual trainees more 'visible' and their individual needs more clear.

The PDs expressed that the programme made it easier to get an overview of the whole group of trainees and their individual progress. All three departments had experienced problem trainees and expressed that the programme was of help in identifying problem-trainees at an earlier stage and in confronting trainees with the problems. Further the assessments were used in diagnosing the problems and in structuring remediation plans. 
[PD1]:"Problem trainees become much more visible. We get attention to the problem at an earlier stage, discuss the problem and take steps to remediation."

[PD2] "We had our doubts about one trainee - didn' know whether he had academic deficiencies or an attitude problem. We asked him to take the assessments. The effect was that he became more explicit in his professional communication with clear formulation of plans for anaesthesia or expressing clearly when he was in doubt, so the nurses felt more safe about him."

\section{Attitude towards assessment}

\section{General attinde}

It was the PDs impression that there was a general positive attitude towards the assessment programme although one PD had difficulties involving the most senior colleagues in assessment activities.

[PD3] "Education is perceived as a private matter in our country, we are not used to examining doctors. Especially the seniors have some resistance. Of course it's also a test for them."

None of the supervisors expressed negative attitudes towards being assessors and the majority of trainees expressed a positive attitude towards assessment in general.

[T12]: "I don't think you should be afraid of making it an examination situation, and doing assessments progressively is good - then you know where you are getting at."

A couple of trainees and a single supervisor found that assessment should be placed in the end of the training year. A single trainee expressed a general negative attitude towards the concept of assessment. [T9] "I find that these assessments are offending to my perception of myself as a professional doctor. I have made up my mind that I have studied enough in my life. I find that the assessments on my organisational and collaborative skills are too personal. I don't like that."

\section{Documentation of competence}

In some aspects the documentation of competence was seen as an advantage especially by the PDs.

[PD1] "Assessment is an assurance that the trainees who have completed the programme and leave our department are good. We are several doctors that have assessed them and that is nice. It gives me a clear conscience."

[PD3]: "We have better documentation of our decision. It's mone professional in this way. It's a national standard, not just my personal opinion." 
Only a few trainees indicated an advantage of documentation on their self-confidence. But in other aspects the mere documentation was apparenty not an important issue to several of the interviewees.

[T8] "It seems a bit ridiculous when you work together with a colleague who knows what you can and then these cards must be filled in."

[S7]: "I don't find that documentation means anything except that filling in these cards become a goal in itself, not a mean to reach the goals."

Several of the interviewees stressed the importance of making assessment mandatory and making that clear to all parties. That was not al ways clear to the trainees in the beginning.

\section{Discussion}

This study reveals that implementation of an in-training assessment programme is beneficial to the learners, the teachers, and the programme directors. The uranimous expression by all three parties of interviewees was that the ITA programme was of benefit in making goals and objectives clear and in structuring training and learning. Also not surprisingly this study demonstrates that assessment fosters teaching and learning ${ }^{9}$. 25 The data suggest three inter-related factors that appeared to influence the perceived value of assessment:

- Link to practice

- Educational benefits to the users

- Attitude and rigour of assessment

\section{Link to proctice}

The results indicate that assessment seems more meaningful if linked to practice and applied progressively as a licence to work more independently rather than being placed as an end of training examination. Included in this aspect was the issue of patient safety. Another aspect of linkage to practice was the theoretical questions in the checklist related to the practical procedures and the reflection on practice in the written assignments. This coupling of theory to practice was highly appreciated and motivated both trainees and supervisors to study and inspired an academic dialogue in general. Although there are more reliable methods for assessing cognitive knowledge such as multiple-choice tests, these may not have the same educational impact and acceptance. 9,24

\section{Ellucational benefit}

In onder for the users to perceive a value of the ITA the relevance to the individual user is of significancel'. In various ways both trainees and supervisors expressed that the assessment should include a challenge 
and have an effect on learning. For instance trainees valued assessments that they learned from even when they did not pass at the first attempt, whereas both trainees and supervisors found the patient communication survey meaningless due to only positive ratings by the patients and hence no effect on learning. Interestingly the mere documentation of competence was not an important issue to either trainees or supervisors and both parties expressed a rather negative point of view on this as 'just marks on a sheet". Only a few trainees expressed that documentation of competence gave them confidence. Perhaps the issue of confidence would have been more pronounced if assessments were coupled to independent practice. Documentation of competence was not a major issue to the supervisors. Due to working schedules clinical teaching is a shared responsibility among all senior clinicians and the progress of the individual trainee is not attributed to the individual supervisor. Thus supervisors might not profit from the mere documentation, but rather see that as an extra burden. The supervisors though profited from the programme in structuring training and teaching activities. The issue of documentation was more important to the PDs. They expressed a sense of securily in having evidence and that documentation was of help in managing problem trainees, which indicate a relevance to the $\mathrm{PDs}^{x}$ practice and overall responsibilities.

\section{Attitude and rigor of assessment}

During introduction of I'TA, resistance to the idea of assessment can be expected because of negative associations with examinations. ${ }^{26}$ In our study only a single interviewee expressed a negative attitude to assessment. The major concern about our programme in practice was not whether it was fair but rather the trainees requested more rigorous assessment. Assessor leniency and scale shrinking have been repeatedly demonstrated when using clinicians as assessors.1, 14, 17, I8 Although assessment instruments using general categories of competence have been shown to have sufficient reliability, they may not be able to demonstrate increasing levels of competence over the first year of training. ${ }^{14}$ One approach to that problem is to have the clinician assessors rate the trainees on narrative developmentally-oriented rating scales without indication of trainee's sufficiency, but leaving judgement and pass/fail decisions to an educational committee. ${ }^{15}$ On the other hand instruments that do not have summative consequences may have minor or no effect on structuring training and learning 27 , whereas an ITA instrument emphasizing sequential mastery of procedures can accelerate the learning process dramatically. ${ }^{7}$ In our study there were several indicators of how the mandatory issues of the TTA were a driving force in the effectiveness and efficiency of the learning. 
The written assignments were seen as a huge challenge especially to those who had not experienced this part of the programme yet. A negative attitude towards the written assignments could be expected in a speciality where procedures are predominant.21, 23,28 However, supervisors have a special role in making explicit the value of engaging in scholarly activities and of motivating trainees in areas in which they do not readily engage. $23,2 *$ This study emphasise the importance of preparing supervisors for that role.

\section{Limitations to the study}

The interviewers (AH, AS) were not familiar with the ITA programme and protocol and data were not processed or discussed along the study. The weakness of this was that emergent themes or misunderstandings that could have come up during the interviews were not probed deeper in subsequent interviews. We chose this disadvantage over the possible bias a content expert (CR) would have imposed on the interviews.

This study was performed $1 \frac{1}{2}$ year after the introduction of formal intraining assessment, so the data do not represent a steady state context. However, the data give a first impression of how the organisation learns through the experience of implementing ITA. Issues of conflict with time and service demands decline over time and experience with the programme. The study included three departments that were known to have implemented the ITA programme. Thus the results, especially the rather positive attitude towards assessment might have been biased and cannot be generalized as to the feasibility of implementing the ITA in general. On the other hand this study demonstrates what educational benefits ITA can induce even in departments where education already has a high priority.

Acknowledgements: We wish to thank the interviewees for their time. We are grateful to Deborah Davis for her editorial assistance.

\section{References}

1. Spike $N$, Alexander $H$, Elliat $S$, Hazlett $C$, Kilminster $S$, Prideaux $D$, Roberts $T$. Intritining assessment - its potential in cohancing clinical teaching. Med Educ 2000; 34: $858-61$

2. Short JP. The importance of strong evaluation standards and procedures in training
resitents. Acad Med 1993; $68: 522-5$.

3. Friednan Ben-David $M$. The mole of assessment in expanding professional horizons. Med Teach 2000: 22: 472-7. 4. Tumbull 1, Gray 1. MacFadyen J hmproving in-training evaluation programs. J Gen Int
Med 1998, 13:317-23. 
5. Feleti C, Cameron D, Dawson-Samders B, Des Groseillers I, Dopley B, Farmer F, McAvoy $P$. Inmtraming assessment. In Newble, D, Iolly, W, Wakeford, R, ads. The certfication and recertification of doctors: lsstes in the assessment of chincal competence Cambridge Unversity Press. 1994: 151-66.

6. Tumbull J, Van Barneveld C. Assessnent of clinical performance ln-traning evaluation. In: Norman, GR, Van der Vleuten, CPM. Newble, Dit, eds Iruternational Handbook of Research in Medical Educatton, Dordrecht. Kuwer Academic Publishers. Printed in Great Britain. 2002:793-810.

7. Long DM. Competency-based residency training: the next advance in gaduate mediCal aducation. Acad Med 2000; 75: 1178-83.

8. Miller GE. The assessment of clinical skills/competence/performance. Acad Med 1990; 65(Supp): $563-7$

9. Var der Weuten CPM. The assessment of professional competence developments, research and practical implications, Adv Health Sci EAuc, 1996:1:41-67.

10. Ringsted $C$, Ostergaand D, Scherpbier. A. Embracing the new paradigm of assessment in residency training. An assessment programme for first year residency thaining in andaesthesiology. Med Teach 2003, 25: 54-62.

11. Reisdorf EI, Hayes OW, Carlson DJ, Walken GL. Assessing the new general competren cies for resident education: A model from an energency medicine program. Acad Med 2001:76:753-7.

12. Prescott LE, Notcini J], MoKinlay $P_{s}$ Rennie JS. Facing the challenges of compertencybased assessment of postgraduate dental train ing: Longitudinal evaluation of performance (LEP). Med Educ 2002; 36:92-7.

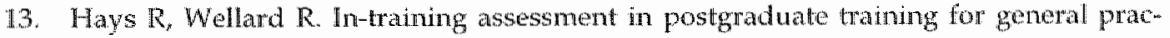
tice. Med Educ 1998; 32; 507-13.

14. Duming SI, Lannie JC, Markert RI, Pangaro LN. Assessing the reliability and walidity of the mini-clinical evaluation exercise for internal medicine residtency training. Acan Med 2002; 77: $900 \div 4$.

15. Yukowsky $R$. Can resident evaluations demonstrate increases in residents' skills over time? Acad Med 1999; 74 (suppl): $5108-10$.

16. Fimucane PM, Barron SR, Dawies HA, Hadfield-Jones RS, Kaigas TM. Towands an acceptance of performance assessment. Med Educ 2002; 36: 959-64.

17. Noel GL, Herbers JF, Caplow MP, Cooper GS, Pangaro IN, Harvey J. How well do internal medicine faculty members evaluate the cimical skills oft residents? Ann Int: Med 1992; 117:757-65.

18. Kroboth FI. Hanusa BH, Parker S, Couldan Jl, Kapoor WN, Brown FH, Kanp M. Levey $\mathrm{CS}$. The inter-rater reliablity and intertal consistency of a chnal evaluation $e x-$ srcise. I Gen Int Med 1992; 7: 174 9

19. Turnbull F, MacFadyen J, van Barmeveld $C$. Noman G. Gincal work sampling. A new approach to the problem of in-training raluation. J Gen Intern MEd 2000; 15:55646.

20. Patel BS, Feerick A. Will competency assessment improve the traning and skills of the trainee andesthetist? Anathesia 2002,57:710-31.

21. Ringsted C, Ostergard D, Scherpbier A. Consultants" opinion on a new practice based assessment programme for first year tranees in anacsthestology. Acta Anacsillasiol Scand 2002; $46: 119-23$.

22. Kestin IG. A statistical approach to measuring the competence of anawsthetic tratibes at practical procedures. Br J Anaesth 1995; 75: 805-9.

23. Rasmussen J. Skills, rules, knowledge, signals, signs and symbols and other distnctions in human performance models. IEEE Trans Systems, Man and Cybernetics 1983, 123: $257-66$

24. Ringsted C, Ostergaard D, Van der Weuten CPM. Implementation of formal in-taining assessment in anaesthesiology and preliminary results of acceptability Acta Anaesthesiol Scand $2003 ; 47: 1196-1203$ 


\section{Chapter 5}

25. Petrusa ER. Clinica performance assessments. In: Norman, GR, Van der Vleuten, CPM, Newble, DI, ods. International Handbook of Researtin Medical Educaton. Kluwer Academic Publishers, 2002: $673-709$.

26. McManus IC, Whider BC. Gordon D. UK doctors attitudes to the General Medical Council's performance procedures, 1997-99. Med Bduc 2001; 35(Suppl): 60-9.

27. Dommars D, Schmidt A, wan der Beck J, Beintema M, Gerver WJ. Does a student log provide a recans to better structure clinical education? Med Educ 1999; 33: 89.94.

28. Baker JD, Cooke JI, Contoy JM, Bromley HR, Hollon MF, Alpert CC Beyond career choce: the role of leaming style andysis in residency training. Med Educ 1988; 22: 527 . 32. 


\section{CHAPTER 6}

\section{Effect of ITA}

\section{on clinical confidence}

Published in Medical Education 2004 (in press)

The effect on in-training assessment on clinical confidence in postgraduate education.

C Ringsted, J Pallisgaard, D Østergaard, A Scherpbier 


\section{Abstract}

Introduction The literature on how in-training assessment (ITA) works in practice and what educational outcomes can actually be acheved is limited. One of the aims of introducing ITA is to increase trainees' clinical confidence based on the assumption that assessment drives learning through its content, format and programming. The aim of this study was to investigate the effect of introducing a structured IT A programme on junior doctors' clinical confidence. The programme was aimed at first year trainees in anaesthesiology.

Methods The study was a nation-wide survey of junior doctors' selfconfidence in clinical performance before (year 2001) and two years after (year 2003) the introduction of an ITA programme. Respondents indicated confidence on a 155-item questionnaire related to performance of clinical skills and tasks reflecting broad aspects of competence. Twentythree of these items related to the ITA programme.

Results Response rate was $377 / 531(71 \%)$ in year 2001 and $344 / 521(66 \%)$ in year 2003. There were no statistically significant differences between mean level of confidence before and two years after the introduction of the ITA programme - neither in aspects related to the programme nor in aspects not related to the programme.

Discussion This study demonstrates that the introduction of a structured ITA programme did not have any significant effect on the trainees' mean confidence on a broad range of aspects of clinical competence. The importance of timeliness and rigorousness in the application of ITA is discussed.

\section{Introduction}

Many authors have described the potential of in-training assessment (ITA) in postgraduate education and a wide variety of assessment instruments for comprehensive ITA programmes have been suggested. ${ }^{1-4}$ Trainees in postgraduate education want ongoing supervision and feedback and on-the-job discussions with consultants. ${ }^{5}$ They want algorithms for medical decision-making, regular sign-offs in a competencies logbook, effective and strategic use of annual assessment, and development of more objective instruments for use in psychomotor skills training and assessment. ${ }^{5}$ However, the literature on how ITA programmes work in practice and what educational outcomes can actually be achieved is limited. 
Orerview

What is aberisy known on this sibiect

Mary atuthors have described the potential benefts of in-traing assessment (ITA) in mostgradhate education is limited.

Wial this study adis

This study demonstrates no difference in mean level of chioal confidence in nation-wide survey of tranees before and wo year after the introduction of fomal ITA. Timeliness of M A related to traines' clinical experienes might influence the effect of $\mathrm{T} A$ on contitence.

Suggestions for further researd

In many specialties application of the principles of secuenced ITA is still in its infancy and the full effect of IT An the learning process and outcomes remans to be exploned in future research.

Assessment drives learning through its content, format and programming. ${ }^{7}$ Introducing assessment in programme aspects that have not previously been part of the assessment curriculum might increase both trainees" levels of competence and change their attitude towards the importance of those aspects. ${ }^{\text {S }}$ Similarly, introducing assessment might change clinical teachers' practice such that they provide increased supervision in those aspects included in formal assessment. ${ }^{9}$ One of the aims of introducing ITA is to increase trainees' dinical confidence based on the assumption that knowledge of actual competence gained through assessment increases self-confidence. ${ }^{10}$ Timeliness of ITA related to clinical experience could be expected to influence the perceived effect on learning. In a previous study on how a specific ITA programme works in actual practice the users recommended that the individual assessments be applied in a timely fashion and used as a licence to practice more independently rather than be placed at a late stage of the training year." Long demonstrated that sequenced ITA considerably reduced training time needed for mastery of procedures. ${ }^{2}$.

The aim of this study was to investigate the effect of introducing a structured ITA programme on junior doctors' dinical confidence. The first research question was: What is the junior doctors' self-confidence in performing a broad range of clinical skills and tasks before and two years after the introduction of a structured ITA programme - both in aspects related to the ITA programme and in aspects not related to the programme? The second research question was: Has the ITA programme been applied on a timely basis according to the assessment protocol? The third research question was: To what extent does ITA contribute to trainees' self-confidence relative to clinical experience? 


\section{Context of the study}

A working group under the Danish Society of Anaesthesiology developed a new nationwide TMA programme for first year trainees in anaesthesiology." The programme was introduced in the spring of 2001. Previously there had been no formal assessment or examination of trainees in Denmark. The ITA programme was developed through an internal rational validation process using literature studies, expert group discussions and piloting of parts of the programme. The programme included twenty-one individual elements addressing aspects of medical expertise as well as general aspects of competence.

Based on the internal rational validation process an assessment protocol was elaborated which recommended that the programme be sequentially dispersed over the entire first year of training with a focus on clinical skills in the beginning of the training year and other aspects of competence at a later stage of the year (see Table 1).

Standards of performance were elaborated in task specific competence cards that included a checklist and some theoretical questions about the procedure. Each card also included a global pass/fail decision on the specific task. The trainee had to pass all elements of the programme in order to have the entire $1^{\text {st }}$ year training approved. These standards and the assessment protocol were distributed to all clinical departments of anaesthesiology. Content validity and agreement on the assessment protocol had been assured by a nation-wide survey among consultants. ${ }^{13}$ In order to prepare the staff for conducting ITA a handbook including instructions to assessors were distributed to all clinicians and a number of seminars were offered across the country by the introduction of the ITA programme. Widespread implementation of the ITA programme was documented through a nation-wide survey $11 / 2$ year after the introduction of the programme. ${ }^{14}$ 
Table 1 Specifications for the 21 elements included in the assessment programme for first year trainees in anaesthesiology.

\section{Clinical skills \\ 1. Managing airways \\ 2. Testing anaesthesia machine \\ 3. General anaesthesia \\ 4. Emergency induction of anaesthesia \\ 5. Preoperative consultation \\ 6. Advanced resuscitation \\ 7. Plan for luid and nutrition. \\ 8. Function of standard respirator \\ 9. Managing intensive care patient 10. Spinal anaesthesia \\ 11. Epidural anaesthesia \\ 12. Central venous catheter}

\section{Experience}

13. Recording of experience

14. Cusum-scoring
These assessments are performed by having a supervisor observe the trainee in practice and score the performance by use of a competencycard with task specific items regarding performance and some questions about theory. Each assessment includes art overall decision regarding pass/fail.

The first six elements are supposed to be passed within the first thee months of training and before the trainee is assigned to on-call duty.

\section{Communication}

15. Survey on patient communication
Recording of experience includes watious kinds of patients and procedures. Cusum-scoring is aregistration of success or fallure rate each time a procedure is performed. Four procedures were planned for Cusum-scoring, spinal anaesthesia, epidural anaesthesia, arterial catheter, and contral venous catheter.

The trainese hands out a questionnaire to 25 patients regarding the preoperative consultathion and elaborates a critical report on the results. The supervisor assesses the report and makes a pass/fail decision.

\begin{tabular}{|c|c|}
\hline $\begin{array}{l}\text { Managerial and collaborative skills } \\
\text { 16. Organisation, collaboration, profes- } \\
\text { sionalism on call } \\
\text { 17. Organisation, collaboration, profes- } \\
\text { sionalism in OR }\end{array}$ & $\begin{array}{l}\text { A senior colleague rates the trainee on a struc- } \\
\text { tured form, one senior colleague rates for as } \\
\text { sessment no } 16 \text {, and two for assessment no } 17 \\
\text { An overall decision is made reganding pass/tail } \\
\text { on behalf of the ratings on each of two assess } \\
\text { ments. }\end{array}$ \\
\hline $\begin{array}{l}\text { Academic aspects } \\
\text { 18. Choice of anaesthetics } \\
\text { 19. Reflection on case } \\
\text { 20. Evidence based medicine }\end{array}$ & $\begin{array}{l}\text { Trainees writen reports are scored according } \\
\text { to specified riteria and an overall pos/tail } \\
\text { deciston is made for each of them. These as- } \\
\text { signments are supposed to be carried oul in the } \\
\text { second half of the training period }\end{array}$ \\
\hline $\begin{array}{l}\text { Self-directed learning } \\
\text { 21. Learning portolio }\end{array}$ & $\begin{array}{l}\text { The trainee identifies individual learning objec- } \\
\text { tives, means to reach the goals and reports on } \\
\text { the learning. The supervisor monitors the pro- } \\
\text { gress of the trainee's leaming and gives an } \\
\text { overall mark on the professional development } \\
\text { according to specified criteria on a checklist. }\end{array}$ \\
\hline
\end{tabular}




\section{Methods}

This study was a nation-wide cross-sectional survey of self-confidence in clinical performance over the entire cohort of junior doctors in anaesthesiology before, $n=531$ (in April, year 2001), and two years after, $n=521$ (in April, year 2003), the introduction of a nation-wide ITA programme. A cross-sectional design was chosen, as introduction-year training programmes do not have a fixed entry term, but varies considerably across the country.

\section{Subjects}

The subjects in the survey included five groups of junior doctors: a group of miscellaneous house staff, three groups of trainees in formal training positions, and a group of specialists in anaesthesiology who had not yet been awarded positions as consultants (hence the classification as junior doctor'). The three groups of trainees in formal training related to three types of positions: 1) an introduction year, 2) a two-years residency including rotations pertinent to anaesthesiology in various surgical subspecialties, intensive care medicine, pain clinic, etc., and 3) a 1/2years senior residency. The group of miscellaneous house staff was a rather heterogeneous group including doctors waiting for formal training positions, either the introduction year or the residency of two years, and doctors in vacancies or short-term appointments used as supplement for other specialities. The ITA programme was aimed toward the introduction year trainees. However, in 2003, two years after the introduction of the programme, experience with the programme by doctors among the miscellaneous house staff and some of the residents were expected as well. The most senior groups of junior doctors were included in the survey in order to assure construct validity of the questionnaire.

\section{Instrwment}

A questionnaire on self-confidence in clinical performance was constructed. The questionnaire included 155 items related to a wide range of clinical skills and other aspects of competence. The list of items was selected by a small group of consultants and reviewed by the working group responsible for the ITA programme for the $1^{\text {st }}$ year training. The list represented the objectives for the entire specialist education as issued in year 2000 by the Danish Society of Anaesthesiology and was supplemented by items related to other aspects of competence, which at the time of the study were not defined in the objectives. The 155 items related to four categories of clinical competence: 1) 55 items on technical procedures, 2) 48 items on anaesthesia related to various ty pes of surgery, 3) 30 items related to management of patient cases such as intensive care or 
emergency care, and 4) 26 items on other aspects of competence such as difficult communications, organisation and management of operation lists, academic competence, and professionalism. Twenty-three of the items $(15 \%)$ related specifically to the IT A-programme.

The respondents were asked to indicate their confidence on each item on a five point scale, $1-5$, where $1=$ not at all confident in performing this skill or task and $5=$ totally confident. For clinical skills $1=$ not at all confident was defined as 'I always need help, advice, support or supervision from a more experienced colleague" and $5=$ totally confident as "I never need help, advice, support or supervision from a more experienced colleague..$^{15}$ For the other aspects of competence $1=$ not at all confident was defined as 'I find this difficult and I have to consciously work at it', and $5=$ totally confident as "This is so inherent in my practice that I do it easily and instinctively". ${ }^{15}$ Also included were questions about type of training position, time served in anaesthesiology, and gender. Finally the questionnaire in 2003 included questions on which of the 21 elements in the IT A programme the respondent had experienced as a trainee.

\section{Data analysis}

Distribution of respondents on types of training positions and gender was explored using Chi ${ }^{2}$-analysis, comparing the data from year 2001 and year 2003. For each respondent a mean level of confidence was calculated separately for those 23 items related to the ITA programme and for those 132 items, which were not related to the programme. Students t-test was used for comparing differences in confidence level within and between groups. Bonferroni correction was used to adjust probability level according to multiple comparisons and $p<0.002$ was required for statistical significant difference at the 0.05 level.

In order to estimate the timeliness of application of ITA, number of assessments performed by the two youngest groups was calculated in time intervals of three months. According to the assessment protocol the first six assessment should be performed within the first three months and the rest of the 21 assessments should be progressively applied over the rest of the first training year. Confidence level was expected to increase according to increasing level of experience in anaesthesiology. The third research question, the contribution of ITA on confidence, was investigated by doing a stepwise linear regression analysis using selfconfidence as a dependent measure and time served in anaesthesiology and number of assessments performed as independent variables. 


\section{Results}

The response rate was $377 / 531(71 \%)$ in year 2001 and $344 / 521(66 \%)$ in year 2003. Three respondents did not indicate position and sixteen indicated having other positions than being specialists, trainees or house staff. These nineteen respondents were omitted from further analysis. About half of the respondents in both years were specialists in anaesthesiology. The distribution of respondents from different training positions was similar in the two years $\left(\mathrm{Chi}^{2}\right.$-analysis, $\left.\mathrm{p}=0.300\right)$, see Table 2 . The ratio men/women within the groups was not statistically significant different in year 2001. compared to year 2003 (Chi²-analyses, $p>0.100$ in all comparisons).

Table 2. Distribution of junior doctors in anaesthesiology who responded to a survey on dinical confidence and experience before (year 2001 ) and two years after (year 2003) the introduction of a stuctured in-training assessiment programme for 1 st year trainees.

\begin{tabular}{lcccccc}
\hline & 2001 & Men & Women & 2003 & Men & Women \\
\hline Total & $377(100 \%)$ & 205 & 160 & $344(100 \%)$ & 181 & 152 \\
& & & & & & \\
Specialist & $187(50 \%)$ & 116 & 71 & $164(48 \%)$ & 96 & 68 \\
Senior residents & $50(13 \%)$ & 22 & 28 & $38(11 \%)$ & 22 & 16 \\
Residents & $53(14 \%)^{*}$ & 28 & 24 & $49(14 \%)$ & 28 & 21 \\
Hst year trainee & $55(15 \%)$ & 28 & 27 & $47(14 \%)$ & 17 & 30 \\
House staff & $21(6 \%)$ & 11 & 10 & $35(10 \%)$ & 18 & 17 \\
& & & & & & \\
\hline
\end{tabular}

One residertl did not indicate gender.

The mean number of years served in anaesthesiology and the mean level of conficlence for the 23 items related to the IT A programme and for the 132 items not related to the programme is shown in Table 3 for each of the five groups of junior doctors. There were no statistically significant differences in comparisons of mean level of confidence between year 2001 and 2003 within any of the groups. In both years there was a statistically significant increase in mean level of confidence related to increasing level of formal training positions, the introduction year, residency, senior residency, and specialists. In the four groups of trainees there were no significant differences in mean confidence between men and women, neither in year 2001 nor in year 2003 (Students t-test, $p>0.060$ in all com- 
parisons). In the group of specialists there was a small but significant difference between men and women in year 2001, mean confidence on items related to ITA $4.8(0.2)$ vs. $4.6(0.3), \mathrm{p}=0.002$, and items not related to ITA, $4.2(9.4)$ vs. $4.0(0.4), p=0.002$. In year 2003 there were no significant differences in confidence levels between men and women.

Table 3. Five groups of junior doctors" clinical confidence before (year 2001) and two years after (year 2003) the introduction of a structured ITA-programme for 1 si year trainees in andesthesiology. Confidence was indicated on 155 items related to aspects of clinical competence and indicated on a scale $1-5$.

\begin{tabular}{|c|c|c|c|}
\hline & $\begin{array}{l}\text { Mean number of } \\
\text { years served in } \\
\text { anaesthesiology }\end{array}$ & $\begin{array}{l}\text { Mean level of confi- } \\
\text { dence on items re- } \\
\text { lated to ITA } \\
(n=23)\end{array}$ & $\begin{array}{l}\text { Mean lev of conti- } \\
\text { dence on items not } \\
\text { related to ITA } \\
\qquad(n=132)\end{array}$ \\
\hline \multicolumn{4}{|l|}{ House staff } \\
\hline Before, $N=21$ & $1.6(1.0)$ & $3.6(0.9)$ & $2.4(0.5)$ \\
\hline \multirow[t]{2}{*}{ After, $\mathbb{N}=35$} & $1.2(0.9)$ & $3.3(1.0)$ & $24(0.7)$ \\
\hline & $p=0,2137$ & 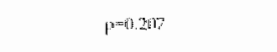 & 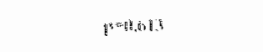 \\
\hline \multicolumn{4}{|l|}{ Introduction year } \\
\hline Before, $N=55$ & $0.8(0.6)$ & $3.4(0.6)$ & $2.2(0.4)$ \\
\hline \multirow[t]{2}{*}{ After, $N=47$} & $0.8(0.6)$ & $3.6(0.8)$ & $2.4(0.6)$ \\
\hline & 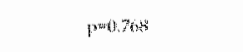 & $\mathrm{p}=010 \mathrm{z} \times \mathrm{k}$ & 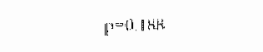 \\
\hline \multicolumn{4}{|l|}{ Residents } \\
\hline Before, $N=53$ & $43(2.5)$ & $4.2(0.4)$ & $3.3(0.5)$ \\
\hline \multirow[t]{2}{*}{ After, $N=48$} & $3.9(1.7)$ & $4.2(0.4)$ & $3.2(0.5)$ \\
\hline & $p=1.763$ & $\mathrm{P}^{\mathrm{xa}} \operatorname{con} 3$ & $\beta=4972$ \\
\hline \multicolumn{4}{|l|}{ Senior residents } \\
\hline Before, $N=50$ & $6.3(1.5)$ & $4.5(0.3)$ & $3.8(0.4)$ \\
\hline \multirow[t]{2}{*}{ After, $N=38$} & $6.2(2.3)$ & $4.5(0.3)$ & $3.8(0.4)$ \\
\hline & pin & Pung & is \\
\hline \multicolumn{4}{|l|}{ Speciualists } \\
\hline Before, $N=187$ & $11.9(4.1)$ & $4.7(0.3)$ & $4.2(0.4)$ \\
\hline \multirow[t]{2}{*}{ After, $N=161$} & $11.8(4.0)$ & $47(0.3)$ & $4.1(0.4)$ \\
\hline & 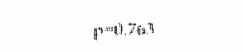 & 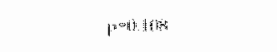 & $\operatorname{man} 27$ \\
\hline
\end{tabular}

In year 2003 twenty-seven $(77 \%)$ of the house staff, forty $(85 \%)$ of the introduction-year trainees, and $31(63 \%)$ residents reported having experienced one or more of the 21 elements included in the ITA programme. In these three groups of junior doctors the trainees ${ }^{\prime}$ experience 
with the ITA-programme increased according to time served in anaesthesiology over the first $11 / 2$ year, Figure 1 . However, there were large variances in number of assessments that the trainees had experienced and among trainees having serwed more than $1 \frac{1 / 2}{2}$ years the lower range approached zero.

Fugure 1. Experience with the 21 eltements of the ITA-programme according to time served in andethasiology among 131 trainees representing house staf, introduction year trainees, and residents. For each three months interval the box plots demonstrate the mediarn (heavy Jine) number of the 21. elements applied, the inter-quartie range (the box) and the range of resporrses (the whiskers).

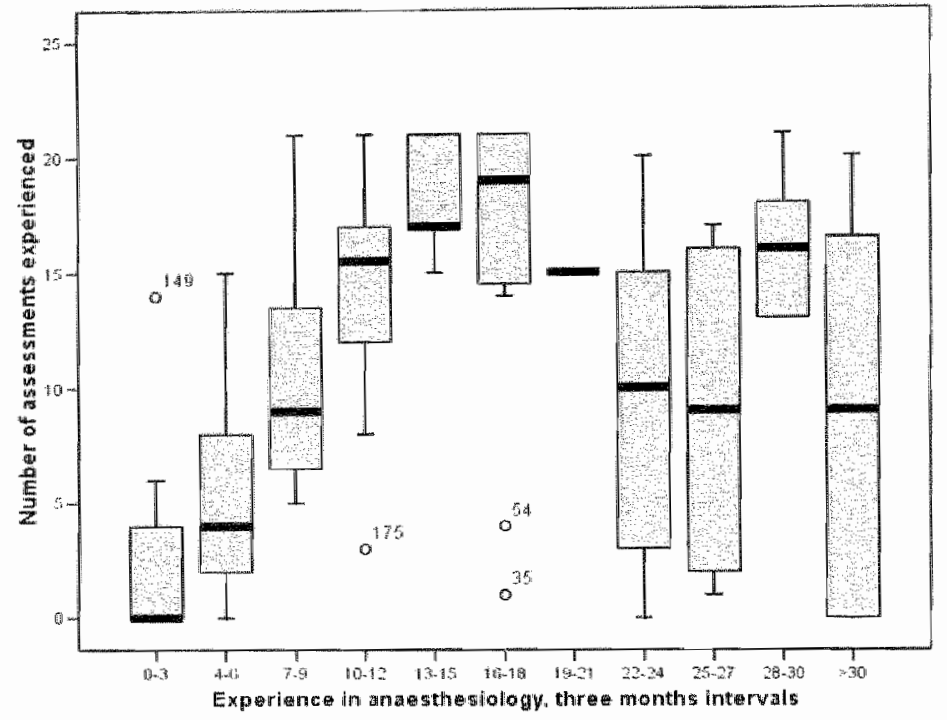

Mean confidence in items related to ITA increased over the first $1 \frac{1 / 2}{2}$ year and then seem to level off, Figure 2. For the 67 trainees having served up to $1 \frac{1}{2}$ year in anaesthesiology mean confidence in items related to ITA correlated significantly to both time in anaesthesiology, $r=0.772, p=0.000$, and number of assessments, $r=0.671, p=0.000$. This correlation was calculated without the outlier, case no 285, see Figure 2. A stepwise linear regression analysis demonstrated a significant contribution of time on mean confidence, $R=0.772, R^{2}=0.595, F=95.654$, $p=0.000$, with a standardized beta coefficient of $0.772, p=0.000$. Number of assessments performed did not contribute significantly to the model, $R^{2}$ change $=0.023$, Fchange $=3.786, p=0.056$. Those 63 trainees who had served more than $1 \frac{1 / 2}{1 / 2}$ year in anaesthesiology had experienced median 12 (inter-quartile range 0 -17) of the 21 elements of the ITA programme. There was no significant 
difference between those who had experienced from zero to three assessments, $\mathrm{n}=25$, and the rest who had experienced from six to $21, \mathrm{n}=38$, in mean confidence on items related to ITA, 4.1 (SD 0.4) vs. 4.2 (SD 0.5), $\mathrm{p}=0.422$, or items not related to the programme, 3.2 (SD 0.5$)$ vs. 3.2 (SD $0.4), p=0.950$.

Figure 2. Mean confidence on items related to T A acording to time served in andastheshol. ogy among 131 trainees representing house staf, introducton year trainees, and residents. For each thee month interwal the box plots clemonstrate the median (heavy line) of mean confidence lewels, the inter-quartile range (the box) and the range of responses (the whiskers).

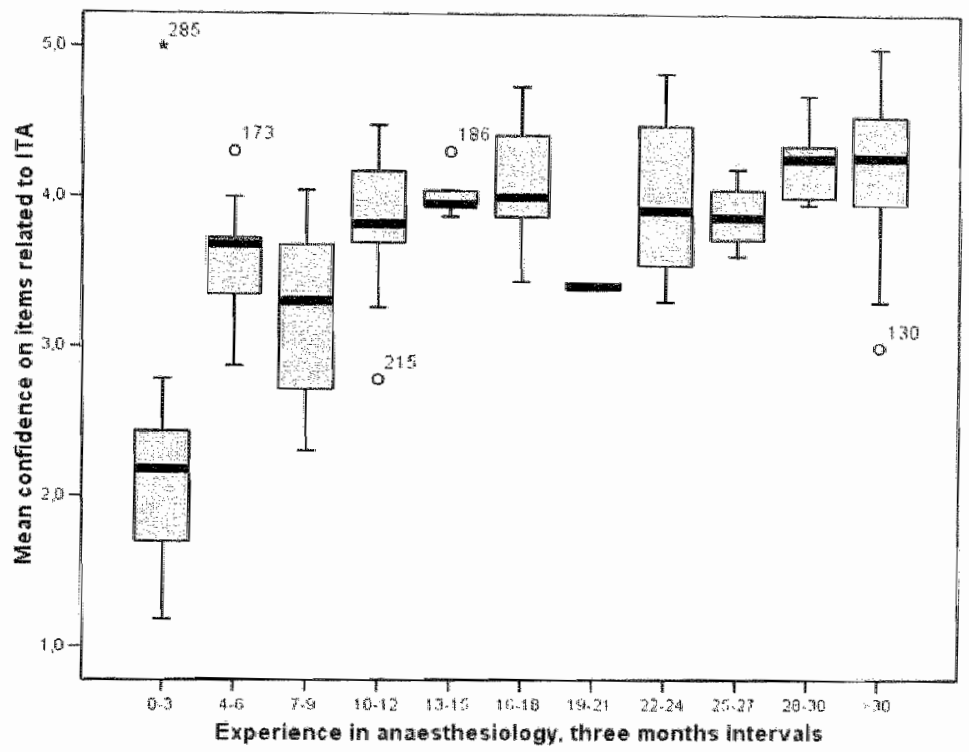

\section{Discussion}

This study is a survey of junior doctors' confidence in performance of a broad range of clinical skills and tasks related to other aspects of competence before and after the introduction of a structured ITA programme. There was an equally high response rate in 2001 and in 2003 with no difference in distribution of respondents from different training positions, which supports the validity of comparisons between the two years. Construct validity of the 155 items surveyed was supported by the observed increase in mean level of confidence over increasing amounts of experience in anaesthesiology. Implementation of the ITA programme was 
confimed by a rather high percentage of trainees reporting experience with the programme.

In previous studies about this ITA, programme directors, supervisors, and trainees have expressed that the TTA had a positive effect on learning and teaching and motivated all to study more. 11.14 However, the results of this study demonstrate that the introduction of a structured ITA programme did not have any significant effect on the junior doctors" mean level of confidence, neither in aspects related to the programme nor in other aspects.

There are several possible explanations for this result. Assessment by direct observation according to standards of performance could make the trainees more realistic about their actual competence. That could lead to a relatively lower rating of confidence counterbalancing a positive effect of ITA on leaming. It has repeatedly been demonstrated that individuals' self-assessment of competence is severely flawed and trainees might feel confident without being competent and vice versa. 16 -19 Hower, at the group level we saw differences in accordance with level of experience in anaesthesiology.

The users of our ITA programme have especially praised the linking of theory to practice and the effect of making the trainees study more. 11,14 However, an effect of ITA on learning within cognitive aspects is probably not reflected to the ratings of confidence in clinical practice. $18-19$ We defined 'confidence' according to the perceived need for support in performing a task. This concept of confidence is not synonymous with the level of competence representing the individuals' actual knowledge and skills related to the task. ${ }^{15}$ Confidence represents an individual's readiness to take on a task including a risk, and that is related to previous experience rather than known levels of competence. ${ }^{15}$ Unfortunately at the time of the study we did not have any data on individuals' actual knowledge and skills. Future studies including these aspects will be necessary to estimate the full effect of ITA on trainees' learning.

The assessors' rigour probably affects the contribution of assessment to the trainees' learning and clinical confidence. "Leniency of clinician assessors is a major problem in IT ${ }^{2023}$ and trainees express that they don't learn from assessments that are not rigorous." The results might also reflect the clinical departments' inexperience with formal assessment and non-compliance with the timely sequencing of assessments acconding to the protocol11, 14 as we saw large variances in number of the 21 elements applied in the first 1/2-year. In a previous study on how the ITA programme works in actual practice the users recommended that the individual assessments be applied in a timely fashion and used as a licence to practice more independently rather than be placed at a late stage of the training year." Timeliness of application of the individual assess- 
ments might have influenced the contribution of assessment to trainees' confidence relative to the time served in anaesthesiology. Learners are better at recognising development of new skills, but seem less able to identify improvement in existing skills. ${ }^{16}$ Thus assessments applied in the beginning as a licence to practice might contribute more to confidence than assessments applied at a late stage of the trainees' professional development.

In our previous studies a few users raised concerns about a risk of taking away responsibility for teaching and learning in aspects not covered by the programme. ${ }^{11,14}$ Any assessment programme can only assess a small sample of the objectives of the entire curriculum and the downside of introducing any structured assessment might be less emphasis on the other aspects of the entire curriculum. However, this potential risk was not confirmed by this study, as the confidence in areas not related to the programme did not change.

In many specialties application of the principles of ITA is still in its infancy and the full effect on the learning process and outcomes remains to be explored. The context of this study was a country with no assessment tradition in postgraduate education and perhaps this study was performed too early after the introduction of ITA. Cultural changes take a long time and there are reasons to believe that users learn over time and experience with ITA. ${ }^{11}$

\section{Conclusion}

This study demonstrates that the introduction of a structured ITA programme did not have any significant effect on the trainees' mean confidence as measured in this study on a broad range of aspects of clinical competence - neither in aspects related to the ITA progranme nor in other aspects. Timeliness and rigorousness in the application of ITA probably contribute to the effect on clinical confidence.

Acknowledgements: The authors wish to thank the numerous anaesthesiologists who took time to answer the questionnaires. We are grateful to D Davis for her editorial assistance and to $H$ Panduro, $S$ Findalen, and A Schmidt for their help with managing the surveys and the data.

\section{Funding}

This study was funded by CHC Postgraduate Medical Institute and in part by grants from the Ministry of Health and from the Danish Society of Anaesthesiology and Intensive Care Medicine. There was no conflict of interest. 


\section{References}

1. Epstein RM, Hundert EM. Defining and assessing professional competence. JAMA. 2002; $287: 226-35$.

2. Murray E, Gruppen L, Catton P, Hays R, Woolliscroft JO. The accountability of clinical education its definition amd assessment. Med Educ 2000; 34: 871-9.

3. Tumbull J, Van Barneveld C. Assessment of clnical performance: In-training evaluation. In: Worman, GR, Van der Vleuten, CPM, Newble, DI, eds. International Handbook of Research in Medical Education, Dordrecht: Kluwer Academic Publishers. Printed in Great Btittain. 2002; 793-810.

4. Friedman Ben-David $M$ The role of assessment in expanding professional horizons. Med Teach 2000; $22: 472-7$.

5. Khera N, Stroobant J. Primhak RA, Gupta R, Davies H. Training the ideal hospital doctor: the specialist registrars" perspective. Med Educ 2001;35: 957-66.

6. Spike N, Alexander H, Eliott $S$, Hazlett $C$. Kilminster $S$, Prideaux $D$, Roberts $T$. Intraining assessment - its potential in enhancing clinical teaching. Med Educ 2000;34:85861.

7. Van der Vleuten CPM. The assessment of professional competence: developments, research and practical implications. Adw Health Sci Educ 1996; 1: 41-67.

8. Newble Dl, laeger $K$. The effect of assessment and examinations on the learning of medical studtents. Med Educ 1983; 17: 165-71.

9. Stillman PL, Haley H-L, Regan MB, Philbin MM. Positive effects of a clinical performance assessment program. Acad Med 1991; 8: 481-3.

10. Ringsted $C$, Ostergaard D, Scherpbier A. Embracing the new paradigm of assessment in resident education. An assessment programme for first year residency training in anaesthesiology. Med Teach $2003 ; 25: 54-62$.

11. Ringsted C, Hentiksen AH, Skaarup AM, Van der Vleuten CPM. Educational impact of in training assessment (ITA) in postgraduate medical education. A qualitative study of an TTA programme in actual practice. Med Educ (in press).

12. Long DM. Competency-based residency training: the next advance in graduate medical education. Acad Med 2000; 75: 1178-83.

13. Ringsted C, Ostergaard D, Scherpbier A. Consultants" opinion on a new practice based assessment progranme for fist year residents in anaesthesiology. Acta Anaesthesiol $\operatorname{Scan} 2002 ; 46: 1119-23$.

14. Ringsted C, Ostergaard D, Van der Vleuten CPM. Implementation of a formal intrining assdessment programme in anaesthesiology and preliminary results of acceptability. Acta Anaesthesiol Scan 2003; 47: 1196-203.

15. Stewart I, Olfalloran C, Barton JR. Singleton SI, Harrigan P, Spencer I. Clarifying the concepts of confidence and competence to produce appropriate self-evaluation measurement soles. Med Educ 2000; 34: 903-9.

16. Whittle SR, Mundodi-Eaton DG. Student-selected projects: can they erithance lifelong leaming skills? Med Teach 2002; $24: 414$.

17. Mavis B. Self-efficacy and OSCE performance among second year medical students. Adv Health Sci Educ 2001; 6:93-102.

18. Amold L, Willoughby TL, Calkins EV. Self-evaluation in undergraduate medical education: A longitudinal perspective. I Med Educ 1985; 60: 21-8.

19. Keget-Flom Predicting supervisor, peer, and self ratings of intern performance. J Med Niduc 1975; 50: 812-5.

20. Ringsted C, Ostergaard D, Ravn L, Pedersen JA, Berlac PA, Van der Vleuten CPM. A feasibility study comparing checklists and global rating forms to assess resident performance in clinical skills. Med Teach $2003 ; 25 ; 6548$. 
21. Noel GL, Herbers JE Caplow MP, Cooper GS, Pangaro JN, Harvey I. How well do internal medicine faculty members evaluate the clinical skills of residents? Am Int Aed 1992; 117: 757-65.

22. Durning SI, Cation LI, Markert RJ, Pangaro LN. Assessing the reliability and validity of the Mini-clinical evaluation exercise for internal medicine residency training. Acad Med 2002; $77: 900-4$.

23. Norcini JJ, Blank LL, Arnold GK, Kmball FR. Examiner difterences in the Mini-Cex. Adv Flealth Sci Educ $1997 ; 2: 27-33$. 


\section{Conclusion and discussion}

This chapter is a discussion and conclusion according to the research questions. The overall research question of this thesis was. "How do theory on education and previous research outcomes inform the design and content of ITA in a work-based postgraduate medical education context and how does that apply to a specific ITA programme in actual practice?"

Six sub-questions were generated from the overall research question and applied to the specific context of $1^{\text {st }}$ year training in anaesthesiology. The first part of this chapter is a review and conclusion of the studies on the specific ITA programme reported in this thesis. The second part is a discussion of some general methodological aspects and practical issues related to the studies. The third part is a reflection on the implications for ITA in a wider context of postgraduate education. Finally, an overall conclusion is drawn and some future research questions are outlined. 


\section{Review and conclusion of the studies in this thesis}

This section is a summary of the findings according to the first research question and a review of the five subsequent studies as they apply to the theoretical considerations and actual outline of a specific ITA programme aimed for $1^{\text {st }}$ year trainees in anaesthesiology.

Research question 1. What is the internal rational zalidity of ITA in postgraduate education? How do theory on edncation and previous research outcomes inform the design and content of a specific ITA programme?

Chapter 1 describes how the theory on education and previous research were used to design a specific UTA programme for $1^{\text {st }}$ year trainees in anaesthesiology. The programme portrayed broad aspects of competence and included 21 elements of which 18 were summative assessments and three served a formative purpose. The resulting design recommended a sequential dispersion of ITA over the training year with emphasis on clinical skills in the beginning of the year and other aspects of competence and reflection on practice at a later stage of the year. Further, the validation process resulted in choosing task specific checklists over global scoring forms addressing general aspects of competence based on the assumption that checklists would provide better accuracy in scoring trainees and that they might serve as a help to the assessors in clarifying expectations of performance. The internal rational validation process contributed to foreseeing problems with implementation of ITA in a work-based busy clinical context and the programme was narrowed down as much as possible. The selected content were elements perceived to be of major importance. Problems of acceptance of the elements of the programme addressing academic competence were expected. Finally it was hypothesised that ITA would be of help to trainers and trainees in structuring the teaching, training, and learning and have a positive impact on the trainees' learning and clinical confidence. The appropriatemess of the design and content, the feasibility and educational impact was explored in five subsequent studies.

Research question 2: What is the content validity of ITA addressing broad aspects of competence? Do clinical experts agree on the composite content and the pre-defined stmidarts for whking decisions about the trainees?

In order to ensure coverage of the curriculum and agreement on the assessment protocol, consensus on the composite content and the predefined standards for making decisions about the trainees was sought through a nation-wide survey among consultants in anaesthesiology, Chapter 2. Based on responses from $251(66 \%)$ of the entire population of consultants we found that more than $75 \%$ strongly agreed on the repre- 
sentativeness of the assessments included in the ITA programme and the appropriateness of the composite programme for making pass/fail decisions. Further, $75 \%$ of the respondents gave high ratings of the comprehensiveness of the content in each of the summative assessments included in the programme. The ratings on the importance of two assessments were slightly lower compared to the others. One was a written assignment on academic competence and the other was an assessment reflecting organisational skills and professionalism on-call. Problems with acceptance of the written assignment were foreseen in the internal rational validation process and confirmed by the studies of the prom gramme in practice, Chapter 4 and 5 . The lower rating of the assessment on organisational skills and professionalism was probably not a disagreement on the content, as the respondents rated the other assessment on similar aspects high. We conclude that the outline of the ITA programme has sufficient content validity defined as the clinical experts" agreement on the composite content and on the pre-defined standards for making decisions about the trainees.

Research question 3: Do clinicinns prefer task specific checklists or global scoring forms with categories of competence when assessing trainees" performance? Is clinicians' agreement on pass/fail decisions better when using checklists compared to global scoring forms?

The internal rational validation process resulted in choosing task specific checklists over global scoring forms addressing general aspects of competence based on the assumption that checklists might serve as a help to the assessors and trainees in clarifying expectations of performance and checklists would provide better accuracy in scoring trainees. Research question 3 was studied using an experimental design with four simulated clinical assessment scenarios and a representative group of 32 clinicians randomised into using either of two scoring formats for assessing a resident's performance. One group used a checklist with task specific items and the other a global rating form with general dimensions of competence. Clinicians rated the appropriateness of the checklists significantly higher than the global scoring format. The studies on experience with the programme in practice presented in Chapter 4 and 5 confirmed the appreciation of checklists by trainers as well as trainees. The results in chapter 3 also demonstrated a poor agreement on pass/fail decisions irrespective of scoring form used. That was explained by assessor leniency rather than lack of vigilance in the observations or disagreements over standards of performance. Assessor leniency and non-compliance with the assessment protocol were confirmed in the studies on the implementation of the programme and how the programme works in practice, Chapters 4 and 5 . We conclude that clinicians prefer task specific checklists to 
global scoring forms in a postgraduate clinical context. However, checklists are no guarantee of consistency in clinicians' scoring of trainees and the internal rational validation process did not foresee the problems with leniency and non-compliance with the protocol.

Research question 4: To what extent can ITA be implemented? How well is ITA accepled by the trainees? What are the positive and negatioe aspects?

No matter how extensive the internal rational validation process and the prospective consensus seeking, barriers to implementing new concepts and imposing ITA in a busy work-based environment can be expected. Research question 4 was studied by of a nation-wide survey addressing the issues of implementation and preliminary evaluation data on trainees' opinion about the ITA programme. Reponses were obtained from 25 $(96 \%)$ programme directors who reported that in total $83(83 \%)$ trainees had been enrolled in the ITA programme. These results were later confirmed in the study reported in Chapter 6 , where between $77 \%$ and $85 \%$ of the trainees reported being enrolled in the programme. In general the programme was well accepted by both trainees and trainers. Barriers to implementation were time constraints and resistance among some of the senior colleagues. The summative parts of the programme were more frequently applied than the formative parts. The positive aspects of the programme included making goals and objectives clear, being of help in structuring training and learning, and in documenting and monitoring trainees' progress. We conclude that the ITA programme was widely implemented and accepted by trainees $1 \frac{1 / 2}{2}$ year after the introduction of the programme. The positive aspects were the advantage of structure and the negative aspects were mainly time constraints.

Reserach question 5: What is the educational impact of the programme in praclice? How does the progranume work in actual practice and how does that affect the trining, tenching and learning?

The possible benefits and the educational impact of ITA are described in the literature. However, the literature on how ITA works in actual practice is sparse. Research question 5 was studied in three clinical departments through semi-structured interviews with programme directors, dinical supervisors, and trainees. In summary the perceived benefits of the programme were structuring training, teaching, and learning, drawing attention to other aspects of competence than exclusively medical expertise, fostering learning and motivating all parties to study more, and being of help in managing problem residents. Issues of uncertainties about standards and conflict with service demands declined over time and experience with the programme and the departments worked towards a more structured planning of the assessments. The results dem- 
onstrated some variance in how the ITA programme was administered in practice and that affected the perceived value of ITA. Timing and sequencing of the programme were important. The users expressed that in order to be meaningful assessments should be placed at an appropriately early stage of training and used as a licence to practice un-supervised rather than after the trainees had been practicing independently for some time. Secondly, the trainers' attitude and the rigour in assessment practice had an impact on the trainees" perception of learning from the assessment and the meaningfulness of doing assessments. Finally, the educators and learners emphasised that the assessments should include a challenge and a learning point rather than being mere documentation of competence.

In conclusion the results of this study support the validity of the design of the ITA programme. Timely and rigorous assessment practice influenced the perceived benefit and educational impact of ITA. The results indicate that ITA might be of help in introducing new and broader concepts of competence in the medical profession and the study gives a first impression of how the organisation learns through the experience with ITA.

Research question 6: What is the effect of ITA in postgraduate education on the trainees' clinical confidence?

It was intuitively hypothesised that ITA drives learning and an increase in trainees confidence in clinical practice was expected. We studied the last research question of this thesis by surveying junior doctors clinical confidence before (year 2001) and two years after (year 2003) the introduction of ITA. Responses to a questionnaire including 155 items on broad aspects of clinical competence were acquired from $377(71 \%)$ doctors in 2001 and from $344(66 \%)$ in 2003 . Junior doctors represented house staff, introduction-year trainees, residents, senior residents, and specialists. Clinical confidence did not increase after the introduction of ITA, neither in aspects related to the ITA programme or in other aspects. This is contradictory to the results presented in Chapter 4 and 5 , where the user of the programme indicated that ITA fostered learning. It is possible that the perceived confidence in clinical practice is not related to competence in terms of actual knowledge and skills. As discussed in Chapters 5 and 6, lack of timely application of assessments according to the trainees' individual practice might in part explain why ITA did not have an impact on trainees' confidence. We conclude that TTA did not have an effect on trainees" clinical confidence. 


\section{Conclusion}

In summary theories on education and previous research outcomes informed the design and content of a specific ITA programme for $\mathbb{1}^{\text {st }}$ year trainees in anaesthesiology. The design included a mastery oriented, sequenced programme emphasising skills in the beginning of the training year and reflection on practice at later stages of the year. Based on the theoretical considerations checklists were preferred over global rating scales as instruments for the skills assessments and these checklists included theoretical questions on the individual skills assessed. Validity of this design was confirmed by clinical experts' agreement on the content and appreciation of checklists over global scoring forms. The programme proved feasibility and was widely implemented rather shortly after the introduction. Both trainers and trainees appreciated the programme for being of help in structuring teaching, training, and learning, and the users expressed a perceived benefit of ITA in fostering learning. However, that was not reflected in trainees" level of clinical confidence 2 years after introduction of ITA. Studies on the programme in practice demonstrated some variance in compliance with the assessment protocol. The value of ITA seemed to be linked to how the programme was administered in practice and timely, sequenced assessment according to trainees' professional development was crucial.

\section{Discussion of methodological aspects}

In this section the methodological aspects of the composite studies in this thesis are discussed under the headings: psychometric considerations, feasibility and educational impact.

\section{Psychometric considerations}

Psychometric properties of an assessment instrument can only be judged in terms of data collected from authentic application. "The six research questions in this thesis relate to the construction and introduction of an ITA programme and the first experience with the programme. The study of validity in Chapter 2 was confined to surveying consultants' opinions. on the outline of the programme. This study is but a start and there are many other important questions related to the validity of ITCA that have to be studied at a later stage.2 Concurrent validity of new assessment strategies are often estimated by comparisons to other measures of competence such as traditional end-of training exams and OSCE formats. That was not possible in the context of our ITA programme, as formal summative assessments or in-training evaluation of trainees in postgraduate education did not exist in our country. Evidence of construct 
vallidity was indirectly demonstrated in Chapter 6 , where junior doctors" clinical confidence on aspects related to the ITA programme increased according to levels of training and experience. In the future direct evidence of construct validity could be obtained by applying the assessments to a wide range of doctors with increasing levels of expertise. Discriminative validity as to whether the instruments can distinguish between poor and correct performance was indicated in the study presented in Chapter 3. Clinical assessors gave significantly lower scores to three simulated video taped performances, where the trainee made deliberate mistakes compared to the scenario, in which the trainees performed correctly. However, there were large variances in the ratings and pass/fail decisions were inconsistent among assessors in the first three scenarios, whereas all assessors passed the trainee in the last one. Holmboe et al." used a similar approach in demonstrating overall discriminative validity of the mini-clinical examination assessment instrument (MiniCEX). Like in our study, they found a wide range in ratings among the assessors. Although checklists might improve accuracy in scoring 7 they are no guarantee for examiner consistency in pass/fail decisions.

The results in Chapter 3 indicate poor reliability of the individual assessments. In ITA sampling across many situations and use of several different assessors alleviate these problems and the composite programme might have sufficient reliability "-13 Studying psychometric properties on a sub-set of the entine ITA programme cannot be a substitute for studying the composite programme as it works in practice. In internal medicine high reliability has been demonstrated for both the Mini-CEX, which is based on direct observation of trainee performance, and the American Board of Internal Medicine monthly evaluation form (ABIM-MEF). ${ }^{1 / 17}$ These instruments are applied on several occasions over time and performance scores on corresponding elements of these instruments are highly correlated. ${ }^{4}$ The high reliability and concurrent validity could be a result of the assessors using mainly the upper part of the scoring scale in both instruments and as a result the instruments are poor in demonstrating trainees increase in performance over time. 16 From a psychometric point of view the advantage of the high reliability appears to be a trade off regarding validity. There are several possible explanations to this scale shrinking. First, the majority of the trainees might be in the top range. In postgraduate education trainees are a highly selected group of learners and the fact that the vast majority of trainees receive scores between 7 and 9 on a 9-point scale corresponds to the prevalence of problem trainees being only around $7 \%, 15,8$ In the study reported in Chapter 5 the programme directors indicated that ITA was of help in identifying problem trainees at an earlier stage as well as specifying remediation plans. The value of ITA is that the staff gets to observe 
trainees in actual practice more than just occasionally. Most probably this serves as a screening for minimal performance standards 19 and is simultaneously used for feed back and instruction when needed. ${ }^{16}$ As discussed in Chapter 3, clinicians' conflicting role of supporting learning and development as well as being a judge could explain the phenomenon of inconsistency in pass/fail decisions on the individual assessments. Suggestions to solve that problem include appointing clinicians to only one of the roles or by leaving the summative pass/fail decisions to a committee. ${ }^{19-21}$ In Chapter 5 trainees indicated that some assessors are lenient and are satisfied with minimal acceptable levels of performance of their trainees. In some cases this might reflect deficiencies in their own performance standards and underlying competence. ${ }^{22-26}$ Finally, in the context of our studies unfamiliarity with the concept of standardised assessment of clinical competence might in part explain the inconsistency in assessors' scoring. However, studies on the Mini-CEX demonstrate similar large inter-rater variability despite almost ten years experience with this instrument."

Several authors emphasise the need for training the clinicians as assessors in ITA $6,27,28$ Our strategies of preparing the clinicians for the role as assessors were apparently insufficient in ensuring adherence to the protocol and rigorous assessment. However, training assessors might have only minor or no effect $t^{7,21,29,30}$ and further research along that line could be a dead end. Rather future studies on what internal and external mechanisms influence assessors' decision-making and dedication would be of interest. ${ }^{2}$ Such mechanisms might include the effect of benchmarking with other measures of outcome, ${ }^{31}$ involving the assessors in the whole process of constructing the instruments, ${ }^{8}$ group decisions, ${ }^{21}$ and external review of assessment practice. ${ }^{32}$

Fensibility

Feasibility as to the implementation of our ITA programme was rather high compared to other composite programmes ${ }^{33}$ and more than $80 \%$ of trainees were enrolled in the programme rather shortly after the introduction, Chapter 4 and 6 . The perception of the programme being a benefit to the users in structuring teaching, training, and learning might well have contributed to the wide implementation, Chapters 4 and 5. However, the number of research studies and surveys performed in relation to the introduction of this particular ITA programme probably had an impact on the implementation as a Halo effect. ${ }^{34}$ Introducing change by concurrent research studies is known to support implementation of innovations in medical education. ${ }^{34}$ The validity study reported in Chapter 2 served the purpose of informing the clinical departments nation-wide about the programme and drawing attention to the elements of the pro- 
gramme and standards of pass/fail decisions. The study on the simulated trainee performance afforded much discussion about standards of performance and various clinical departments subsequently used the videos in faculty development programmes. The studies on implementation and the effect on trainees' confidence contributed to a continuous follow up on this new initiative. This ITA programme was the first of its kind in the country and that could have afforded a pioneer spirit. All of these aspects are included in recommendations for managing change in medical education. ${ }^{34}$

Implementation of the programme was studied through questionnaire surveys. Response rates were generally high and we feel confident in concluding on the results. However, a more substantiate evidence of the implementation would be a continuous collection of documentation of assessments performed. That was not possible in the context of this specific ITA programme, as no authorities requested systematic reporting on educational results from graduate medical programmes. However, keeping national databases on assessment initiatives is highly recommendable for the monitoring and improving the quality of the programme over time and benchmarking across programmes or jurisdictions. ${ }^{35-37}$ Evaluation of data collected over a time is necessary for research into psychometric properties and databases are valuable in studying the effect of new initiatives and reviewing existing educational practices accordingly. ${ }^{2,15,16,32,38,39}$ Coupling educational databases with the growing number of clinical databases holds promises for future studies on the predictive validity of assessment practices and programme characteristics for clinical outcome and quality of clinical practice..$^{40-42}$

\section{Educational impact}

The studies on the educational impact included a qualitative study, Chapter 5 , and a study of trainees' clinical confidence before and after the introduction of ITA, Chapter 6. As discussed in these chapters, further research is needed in order to measure the effect of ITA on actual competence in terms of knowledge and skills. One way to pursue this question in the future could be elaborating a written test on cognitive knowledge and knowledge of skills. For research purposes, measures like that have been demonstrated to be valid estimates in comparing programmes and studying the effect of educational innovations on cohorts of trainees. ${ }^{43-4}$ Although knowledge of skills tests cannot be used for assessing individuals' actual performance it might be a valuable supplement: to IT'A, especially if applied as a progress test. ${ }^{45}$ Secondly, full-scale simulation could be used to study some of the other aspects of competence such as clinical decision-making, crises-resource management, interpersonal skills, teamwork, and professionalism. However, despite simulation 
technology especially in anaesthesiology is rather advanced only few studies have investigated the psychometric properties and efficiency of these methodologies. 48

\section{Sumnary}

The six research questions in this thesis relate to the construction and introduction of an ITA programme and the first experience with the programme. The strength of the studies lies in the process and considerations in outlining the programme and the developmental approach in the preliminary studies on the programme in practice. A number of future studies are required to estimate the psychometric properties of ITA and the impact on learning in terms of gain in actual knowledge and skills. Keeping national databases on assessments performed and linking those to other measures of competence and indicators of clinical practice is recommended.

\section{Implications}

Our programme was designed for $1^{\text {st }}$ year trainees in anaesthesiology and that has several implications as to the generalisability of the specific model. This section is a reflection on ITA in a wider perspective and a discussion of implications to other specialties and higher levels of training. The aspects will be addressed according to the medical and the nonmedical aspects of competence.

\section{Medical aspects of competence}

The various medical specialties differ substantially in their work place organisation and their approach to professional development of their trainees. An ITA strategy suitable for one specialty might not be appropriate for another. The most striking difference among specialties is whether they are predominantly 'technical task oriented' or "cognitive task oriented" specialties. This classification is far too simple, but is used here as an example of how this might influence the appropriateness of various ITA strategies in postgraduate education, Figure 1.

In 'technical task oriented' specialties like anaesthesiology and surgery the main training strategy is assigning the trainee increasingly complex tasks over the years, starting with rather simple tasks, standard cases, and one task at time and gradually presenting the trainees to more complicated tasks and patients in increasingly complex environments. ${ }^{50}$ The personal growth in competence is like a stepwise incremental bricklaying construction and is ruled by skills acquisition through practicing and experience. ${ }^{22}$ The clinical teaching strategies include instruction, di- 
rect supervision, and scaffolding. In these specialties mastery oriented, sequenced task specific ITA strategies like the one presented in this thesis and the one presented by Long in neurosurgery seem appropriate. ${ }^{51}$

Figure 1. Personal growth in trainees" competence in 'Technicat task oriented' specialties, ex. andesthesiology and surgery and 'Cognitive task oriented' specialities, ex. internal medicine and family medicine.

Teethnical tasks oriented specialties

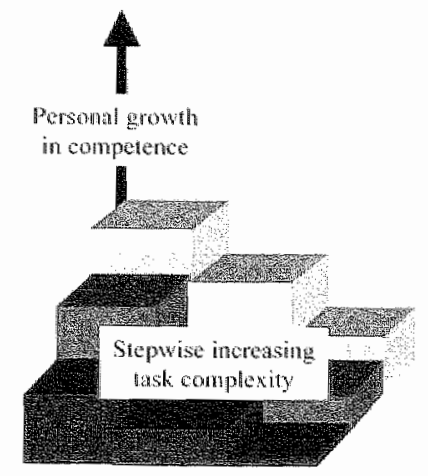

Cognitive task oriented specialties

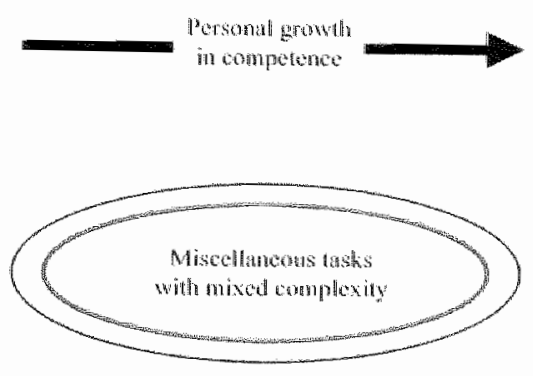

In 'cognitive task oriented' specialties like internal medicine, family medicine and paediatrics the complexity of task and context is not used strategically in the same way. Trainees are assigned to a rather unselected miscellaneous group of tasks and patients in whatever context they work such as ward rounds, admittance, and ambulatories. "16 Although task complexity varies across settings and patients, mean task complexity does not vary across time in the training year. ${ }^{16}$ The main strategy here is to let the trainee take care of increasingly wider aspects of the individual tasks. ${ }^{39,52}$ The clinical teaching strategies include more distant supervision, post hoc discussion of cases, and conferences. $1 \$$ The personal growth in competence is pictured as rings in the water and is ruled by knowledge acquisition through experience. ${ }^{53.58}$ In these specialties instruments that adapts to a broad range of clinical situations and settings and include the possibility of grading performance on general characteristics of the tasks seems more feasible than mastery oriented task specific instruments. $14,17.52$.

The specialty characteristics are reflected in the link between various aspects of competence and that has implications for the validity of various assessment strategies. In 'cognitive task oriented' specialties the link between knowledge and clinical performance is generally strong. ${ }^{15,12}$ For 
example in paediatrics a strong correlation ( $r=0.7 \mathrm{l}$ ) was found between in-training examination scores and performance in an OSCE containing predominantly interview, chart review, and interpretation stations and only a few physical examination stations. ${ }^{54}$ As cognitive tasks are dominant in these specialties, in-training theoretical examinations can be used in monitoring trainees' progress and identifying problem trainees. ${ }^{i s}$ In contrast the relation between knowledge and clinical performance in 'technicall task oriented' specialties is generally poor ${ }^{60,61}$ In surgery Scott $e t a l$ demonstrated that in-training examination scores were not correlated to scores on a skills test, $\mathrm{r}=0.151$, or scores on intra-operative performance, $r=0.106$. The acquisition of skil.ls often comes before and eventually even without the full theoretical knowledge. ${ }^{62,63}$ For example in anaesthesiology Sivarajan et al. ${ }^{63}$ found that scores on a spinal anaesthesia skills test were significantly higher than scores on a complementary knowledge test of that skill and the two sets of scores were not correlated, $r=0.19$. In these specialties performance on in-training examinations and performance in practice is not linked, but rather a co-existing phenomenon ${ }^{60,61}$ and cognitive tests are not useful in identifying problems in practice. ${ }^{\text {ins }}$

The above-mentioned classification of specialties is much too simple and in every specialty there is a need for learning some technical as well as some cognitive oriented skills.22,65 In Chapter 1 we discussed how different specialties have different values, traits and preferred learning styles. The various specialties probably attract trainees with certain personality characteristics ${ }^{66}$ and the trainees are formed by the culture in which they are trained. ${ }^{67}$ This is reflected in performance on various aspects of competence. In 'cognitive task oriented' specialties doctors are likely to have deep intellectual curiosity and focus on thinking rather than acling 17, in and scores on cognitive tasks tend to be higher than scores on technical oriented tasks. ${ }^{5 \%, 6 \%}$ For example in intemal medicine residents scored significantly higher on test interpretation stations than physical diagnosis stations in an OSCE ${ }^{\text {th }}$ and mean scores on physical examination or procedural skills on the Mini-CEX and the ABIM are lower than scores on cognitive aspects of competence. $14.1^{16}$ In 'technical oriented specialties' focus is on acting ${ }^{6 / 7}$ and scores on technical performance can be significantly higher than scores on related cognitive tests. ${ }^{4,61,63}$ For example Sloan et $a l^{\text {d, ht }}$ found generally higher sub-scores on procedural and technical stations in an OSCE compared to interpretation stations.

These aspects have implications for choosing assessment strategies and ITA can be used strategically in driving learning in the nondominant areas of a specialty, 10.67 In the context of our programme the non-dominant area was the cognitive one and we deliberately targeted 
cognitive aspects by including theoretical questions in the checklists on procedural skills and by including reflective assignments in the ITA programme, Chapter 1. As reported in Chapter 4 and 5 , the trainees appreciated the cognitive aspects and both trainees and trainers indicated that the ITA programme made them study more. Future studies are needed to demonstrate whether ITA actually has an effect on those aspects of learning and how that might influence clinical performance and quality of practice ${ }^{70,71}$ However, studies on the programme in practice also demonstrated that implementing elements targeting the non-dominant areas, in this case written assignments on academic aspects of competence, might meet resistance from both trainees and trainers, Chapter 2, 4, and 5. In 'cognitive task oriented' specialties the non-dominant areas are skills and a structured approach to the tasks. This means that less attention is paid to train and practice these aspects in order to become an expert.22 For example performing ward rounds is a substantiate part of internists' practice. However, standards of efficient or 'good' ward rounds are rarely defined, taught or assessed.5.72 A structured approach to tasks might free up mental resources to deal with the cognitive challenges?2 and increase efficiency and outcome in patient management. ${ }^{72,73}$ Thus, 'cognitive task oriented' specialties might benefit from using ITA in driving learning of basic skills and taking a structured approach to the tasks.

In both types of specialties the need for better training and assessment of even very basic procedural skills has repeattedly been demonstrated ${ }^{69974-76}$ In a postgraduate work-based context the focus in the early training is on learning a number of new procedural skills and the learning of cognitive oriented aspects of competence comes second and slower. $22,62,77$ This order is opposite to the traditional undergraduate medical curriculum, but imperative for the trainees to be able to function in the postgraduate work-based context. Chapter 1 . During professional development, integration of skills, knowledge, and behaviours are increasingly expected as are the ability to handle uncertainties and more complex situations. ${ }^{78}$ In Chapter 6 we demonstrated that trainees level of clinical confidence was related to time spent in training. Although practice and clinical experience may lead to increased confidence this is no guarantee of actual competence and quality of practice. ${ }^{22,74}$ Quality of performance in practice depends on time spent in practice as well as the ability to assess the quality of one's own practice and an attitude towards continual improvement. ${ }^{22}$ In postgraduate education the challenge is to support the development of an integrated, deep, holistic learning and an attitude towards self-directed learning through continuously monitoring and reflecting on quality of practice. ${ }^{22,39,80,83}$ Future research should inves tigate how IT"A programmes can support the development of such skills and attitude and how they should be assessed. 
Non-medical aspects of competence

The non-medical aspects of competence are embraced in many of the roles of future specialists such as communicator, collaborator, scholar, and professional. ${ }^{85,86}$ The educational authorities have defined the future roles and the underlying aspects of competence as they apply to all specialists in general. ${ }^{85,86}$ A number of new tools have been suggested for assessing these general aspects. ${ }^{30,86,88}$ However, just as with the medical aspects of competence ITA programmes will have to address the nonmedical aspects relative to characteristics of each specialty ${ }^{89}$ The values and characteristics of a specialty is often part of a hidden curriculum and using professionals' verbalisation of professional practice could be of help in defining appropriate objectives and constructing ITA programmes accordingly. ${ }^{601-492}$ In addition, experience from other organisations may be valuable in defining the non-medical aspects of competence such as teamwork. $47,49,93$ Future studies are needed on professional practice in order to better understand and define these aspects of competence $49, y_{3}$ and qualitative research approaches in a joint collaboration between medical professionals and professional educators such as psychologists or sociologists will probably add significantly to the insight and verbalisation of these tacit areas, $707,790,92$ Emphasising broader aspects of competence in medical education including non-medical aspects was based on societies" needs and critique of prevailing practice ${ }^{94}$ and the present staff of clinical teachers may not be dependable in teaching and assessing professional values, attitudes, and behaviours. $23-26$ Training the trainers in these aspects is necessary $y^{95}$ - and specifying appropriate behaviour in ITA instruments could be of help in qualifying all parties as indicated in Chapter 5. However, much more research is needed into which strategies are effective and efficient in qualifying all parties and ensuring an outcone that meets various stakeholders" expectations. ${ }^{26}$

A major challenge to the professions and medical educators is defining and specifying the developmental stages that the trainees run through over the time of professional growth.22.39.91 Various aspects of competence as they apply to the future roles of specialists are emphasised at various levels of training and professional development.22,39,82 For example issues of professionalism relevant to the specialist such as the social contract, codes of ethics, participation in professional societies, and altruism are not on the agenda in the trainees' daily activities ${ }^{96}$ Experts in a domain often have difficulties in verbalising both medical and nonmedical aspects of competence ${ }^{78}$ and they may not be aware of the problems trainees experience related to their specific tasks and contexts. In the process of defining objectives and tailoring programmes and ITA instruments to the various training levels it may be helpful to include trainees and other stakeholders working closely with the trainees. ${ }^{97.98}$ 


\section{Summary}

Medical specialties differ substantially in preferred training strategies and culture according to whether they are primarily 'technical task oriented" or "cognitive task oriented" specialties. This has implications for choice of ITA strategies and a model suitable for one specialty might not be appropriate in another. ITA programmes should be tailored to the trainees" professional development and relevant daily work activities and support the acquisition of basic clinical skills as well as deep, holistic aspects of competence. ITA can be used to drive learning in nondominant areas of a specialty.

\section{Conclusion and future research}

The overall research question of this thesis was. "How do theory on education and previous research outcomes inform the design and content of ITA in a work-based postgraduate medical education context and how does that apply to the feasibility and educational impact of ITA in actual practice? This research question was studied through generation of six sub-questions applied to a context of a specific IT A programme designed for $1^{\text {st }}$ year trainees in anaesthesiology and a subsequent theoretical discussion as to the generalisation of the specific model and implications of the findings in a wider perspective.

Conclusion on the first part of the research question is that theory on education and previous research outcomes inform that ITA strategies appropriate in one specialty might not be appropriate in another. Design and content of composite ITA programmes must address trainees' levels of experience and work-related context and support the development of broad, holistic aspects of competence. In technical task oriented specialties mastery oriented, sequenced programmes seem more appropriate than in 'cognitive task oriented" specialties, where global instruments adapting to a wide variety of clinical situations and settings could be a better choice. Irrespective of specialty, ITA can be used in driving learning in the non-dominant areas. In "technical task oriented" specialties this includes the cognitive aspects of competence and in 'cognitive task oriented" specialties this includes focus on basic skills and structure in the approach to the tasks. In all of the medical specialties there is a need for defining standards of performance in both medical and non-medical aspects of competence. Using checklists and sufficiently elaborate instruments can be of help in making standards clear to trainees and assessors.

The conclusion on the last part of the research question is drawn from applying the theories to a specific ITA programme designed for $1^{\text {th }}$ year 
trainees in anaesthesiology and studies of this programme in actual practice. The programme proved feasible as to the implementation of ITA. Studies on the programme in practice demonstrated some variance in compliance with the assessment protocol. Nevertheless, the users found the programme helpful in guiding teaching, training, and learning and in identifying and managing problem trainees. Trainees and clinical teachers appreciated the details in the checklists and clinical assessors found checklist more appropriate than globall rating forms. The users of the programme indicated that the cognitive aspects of the programme made all parties study more. The programme had no effect on level of trainees' clinical confidence measured before and two years after introduction of ITA. The perceived value of ITA seemed to be linked to how the programme was administered in practice and timely, rigorous assessment was crucial. There are reasons to believe that the clinical departments learn over time and experience with the programme and the full potential of the specific programme remains to be explored. The impact of ITA on actual competence in terms of knowledge and skills remains to be studied in the future.

The process and considerations involved in outlining the specific ITA programme presented in this thesis might serve as a template for those who wish to design similar programmes. The specific model will have to be adapted to the characteristics of the specialty and training level. The studies presented in this thesis are but a start and points to several aspects of ITA to be studied in the future:

- Are specialty specific ITA models better than global models assessing general aspects of competence defined as an integrative habit of action?

- Are ITA models tailored to trainees' professional development more efficient than global models addressing general aspects of competence defined as an integrated habit of action?

- How important is challenging the non-dominant areas of the specialties and will that contribute to an effect on actual competence and quality of practice?

- Does ITA on clinical performance alone suffice in ensuring trainees" achievement of competence or is assessment of actual skills and knowledge a necessary compliment as to ensure quality of performance in practice?

- What internal and external mechanisms influence clinicians' assessment practice? What is the effect of benchmarking with other measures of outcome and external review of assessment practice? How can clinician assessors effectively be prepared for ITA? 
- What is the effect of various models of IT A on quality of clinical practice in training as well as in subsequent continuous practice?

- What are the psychometric properties of composite ITA programmes addressing broad aspects of medical and non-medical aspects of competence and what kind of evidence is useful for estimating that?

- How can ITA foster development of an integrated, deep, holistic learning and an attitude towards self-directed learning and an attitude towards continuously monitoring and reflecting on quality of practice? How can these aspects be assessed?

- How can national databases on assessment, educational practice and clinical practice be established and used without fostering a repressive culture of fear, shame and blame?

Constructing meaningful ITA programmes as they apply to the workbased postgraduate education context in a wide variety of specialties and cultures is a huge challenge to educators. The approach taken to develop the specific ITA programme and studying the programme in practice is recommended. Establishing national databases on trainees and assessment practice across programmes would be of help in the studies of feasibility and educational impact of various strategies. ITA seems to be a valuable strategy in addressing broad aspects of clinical performance and integrating assessment in the learning process. However, due to problems of assessor bias in clinical practice ITA may not be sufficient in prom viding evidence of expected learning outcomes and supplementary assessment strategies might be needed.

\section{References}

2. Dauphinee WD, Blackmore DE Assessing the assessors' assessment. Mted lwhe 2001; $35: 317-8$.

2. Hutchinson L, Aitken P. Hayes. T. Are medical postgraduate certification processes vald? A systematio review of the published endence. Med Edac 2002, 36:73-91.

3. Hodges B, Regehr G, Hanson M, McWaughton W. Validation of an objuclve structuded clinical examination in psychiatry. Aad Med 1998; 73:910-2.

4. Sloan DA, Donnelly MB, schwantr RW, Gets JL, Blue AV, Strodel WL. The ne of the objective stuctured clincal examination (OSCE) for evaluation and instruction in graduate medical education. I Surg Ras 1996; 63:225-230.

5. Norgard $K$, Ringsted $C$, Dolmans D. Validation of a checklist to assess wand round performance in internal medicine. Medical Euducation 2004 (ir press).

6. Holmboe ES, Huot S, Chung I, Moncini I, Hawkins RE Construct widity of the MintClinical axaluation exercise (Minclex). Acad Med 2003, 78:826-830

7. Noel GL, Herbers IE, Caplow MP, Cooper GS, Pangaro JN, Marwey J. How well do intemal medicint taculty members evaluate the clinioal skils of residents? Amn lnt Med 1992; 117:757-65. 
8. Wilkinson TJ, Frampton CM, Thompson-Fawcett M, Egan T. Objectivity in objective structured clinical examinations: checklists are no substitute for examiner commitment. Acad Med 2003; $78: 219.23$.

9. Hays RB, Fbb WE, van der Vleuten CPM. Reliability of the fellowship examination of the Royal Australian College of General Practitioners. Teach Learn Med 1995; 7: 43-50.

10. Van der Vleuten CPM. The assessment of professional competence: developments, research and practical implications. Adv Health Sci Educ, 1996: 1: 41-67.

11. Replogle WH. Interpretation of the American board of family practice in-training examination. Fam Med 2001; 33: 98-103.

12. Wass $V$, McGibbon $D$, van der Vleuten $C$. Composite undergraduate clinical examinations: how should the components be combined to maximized reliability? Med Educ 2001; 35: 325 330 .

13. Crossley I, Davies H, Humphris G, Jolly B. Generalisability: a key to unlock professional assessment. Med Educ 2002; 36: $972-978$.

14. Durning SI, Cation LJ, Jackson JL. The reliability and validity of the American Board of Internal Medicine monthly evaluation form. Acad Med 2003; 78: 1175-82.

15. Durning S1, Lannie JC, Markert RJ, Pangaro LN. Assiessing the reliability and validity of the mini-clinical evaluation exercise for internal medicine residency training. Acad Med 2002; $77: 9004$.

16. Norcini JI, Blank LL, Duffy FD, Fortna GS. The Mini-CEX: A method for assessing clinical skills. Ann Intern Med 2003; 138: 476-81.

17. Norcini J), Blank LL, Arnold GK, Kimball HR. Examiner differences in the Mini-Cex. Adv Health Sci Educ 1997; 2: 27-33.

18. Yao DC, Wright SM. National survey of internal medicine residency programme directors regarding problem residents. JAMA 2000; 284: 1099-1104.

19. Gordon MJ. Cutting the Gordian Knot: $A$ two-part approach to the evaluation and professional development of residents. Acad Med 1997; 72:876-880.

20. Yudkowsky $R$. Can resident evaluations demonstrate increases in residents' skills over time? Acad Med 1999; 74: S108-10.

21. Williams RG, Klamen DA, McGaghie WC. Cognitive, social and environmental sources of bias in clinical performance ratings. Teach Learn Med 2003; 15: 270-92.

22. Guest CB, Regehr $G$, Tiberius RG. The life long challenge of expertise. Med Educ 2001, 35: 78-81.

23. Paice $\mathbb{E}$, Heard $\mathrm{S}$, Moss $\mathrm{F}$. How important are role models in making good doctors? BMJ 2002; 325: 707-10.

24. Vernooij-Dassen MJ Ram PM, Bremninkmeijer WJ, Franssen L, Bottema BJ, van der Vleuten CP, Grol RP. Quality assessment in general practice traimers. Med Educ 2000 : 34: $1001-6$.

25. Lirola T, Lund VE, Katila AJ, Mattila-Vuori A, Palve H. Teaching hospital physicians" skills and knowledge of resuscitation algorithms are deficient. Acta Anaesthesiol Scand 2002; $46: 11504$.

26. Kenny NP, Mann KV, MacLeod H. Role modelling in physicians' professional formation: reconsidering an essential but untapped educational strategy. Acad Med 2003; 78: $1203-10$.

27. Turnbuld J. Gray J, MacFadyen. Improving in-training evaluation programs, JGIM 1998: 13: 317-23.

28. Feletti G, Cameron D, Dawson-Saunders B. Des Groseilliers J, Dooley B, Farmer E, McAvoy P. In-training assessment. In: Newble D, Jolly B, Wakeford $R$, eds. The certification and recertification of doctors: Issues in the assessment of clinical competence. Cambridge University Press. 1994: 151-66.

29. Haber RI, Awins AL. Do ratings on the American Board of Internal Medicine resident evaluation form detect differences in clinical competence? I Gen Intern Med 1994: $140-5$. 
30. Newble DI, Hoare 1, Sheldrake PF. The selection and training of exaniners for dinical examinations. Med Educ 1980; $14: 345-349$.

31. MacRae HM, Vu NV, Graham B, Word-Sims M, Colliver JA, Robbs RS. Comparing checklists and databases with physicians' ratings as measures of students' history and physical examination skills. Acad Med 1995; 70: 313-7.

32. Forwell SL, Southgate LI, Bligh JG. Evaluating assessment: the missing link? Med Educ 1999; $33: 276-81$.

33. Houghton $G$, Wall $D$. Trainers evaluations of the West Midlands formative assessment package for GP registrar assessment. Med Teach 2000; 22: 399-405.

34. Gale $R$, Grant $J$. AMEE Medical education gudde No. 10: managing change in a medical context: guidelines for action. Med Teach 1997; 19: 239-49.

35. Garibaldi RA, Subhyyah R, Moore ME, Waxman H. The in-traning examination in internal medicine: an analysis of residents" perfomance over time. Ann fntem Med 2002; 137: 505-10.

36. Hall JR, Cotsonis GA. Analysis of residents" performances on the in-training examination of the Americal Board of Anesthesiology-American Society of Anesthesiologists. Acad Med 1990; 65: 475-7.

37. Wolfshal SD, Beasley BW, Kopelman R, Stickley W, Gabryel T, Kahn MJ, Membership. survey and scientific data committee, the association of program directors of internal medicine. Benchmarks of support in internal medicine residency training programs. Acad Med 2002; 77: 50-6.

38. Paice $\mathrm{E}$, Aitken $\mathrm{M}$, Cowan $\mathrm{G}$, Heard $\mathrm{S}$. Trainee satisfaction before and after the Calman reforms of specialist training: questionnaire survey. BMJ 2000; 320: 832-6.

39. Epstein RM, Hundert EM. Defining and assessing prolessional competence. IAMA $2002 ; 287: 226.35$.

40. Sharp LK, Bashook PG, Lipsky MS, Horowitz SD, Miller SH. Specially board certifica tion and clinical outcomes: The missing link. Acat Med 2002; 77; 534-42.

41. Whitcomb ME. It's time to focus on the quality of GME. Acad Med 2003; 78: 1-2.

42. Tamblyn R, Abrahamowicz M, Dauphinee WD, Hanley JA, Norcini $\mathbb{J}$, Girard $N$. Grand'Maison P. Brailowsky C. Association between licensure examination scores and practice in primary care. JAMA 2002; 288: 3019-26.

43. Remmen R, Scherpbier A, Denekens J, Derese A, Hermann I, Hoogenboom R, Van der Vleuten C, Van Royen P, Bossaert $L$. Correlation of a written test of skills and a performance based test: a study in two traditional medical schools. Med Teach 2001; 23 : $29-32$.

44. Ram P, Van der Vleuten C, Rethans J-1, Schouten B, Hobma S, Grol R. Assessment in general practice: the predictive value of written-knowledge tests and a multiple-station examination for actual medical performance in dally practice. Med Educ 1999; 33: 197. 203.

45. Kramer AW, Jansen J1, Zuithoff P, Dusman H, Tan LH, Grol RP, van der Vlouten CP. Predictive valiclity of a written knowledge test of skills for an OSCE in postgraduate training for general practice. Med Educ 2002; 36: 812-9.

46. Van der Vleuten CPM, Van Luyk SI, Beckets HIM. A written test as an alternative to pertormance testing. Med Educ 1989; 23:97-107.

47. Glavin RJ, Maran NJ. Integrating human factors into the medical curriculum. Med Educ 2003:37(Suppl): 59-64.

48. Byrne A], Greaves JD. Assessment instruments used during anaesthetic simulation: review of published studies. Br I Anaesth 2001; 86: 445-50.

49. Fletcher GCL, MOGeorge P, Flin RH, Glavin RJ, Maran NJ, The rote of non-fechnical skills in andesthesia: a review of current literature. Br I Anaesth 2002,88:418-29.

50. Patel BS, feerick A. Will competency assessment improve the training and skills of the trainee anaesthetist? Anaesthesia 2002,57:711-2.

51. Long DM. Competency-based residency training; the next advance in graduate nedical education. Acad Med 2000; 75: 1178-83. 
52. Pangaro 1 . A new vocabulary and other innovations for improving descriptive intraining evaluations. Acad Med 1999; 74: 1203-7.

53. Steel K, Norcini I, Brummel-Smith $K$, Erwin D, Markson L. The first certifying examination in geriatric medicine. I Am Geriatr Soc 1989; 37: 1188-91.

54. Norcini IJ Grosso LJ, Shed JA, Webster GD. The relationship between features of residency tratining and $A B M$ certifying examination performance. I Gen Intern Med $1987 ; 2: 330-6$.

55. Norcini IJ, Lipner RS. The relationship between the nature of practice and performance on a cognitive examination. Acad Med 2000; 75(Suppl): S68-70.

56. Norcini 1], Shea JA, Langdon LO, Hudson LD. First American Board of Internal Medicine critical care examination: process and results. Crit Care Med 1989; 17:695-8.

57. Norcini IJ. Indicators of educational effectiveness of subspecially training programs in internal medicine. Acad Med 1995; 70:512-6.

58. Kramer AWM, Düsman H, Tan LHC, Jansen KJM, Grol RPPM, Van der Vleuten CPM. Effect of extension of postgraduate training in general practice on the acquisition of knowled ge of trainees. Family Practice 2003; 20: 207-12.

59. Joorabch B. Objective structured cinical examination in a pediatric residency program. AJDC 1991; 145; 757-62.

60. Scott DI, Valentine R], Bergen PC, Rege RV, Laycock R, Tesfay ST, Jones DB. Evaluating surgical competency with the American Board of Surgery in-training examination, skill testing, and intraoperative assessment. Surgery 2000; 128:613-22.

61. Sloan DA, Donnelly MB, Schwartz RW, Strode] WE. The objective structured clinical examination. The new gold standard for evaluating postgraduate clinical performance. Ann Surg 1995: 222: 735-42.

62. Rasmussen ]. Skills, rulles, knowledge, signals, signs, and symbols and other distinctions in human performance models. IEEE Transaction Systems, man and Cybernetics $1983 ; 123 ; 257-66$.

63. Siwarajan $M$, Miller E, Hardy $C$, Herr $G$, Liu $\mathbb{P}$, Willenkin $R$, Cullen $\mathbb{B}$. Objective evaluation of clinical performance and correlation with knowledge. Anesth Analg 1984; 63: $603-7$.

64. Cusimano MD, Yonke AM, Tucker WS. An analysis of attrition from Canadian neurosurgery residency programs. Acad Med 1999; 74:925-31.

65. Moorthy K, Munz Y, Sarker SK, Darzi A. Objective assessment of technical skills in surgery. BMJ 2003; 327: 1032-7.

66. Hojat M, Brigham TP, Gottheil E, Xu G, Glaser K, Veloski JI. Medical students' personal valtues and their career choices a quarter-century later. Psychol Rep 1998; 83: 2438.

67. Baker JD, Cooke JE, Contoy JM, Bromley HR, Hollon MF, Alpert CC. Beyond coreer choice: the role of learning style analysis in residency training. Med Educ 1988; 22: 527 . 32.

68. Hojat M, Nasca TJ Magee M, Jieeney K, Pascual R, Urbano IF, Gonnella IS. A comparison of the personality profiles of internal medicine residents, physician role models, and the general population. Acad Med 1999; 74: 1327-33.

69. Dupras DM, Li JTC. Use of an objective structured clinical examination to determine clinical competence. Acad Med 1995; 70: 1029-34.

70. Klemola U.M, Norros L. Analysis of the chinical behaviour of anaesthetists: recognition of uncertainty as a basis for practice. Med Educ 1997; 31: 449-56.

71. Klemola U-M, Norros L. Practice-based criteria for assessing anaesthetists" habits of action: ontline for an reflexive turn in practice. Med Educ 2001; 35: 455-64,

72. Pronovost P, Berenholtz S, Dorman T, Lipsett PA, Simmonds T, Haraden C. Improving commumication in the $1 \mathrm{CU}$ using daily goals. J Crit Care 2003; 18: 71-6.

73. Risser $D$. Simon R, Rice M, Salisbury M. The potential for improwed teamwork to reduce medical errors in the emergency department. Ann Emergency Med 1999; 34: $373-83$. 
74. Jansen JMM, Scherpbier AJ]M, Metz JCM, Grol RPTM, van der Vleuten CPM, Rethans Jy. Performance-based assessment in continuing medical education for general protitioners: construct validity. Med Educ 1996; 30: 33944.

75. Kelly MH, Campbell LM, Murray TS. Clinicall skills assessmend Br J Gen Prac 1999; 49: $447-50$.

76. Fox RA, Clark CLI, Scotland AD, Dacre IE. A study of pre-registration house officers" clinical skills. Med Educ 2000; 34: 1007-12.

77. Marel GM, Lyon PM, Field MI. Barnsiey L, Hibbert E, Parise A. Clinical skills in early postgraduate medical trainees: patterns of acquisition of confidence and experience among junior doctors in anversity teaching hospital. Med Educ 2000:34: 10135.

78. Dreyfus HL, Dreyfus SE. Mind over machine: The power of human intuition and expertise in the era of the computer. Oxford, Basil Blackwell. 1986

79. Marteau TM, Wynne G, Kaye W, Evans TR Resuscitation: experience without feedback increases confidence but not skill. BMJ 1990:300:849.50.

80. Coles C. Developing professional judgment. I Cont Educ Health Prof 2002,22:3-10

81. Friedman Ben-David $M$. The role of assessment in expanding professional horizons. Med Teach $2000 ; 22 ; 472-6$.

82. Leung W-C.Competency based medical training review. BMI 2002; 325:693-6.

83. Fraser SW, Greenhalgh T. Coping with complexity: educating for capability. BMI 200!; 323: 799-803.

84. Hojat M, Nasca TJ, Erdmann JB, Frisby AJ, Veloski JI, Gonella JS. An operational measure of physician lifelong learning: its development, components and preliminary psychometric data. Med Teach 2003; 25: 433-7.

85. CanMEDS 2000: Extract from the CanMEDS 2000 Project Societal Needs Working Group Report. Med Teach 2000; 22: 549-54.

86. ACGME Outcome project. Accreditation Council for Graduate Medical Education Web site: hittp:/ /www acgme org. 2000. Accessed April 2003.

87. JCHMT: Higher medical training. Generic curriculum. Joint Committee for Higher Medical Training Web site: htip//fwww jchmtorg. uk 2003. Accessed April 2003.

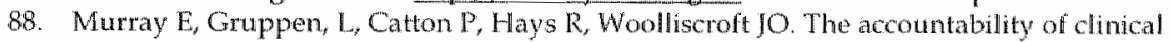
education: its definition and assessment. Med Educ 2000; 34:871-9.

89. Fojat $M$, Gonnellla JS, Nasca T], Mangione S, Vergare M, Magee M. Physician empathy: definition, components, measurement, and relationship to gender and specialty. Am J Psychiatry 2002; 1.59; 1563-9.

90. Coles C. A qualitative jook at practice. A comment on 'Analysis of the clinical behavjour of anaes thatiss'. Med Ed unc 1997,31:448.

91. Greaves JD, Grant J. Watching anaesthetists work: using the professional judgenend of consultants to assess the developing clinical competence of trainees. Br I Anaesth 2000\% 84: $525-33$.

92. Pope C, Smith A, Goodwin D. Mort M. Passing on tacit knowledge in anaesthesia: a quälitative study. Med Educ 2003; 37:650m.

93. Fletchen $G$, Flin $R$, MoGeorge $\mathbb{P}$, Glawin $R$, Maran $N$, Patey R. Anaesthetists nontechical skills (ANTS) evaluation of a behavioural marker system. B. A Anats th 2003; 90: $580-8$.

94. Neufeld VR, Maudsley RF, Pickering RJ, Turnbull JM, Weston W, Brown MG, Simpson IC. Educating future plyysicians for Ontario. Acad Med 1998; 73: 1133-48.

95. Wright $S M$, Carrese $A$. Excellence in role modelling: insight and perspectives from the pros. CMAJ 2002; 167: 638-43

96. Brownell AKW, Côte L. Senior residents view on the meaning of professionalism and how they leam about it. Acad Med 2001; 76:734-7.

97. Ringsted C, Schroeder TV, Henriksen J, Ramsing B, Lyngdonf P, Jansson V, Scherpbier A. Medical students experience in practical skills is far from stakeholders expectathons. Med Teach 2001; 23: 412-6. 
Conclusion and discussion

98. Skaarup M, Henriksen A, Ringsted C. Using SHOs' verbalisation of competencies and leaming needs. Presentation at the Association for Medical Education in Europe, AMEE Conference, Lisbon, Portugal 2002. 


\section{Summary}

This thesis builds around the theme in-training assessment (ITA) as it applies to a work-based postgraduate medical education context, in this case anaesthesiology. By the introduction of a broad and practice-based concept of competence traditional strategies of assessment in postgraduate education comes short. In order to ensure structured development of the trainees into competent individual practitioners there is a need for a new approach in medical education using assessment as an on-going part of the learning process, and ITA strategies seem to be a means to meet that end. The special conditions for postgraduate education being based in a busy working context and not a teaching institution offers some unique challenges to those who are responsible for constructing the programme. These challenges include compiling a programme that sufficiently covers the content and at the same time is feasible in practice without bureaucratic overloading of the users. Despite evidence that instruments using gllobal scoring of competence is more efficient to develop and administer the instruments of the programme will need to be sufficiently specific to serve as a tool for learning and be of help to the trainers in providing feedback and monitoring progress. Finally, the programme should aim at avoiding a blame and shame culture while serving its summative purpose of ensuring performance standards and quality of care and patient safety.

The overall researcl question was: How do theory on education and previous research outcomes inform the design and content of ITA in a workbased postgraduate medical education context and how does that apply to a specific programme in actual practice?

Chopter one deals with the internal rational validation process and how the theory on education and previous research outcomes informed the design and content of a specific ITA programme for $1^{\text {st }}$ year residents in anaesthesiology. The main results of the rational validation process were that the programme should be sequentially dispersed over the training 
year with emphasis on clinical skills in the beginning of the year and other aspects of competence and reflection on practice at a later stage of the year. Further, task specific checklists were preferred over global rating forms. The programme should be narrowed down as much as possible in order to be feasible in a work-based busy clinical context. Finally tailoring content, format, and programming of ITA to level of training and to the specific specialty was important. Problems with certain aspects of competence could be expected according to which specialty the ITA programme was meant for.

The programme was elaborated by a working-group under the Danish Society of Anaesthesiology and Intensive Care Medicine. The resulting programme addressed a broad aspect of competence and included twenty-one individual elements. In the ITA programme standards of performance were defined in task specific competence cards that included a checklist and some theoretical questions applying to the procedure. Each card also included a global pass/fail decision on the specific task. Eighteen of the elements were summative and three were formative. Trainees should pass all the summative elements of the programme in order to have the entire $1^{\text {sin }}$ year training approved. The internal rational validation process contributed to foreseeing barriers to implementing the written assignments included in the ITA programme, which addressed academic aspects of competence and aimed at reflection on practice and developing life-long learning skills. The ITA programme and an accompanying assessment protocol were distributed to all clinical clepartments of anaesthesiology.

Chapter two describes the content validity of the outline of the ITA programme. This was obtained by surveying consultants" opinion of the programme in terms of the representativeness of the aspects assessed, the perceived suitability of the programme as a basis for pass/faill decisions, and the rellevance and sufficiency of the content of the different assessment instruments. Two hundred and fifty one consultants $(66 \%)$ responded to the survey questionnaire. More than $75 \%$ of these agreed that the ITA programme offered adequate coverage of the curriculum for first-year trainees and was appropriate for making overall pass/fail decisions. There was a sufficiently high agreement among consultants that the content of each of the 18 summative assessments were relevant and sufficient for pass/fail decisions. For two elements, one on organisational. skills and one on academic aspects of competence, there was a slightly lower agreement on the importance of the element. In conclusion this study demonstrates sufficient external validity of the ITA programme. However, the study was limited to the consultants opinion on the out- 
line of the programme and aspects of validity according to actual experience with the programme need to be studied further.

Chapter three evaluated the feasibility of task specific checklists vs. global rating forms addressing general aspects of competence for the purpose of assessing trainees clinical performance in postgraduate education. A representative sample of 32 clinicians participated in an experimental study. The participants were randomised into two groups each of which used one of the scoring formats to assess a resident's pertormance in four simulated clinical scenarios on videotape. The clinicians rated the appropriateness of the scoring forms on a scale 1-5. The checklist format was rated significantly higher compared with the global rating form (mean 4.6 SD 0.5 vs. mean 3.5 SD 1.4, $<<0.001$. The inter-rater agreement regarding pass/fail decisions was poor irrespective of the scoring form used. This was explained by clinicians" leniency as assessors and noncompliance with the assessment protocol rather than by lack of vigilance in the observations or disagreements on standards for good performance. Issues of reliability of the whole programme as it works in practice will have to be studied further.

Chopter four deals with the feasibility of the ITA programme and reports the results of a survey of the implementation nation-wide. Responses were obtained form $25(96 \%)$ of the clinical departments who reported that in total 83 out of 100 possible candidates had been enrolled in the programme. The vast majority of the 21 elements of the programme were implemented although the summative elements were applied to a larger extent than the three formative elements. In general the programme was well accepted by both trainees and trainers. The positive aspects of the programme included making goals and objectives clear, being of help in structuring training, teaching, and learning, and in documenting and monitoring trainees' progress. Barriers to implementation were time constraints and resistance among some of the senior colleagues to take on the task of being assessor. The perceived benefits probably supported the implementation. However, a Halo effect of the number of research studies on this particular ITA programme might have contribuled.

Chapter five reports on how the programme works in actual practice and how that affects the perceived educational impact. Information on these issues was obtained from three clinical departments by semi-structured interviews of programme directors, supervisors, and trainees. The users found the programme being of help in guiding teaching, training, and learning and in identifying and managing problem trainees. Trainees and clinical teachers appreciated the details in the checklists and indicated 
that the cognitive aspects of the programme made all parties study more. Studies on the programme in practice demonstrated some variance in compliance with the assessment protocol. Three inter-related factors appeared to influence the perceived vallue of ITA: The link to patient safety and individual practice using assessment as a licence to practice unsupervised rather than end of training assessment. Secondly, the benefit to educators and learners in the educational process rather than mere documentation of competence, and finally the attitude and rigour of assessment practice. There are reasons to believe that the clinical departments learn over time and experience with the programme and the full potential of the specific programme remains to be explored.

Chnpter six was a nation-wide study of junior doctors' clinical confidence before and two years after the introduction of ITA. The results demonstrated that confidence within a broad spectrum of clinical competence did not change as a result of introducing ITA. Although the underlying concept of confidence is complex the results indicate that ITA did not have a significant effect on clinical competence. This is contradictory to the results of the previous studies indicating that ITA fostered learning. It is likely that the perceived confidence in clinical practice is not related to competence in terms of actual knowledge and skills. Lack of timely application of assessments according to the trainees' individual practice seems to a plausible explanation of the results. Future studies on the effect of ITA on trainees' actual competence are needed.

Conclusion on the first part of the overall research question is that theory on education and previous research outcomes inform that ITA strategies appropriate in one specialty might not be appropriate in another. Medical specialties differ substantially in preferred training strategies and culture according to whether they are primarily 'technical task oriented' or 'cognitive task oriented' specialties. This has implications for choice of ITA strategies and a model suitable for one specialty might not be appropriate in another. Design and content of composite ITA programmes must address trainees ${ }^{\prime}$ levels of experience and work-related context and support the development of broad, holistic aspects of competence. ITA can be used strategically to drive learning in non-dominant areas of a specialty.

The conclusion on the last part of the overall research question is drawn on behalf of applying the theories to the design of a specific ITA programme for $1^{\text {st }}$ year trainees in anaesthesiology and studies of this programme in actual practice. The resulting programme was a sequenced, mastery oriented ITA design using checklists to specify performance expectations. The programme emphasised skills at the early stages of the training year and reflection on practise at later stages. The 
programme proved feasible as to the implementation and the users appreciated the structure in the programme and the checklists. Studies on the programme in practice demonstrated some variance in assessors' rigorousness and compliance with the sequencing of the assessments. However, both trainers and assessors indicated that the perceived value of ITA in a work-based context was linked to timeliness of assessments. The studies gave a first impression of how the organisation learns through the experience with ITA and departments worked towards a better planning of assessments. The programme had no effect on trainees" level of clinical confidence measured before and two years after introduction of ITA. The impact of ITA on actual competence in terms of knowledge and skills remains to be studied in the future. 
$*$ 


\section{Samenvatting}

Het onderwerp van dit proefschrift is 'in-training assessment' (ITA) in de specialistenopleiding, in het bijzonder de opleiding anesthesiologie. Door invoering van een brede, aan de praktijk ontleende definitie van competentie waren de beoordelingsmethoden die traditioneel in de specialistenopleiding gebruikt werden niet meer toereikend. Om een goede structuur te ontwerpen voor de ontwikkeling van assistenten-in-opleiding tot competente specialisten was een nieuwe benadering van de opleiding nodig waarbij toetsing geïntegreerd werd in het leerproces. ITA lijkt hiervor een goede methode. Doordat de specialistenopleiding zich afspeelt in een drukke werkomgeving en niet in een opleidingsinstituut biedt dit onderwijs unieke uitdagingen aan programmaontwikkelaars. Een van deze uitdagingen is om een programma te ontwikkelen dat zowel aan inhoudelijke opleidingseisen voldoet als praktisch uitvoerbaar is en geen onnodige administratieve rompslomp met zich meebrengt voor de betrokkenen. Ondanks aanwijzingen dat het efficiënter is om instrumenten te ontwikkelen en toe te passen die algemene competentie toetsen, zal het toetsprogramma voldoende specifiek moeten zijn om niet alleen het leren van assistenten te sturen, maar ook als hulpmiddel te dienen voor docenten bij het geven van feedback en het volgen van de voortgang van de assistenten. Ten slotte dient vermeden te worden dat het programma een sfeer doet ontstaan waarin assistenten op een beschuldigende manier op hun fouten worden aangesproken, terwijl het programma wel summatieve beoordelingen mogelijk moet maken om de kwaliteit van de zorg en de veiligheid van de patiênten te kunnen waarborgen.

Centraal in dit proefschrift stant de onderzoeksorag: Hoe kunnen onderwijskundige theorie en resultaten van onderzoek van onderwijs gebruikt worden bij het ontwerpen van vorm en inhoud van een ITA-programma in de specialistenopleiding en hoe kan een dergelijk programmaontwerp uitgewerkt worden voor de onderwijspraktijk van een specifiek opleidingsprogramma. 
In hoofdshk 1 wordt ingegaan op de interne rationele procedure voor het valideren van toetsmethoden en de wijze warop onderwijskundige theorie en onderzoeksresultaten vorm en inhoud van een ITA-programmat voor eerstejaars assistenten in opleiding tot anesthesioloog mede hebben bepaald. De belangrijkste resultaten van de rationele procedure om de toetsing te valideren waren dat het programma gespreid diende te worden over het gehele opleidingsjaar, waarbij de nadruk in het begin van het jaar moest liggen op klinische vaardigheden, terwijl andere aspecten van competentie en reflectie op de klinische praktijk pas later in het jaar aan de orde moesten komen. Daarnaast werd de voorkeur gegeven aan specifieke checklisten boven globale scoringsformulieren. Het programma moest zo veel mogelijk tot de essenties beperkt blijven om halbaar te kunnen zijn in een drukke klinische werkomgeving. Ten slotte was het van belang om inhoud, vorm en programmering van het ITAprogramma toe te snijden op het opleidingsniveau van de assistenten en het specialisme. Er werd rekening mee gehouden dat, al naargelang het betrokken specialisme, bepaalde aspecten van competentie problemen zouden kummen opleveren.

Het programma werd uitgewerkt door een werkgroep van de Deense Vereniging voor Anesthesiologie en Intensive Care. Het bestreek een breed competentiedomein en bestond uit 21 afzonderlijke onderdelen. De in het toetsprogramma gehanteerde beoordelingseisen waren vastgelegd op taakspecifieke competentiekaarten waarop onder andere een checklist stond en theoretische vragen over de betreffende procedure. Elke kaart beschreef ook een globale zak/slaagbeslissing woor de specifieke taak. Achttien toetsonderdelen waren summatief en drie formatief. De assistenten-in-opleiding slaagden voor het eerste jaar van de opleiding als ze een voldoende beoordeling kregen op alle summatieve onderdelen van het toetsprogramma. De interne rationele procedure om het toetsprogramma te valideren droeg bij tot vroegtijdige signalering van obstakels voor het gebruik van schriftelijke opdrachten in het ITA-programma. Deze schriftellike toetsing betrof theoretische aspecten van competentie en was gericht op reflectie over de praktijk en het stimuleren van vaardigheden voor levenslang leren. Het toetsprogramma werd met het bijbehorende toetsprotocol verspreid onder alle klinische afdelingen anesthesiologie.

Hoofstuk 2 beschrijt de inhoudsvaliditeit van het ontwerp voor het ITAprogramma. De inhoudsvaliditeit werd bepaald aan de hand van een enquête warin specialisten gevraagd werd hun mening te geven over de representativiteit van de onderdelen die getoetst werden, de mate warin zij het programma geschikt achtten voor het nemen van zak/slaag- 
beslissingen en de relevantie en reikwijdte van de inhoud van de verschillende toetsinstrumenten. De enquète werd ingevuld door 251 specialisten (respons $66 \%$ ). Ruim $75 \%$ was van mening dat het toetsprogramma de inhoud van het eerste jaar voldoende dekte om te kunnen dienen als basis voor zak/slaagbeslissingen. Er was voldoende overeenstemming tussen de specialisten over de relevantie van de achttien summatieve toetsen en hun bruikbaarheid als basis voor zak/slaagbeslissingen. Er was wat minder overeenstemming ten aanzien van het belang van twee onderdelen, een onderdeel betreffende organisatorische vaardigheiden en een onderdeel aangaande academische aspecten van competentie. Geconcludeerd kan worden dat de externe validiteit van het ITAprogramma voldoende was. Hierbij moet worden opgemerkt dat het onderzoek uitsluitend bestond uit een opiniepeiling onder specialisten over de opzet van het programma. Verder onderzoek is nodig om aspecten van de validiteit van het programma te bepalen op basis van praktijkervaringen.

Hoofdstuk 3 beschrijft een vergelijkend onderzoek naar de bruikbaarheid van taakspecifieke checklisten en globale beoordelingsformulieren voor algemene aspecten van competentie voor het ITA-programma. Er werd een experiment uitgevoerd waaraan deelgenomen werd door een representatieve steekproef van 32 specialisten. De deelnemers werden willekeurig in twee groepen ingedeeld. Elke groep beoordeelde met behulp van een van de scoringsmethoden het klinisch handelen van een assistent in vier op video opgenomen gesimuleerde klinische scenario's. De specialisten gaven hun oordeel over de geschiktheid van de beoordelingsformulieren op een vijfpuntsschaal. De checklist kreeg een significant betere beoordeling dan de globale beoordelingsformulieren (gemiddeld 4.6, SD 0.5 tegenover gemiddeld 3.5 SD 1.4, $<<0.001$ ). De interbeoordelantsovereenstemming voor de zak/slaagbeslissingen was laag voor beide beoordelingsformulieren. Dit kan verklaard worden doordat de specialisten zeer mild oordeelden en zich niet hielden an het beoordelingsprotocol en niet zozeer doordat zij onzorgvuldig observeerden of van mening verschilden over wat een goede prestatie inhield. Betrouwbaarheidsaspecten van het programma als geheel bij toepassing in de praktijk dienen nader onderzocht te worden.

Hoofdstuk 4 behandelt de haalbaarheid van het ITA-programma en beschrijft de resultaten van een enquete over de landelijke toepassing van het programma. De enquête werd ingevuld door 25 (96\%) van de klinische afdelingen. Volgens de afdelingen namen 83 van de 100 potentiele kandidaten deel aan het programma. De overgrote meerderheid van de 21 programmaonderdelen werd gebruikt. De summatieve onderdelen 
werden vaker gebruikt dan de drie formatieve onderdelen. Over het algemeen werd het programma door zowel opleiders als assistenten goed ontvangen. De positieve aspecten van het programma waren de duidelijk omschreven doelstellingen en eindtermen en de bijdrage die het programma leverde aan het structureren van opleiding, onderwijs en leren en de registratie en het volgen van de voortgang van de assistenten. Belemmeringen voor invoering van het programma waren tijdgebrek en bedenkingen van enkele oudere collega's ten aanzien van het optreden als beoordelaar. De waargenomen voordelen hadden naar alle waarschijnlijkheid een gunstige invloed op de invoering van het programma. Mogelijk speelde ook een rol dat er een halo-effect ontstond doordat het programma onderwerp van verschillende onderzoeken was.

In hoofdstuk 5 wordt besproken hoe het programma in de praktijk werkte en de invloed daarvan op de ervaren onderwijskundige effecten. De gegevens voor dit onderzoek werden verkregen aan de hand van semigestructureerde interviews met opleidingsdirecteuren, begeleiders en assistenten uit drie klinische afdelingen. De gebruikers gaven aan dat het programma een positieve bijdrage leverde ondat het als leidraad diende voor onderwijs, training en leren en de opsporing en begeleiding van probleemstudenten. Zowel assistenten als opleiders waardeerden de detaillering van de checklisten. $Z$ ij gaven aan dat de cognitieve aspecten van het programma alle betrokkenen stimuleerden om meer te studeren. Onderzoeken naar de toepassing van het programma in de praktijk lieten zien dat er verschillen waren in de mate waarin men zich aan het toetsprotocol hield. Drie onderling samenhangende factoren leken van invloed te zijn op de ervaren waarde van het ITA-programma: de relatie met de veiligheid van de patiënt en de individuele praktijk, waarbij het doel van toelsing was toestemming te verlenen om zonder begeleiding te mogen werken in plaats van het geven van een oordeel aan het eind van de opleiding.

Op de tweede plaats had het programma een gunstige invloed op het onderwijsproces voor zowel opleiders als assistenten in plaats van beperkt te blijven tot het registreren van competentie. Ten slotte was er waardering voor de aandacht voor attitude en de grondigheid van de beoordeling in de praktijk. Er is aanleiding om aan te nemen dat klinische afdelingen tijd nodig hebben om ervaring op te kunnen doen met het programma en dat nog niet alle mogelijkheden van het programma verkend zijn.

Hooflstuk 6 behelst een landelijk onderzoek naar het zelfvertrouwen van assistenten-in-opleiding betreffende hun functioneren in de klinische praktijk waarbij een vergelijking gemaakt werd tussen het zelfvertrou- 
wen voor en twee farar ma invoering van het ITA-programma. De resultaten wezen uit dat het zelfvertrouwen betreffende het volledige scala aan klinische competenties niet veranderde door invoering van het toetsprogramma. Hoewel zelfvertrouwen een complex concept is, waren er geen resultaten die wezen op een significant effect van ITA op het vertrouwen in de eigen klinische competentie. Waarschijnlijk houdt het ervaren zelfvertrouwen in de klinische praktijk geen verband met competentie in termen van werkelijke kennis en vaardigheden. Het ontbreken van toetsing die direct aansluit bij actuele praktijkervaringen van de individuele assistent lijkt een voor de hand liggende verklaring voor: de resultaten. Verder onderzoek is nodig om de invloed van het ITA-programma te bepalen.

De conclusie betreffende het eerste deel van de centrale onderzoeksvraag is dat onderwijskundige theorie en onderzoeksresultaten aangeven dat een ITA-programma dat geschikt is voor het ene specialisme niet automatisch geschikt hoeft te zijn voor andere specialismen. Medische specialismen vertonen aanzienlijke verschillen wat betreft voorkeuren voor opleidingsprogramma's en opleidingscultuur. Deze voorkeuren hangen samen met de verschillen tussen primair technisch of cognitief georiënteerde specialismen. Dit heeft gevolgen voor de keuze van toetsvormen. Het betekent ook dat een toetsmodel dat geschikt is voor het ene specialisme niet geschikt hoeft te zijn voor het andere. Vorm en inhoud van een ITA-programma met verschillende onderdelen moeten aansluiten bij het ervaringsniveau en de werkomgeving van de assistenten en bijdragen aan het ontwikkelen van brede en holistische aspecten van competentie. Een ITA-programma kan strategisch ingezet worden om het leren ten aanzien van minder prominente gebieden van een specialisme te bevorderen.

De conclusie ten aanzien vam het laatste deel van de centrale onderzoeksvraag is gebaseerd op de toepassing van theorieën bij het ontwerpen van een ITA-programma voor eerstejaars assistenten anesthesiologie en op verschillende onderzoeken naar het functioneren van dit programma in de praktijk. Het programma bestond uit een gefaseerd toetsprogramma gericht op de beheersing van kennis en vaardigheden waarbij gebruik gemaakt werd van checklisten om de beoordelingseisen te specificeren. In het begin van het jaar lag de nadruk in het programma op vaardigheden terwijl later in het jaar de nadruk kwam te liggen op reflectie over de praktijk. Het programma bleek uitvoerbaar te zijn en de gebruikers toonden waardering voor de structuur van het programma en de checklisten. De onderzoeken naar de toepassing van het programma in de praktijk gaven enige variatie te zien wat betreft de strengheid van de beoordelaars en het aanhouden van de volgorde van de beoordelin- 
gen. Niettemin gaven zowel opleiders als beoordelaars te kennen dat wat hen betrof de waarde van het toetsprogramma gelegen was in het juiste tijdstip van de beoordelingen. De onderzoeken gaven een eerste indruk van hoe een organisatie leert door ervaringen met een ITA-programma en het streven naar een betere planning van beoordelingen door de afdelingen. Een onderzoek waarin een vergelijking werd gemaakt tussen het zelfvertrouwen van de assistenten ten aanzien van hun klinisch functioneren woor en twee jaar na invoering van het ITA-programma liet geen invloed van het programma zien op dat zelfvertrouwen. De invloed van ITA op de werkelijke competentie van assistenten in termen van kennis en vaardigheden moet nader onderzocht worden. 


\section{Acknowledgements}

The working group behind the ITA programme for 1st year residents in anaesthesiology were: Andersen $\mathbb{N}$, Berlac PA, Bested $K$, Callesen $T$, Christensen $\mathrm{P}$, Jensen $\mathrm{E}$, Jensen JW, Lemholt $\mathrm{K}$, Lund J, Malling $\mathrm{B}$, Mandøe $H$, Nørregaard O, Pedersen BD, Petersen JA, Ravlo O, Ravn L, Skjelsager K, Sprehn M, Ostergaard D. The time we spent in developing the ITA programme was most enjoyable and constructive. The honour of the ITA programme and its introduction nation-wide rests with this group of enthusiastic pioneers.

I deeply respect the Danish anaesthesiologists, the trainees as well as trainers, for their willingness and effort to make the ITA programme work in practice. This thesis is built around a number of studies evaluating the ITA programme. I' $m$ indebted to all the anaesthesiologists who took their time to fill in the questionnaires and generously shared their experience with us. Their constructive comments and reflections on how the programme can be improved have been extremely valuable for the review of this programme.

The Danish Society of Anaesthesiology and Intensive Care Medicine has backed up the projects all the way and in part sponsored the implementation and evaluation of the ITA programme. They have repeatedly placed ITA on the agenda at the Society meetings over the years. Without their everlasting support this ITA programme would never have become a reality.

The Ministry of Health and The National Board of Health has in part sponsored the studies included in this thesis. A special thanks to Karsten Beck from The National Board of Health for supporting the introduction of in-training assessment in anaesthesiology at a time where this was not common practice in Denmark.

This research is a result of the visionary directors of the Copenhagen Hospital Corporation, who founded the Postgraduate Medical Institute and as such funded the studies of this thesis. I wish to thank especially director Lone de Neergaard for constantly supporting innovation in postgraduate medical education and being a promoter of the institute. 
I want to express my deepest gratitude to the Danish co-authors Doris Ostergaard, Lisbet Ravn, Asger Petersen, Peter Berlac, Ann-Helen Henriksen, Anne Marie Skaarup, and Jane Pallisgaard for their great efforts. and contributions. Above all, I want to thank you, Doris, for the exiting and joyful collaboration we've had on these and several other projects. I cannot express how highly I appreciate that.

Hanne Panduro and Susanne Findalen have been of great help with managing the surveys and gathering the data.

I'm indebted to Deborah Davies for her editorial assistance and help with the English.

I wish to thank my former chief Svend Juul Jørgensen for encouraging me to pursue $\mathrm{a} \mathrm{PhD}$ and supporting me in getting the work done.

I have had the best of supervisors for this thesis: Albert Scherpbier and Cees van der Vleuten. I'm deeply thankful for their everlasting support and encouragement. I'm impressed by their supervisor skills that reach across distances between countries. I always got immediate feedback on papers sent to them and gentle motivating mails or letters in times, when things slowed down. Their constructive criticism and professional guidance on my work has been invaluable. Thank you so much. 


\section{Curriculum vitae}

Charlotte Ringsted was born in Copenhagen, Denmark on 21.1 September 1953. She obtained a M.D. degree in the University of Odense, Denmark, in 1978 and a certificate of Specialist in Anaesthesiology in 1991. She left clinical medicine in 1993 for a position as hospital coordinator of clinical education at Copenhagen University Hospital, Rigshospitalet. During the time at Rigshospitalet she designed and set up the first skills lab in Denmark in 1996, in collaboration with the hospital coordinator of students ${ }^{r}$ clinical affairs, professor Torben Schroeder. She obtained a Master degree in Health Professions Education (MHPE) in 1997 in Maastricht University. In 1997 she was appointed the leader of a new Postgraduate Medical Institute for the Copenhagen Hospital Corporation. Her responsibillities include research and development within postgraduate medical education, curriculum design, development of assessment programmes, residency programme evaluation, and faculty development. In 2003 she was elected president of the Danish Association of Medical Education. She started on this PhD in Maastricht in 2000 . 